\title{
A METHOD TO INCREASE CURRENT DENSITY IN A MONO ELEMENT INTERNAL TIN PROCESSED SUPERCONDUCTOR UTILIZING ZR OXIDE TO REFINE GRAIN SIZE
}

\author{
Final Report \\ For Period August 27, 2001 to February 28, 2007 \\ Principle Investigator - Bruce A Zeitlin \\ Contributing Researcher - Dr. Eric Gregory
}

Supergenics LLC

1233 Tree Bay Lane

Sarasota Fl. 34242

March 2008

Prepared for

The U.S. DEPARTMENT OF ENERGY

Under SBIR Award No. DE-FG02-01ER83331 


\begin{abstract}
The effect of Oxygen on $(\mathrm{Nb} 1 \mathrm{Zr})_{3} \mathrm{Sn}$ multifilament conductors manufactured by the Mono Element Internal Tin (MEIT) process was explored to improve the current density by refining the grain size. This followed work first done by General Electric on the $\mathrm{Nb}_{3} \mathrm{Sn}$ tape process. Techniques to fabricate the more difficult $\mathrm{Nb} 1 \mathrm{Zr}$ composites are described and allowed fabrication of long lengths of .254 mm diameter wire from an 88.9 $\mathrm{mm}$ diameter billet. Oxygen was incorporated through the use of $\mathrm{SnO}_{2}$ mixed with tin powder and incorporated into the core. These were compared to samples with $\mathrm{Ti}+\mathrm{Sn}$ and $\mathrm{Cu}+\mathrm{Sn}$ cores. Heat treatments covered the range of $700^{\circ} \mathrm{C}$ to $1000^{\circ} \mathrm{C}$. Current density vs. $\mathrm{H}$, grain size, and reaction percentages are provided for the materials tested. The Oxygen gave superior results in the temperature range of $815-1000^{\circ} \mathrm{C}$. It also stabilized the filament geometry of the array in comparison to the other additions at the higher temperatures. At $815^{\circ} \mathrm{C}$ a peak in layer $\mathrm{J}_{\mathrm{c}}$ yielded values of $2537 \mathrm{~A} / \mathrm{mm}^{2}$ at $12 \mathrm{~T}$ and 1353 $\mathrm{A} / \mathrm{mm}^{2}$ at $15 \mathrm{~T}, 8-22 \%$ and $30-73 \%$ greater respectively than $700^{\circ} \mathrm{C}$ values. Results with Oxygen at high temperature show the possibility of high speed continuous reaction of the composite versus the current batch or react in place methods. In general the Ti additions gave superior results at the lower reaction temperature. Future work is suggested to determine if the $815^{\circ} \mathrm{C}$ reaction temperature can lead to higher current density in high tin $\left(\mathrm{Nb} 1 \mathrm{Zr}+\mathrm{O}_{\mathrm{x}}\right)_{3} \mathrm{Sn}$ conductors. A second technique incorporated oxygen directly into the $\mathrm{Nb} 1 \mathrm{Zr}$ rods through heat treatment with $\mathrm{Nb}_{2} \mathrm{O}_{5}$ at $1100^{\circ} \mathrm{C}$ for 100 hours in vacuum prior to extrusion. The majority of the filaments reduced properly in the composite but some local variations in hardness led to breakage at smaller diameters.
\end{abstract}

NOTICE

This report was prepared as an account of work sponsored by the United States Government. Neither the United States nor the United States Department of Energy, nor any of their employees, nor any of their awardees, subcontractors, or their employees, makes any warranty, express or implied, or assumes any legal liability or responsibility for the accuracy, completeness, or usefulness of any information, apparatus, product or process disclosed or represents that its use would not infringe privately-owned rights 


\section{a. Identification and Significance of Problem}

The High Energy Physics community has been encouraging and sponsoring the development of Superconductors for Accelerator applications for over forty years. The Superconducting Tevatron at Fermilab and the Large Hadron Collider (LHC) under construction at CERN are evidence that these efforts have born fruit. It would be fair to say that superconductors have been an enabling technology for many of the community's discoveries over the last several decades.

Accelerators of today make use of the workhorse of superconductivity, Niobium Titanium (NbTi). This material provides operational fields of up to 8.4 Tesla as in the LHC. To substantially increase the energy of future accelerators requires significantly higher fields as well as lower cost for a given performance ${ }^{1}$. The development of $\mathrm{Nb}_{3} \mathrm{Sn}$ dipoles has progressed significantly in the last few years. Lawrence Berkeley National Lab ${ }^{2}$ (LBNL), Fermilab ${ }^{3}$ (FNAL), Brookhaven National $\mathrm{Lab}^{4}$ (BNL) and Texas A \& M University ${ }^{5}$ (TAMU) have all reported encouraging results. The LBNL group reported a new world's record dipole field strength of 16 Tesla from the experimental magnet HD- $1^{2}$. These programs are based on $\mathrm{Nb}_{3} \mathrm{Sn}, \mathrm{a}$ material of reasonable maturity but still with significant potential. Magnet technology, developed to utilize a brittle material such as $\mathrm{Nb}_{3} \mathrm{Sn}$, will also be applicable to the High Temperature Superconductors (HTS).

Superconductors for the next generation magnets as presently envisioned to support the VLHC concepts, have as goals a current density $J_{c}$ of $3000 \mathrm{~A} / \mathrm{mm}^{2}$ at 12 Tesla in the non- $\mathrm{Cu}$, an effective filament size of 40 microns, a 10,000 meter piece length and costs less than $\$ 1.5$ - $\$ 1 /$ kiloampere meter $(\$ / \mathrm{kAm}){ }^{1}$. Fields of 15 Tesla or higher are envisaged for the magnets.

\section{b. Background}

Niobium Tin in commercial production today utilizes two processes: -

1.The Bronze process first discussed by Pickett and Kaufman ${ }^{6}$ and by Tachikawa ${ }^{7}$.

2. The Internal Tin process (ITP) first discussed by Hashimoto ${ }^{8}$.

The Bronze process has found extensive use in high field NMR magnets and various research magnets. The internal tin process has evolved significantly from its original concept ${ }^{9}$ to meet the needs of the Magnetic Fusion community. The bronze process because of the inherent limitation of the amount of tin available to form niobium tin (9-10 at.\%) compared to $23-24$ at. $\%$ in the internal tin process is not a viable candidate for $15 \mathrm{~T}$ accelerator magnet applications. It is also inherently more expensive because of processing and material factors. Internal tin on the other hand does not have these constraints and has been demonstrated in the earlier D20 13.5 T magnet built at $\mathrm{LBNL}^{10}$. Delivery of over eleven metric tonnes of conductor to a very demanding 
specification for the KSTAR program by Luvata Waterbury (formally IGC ASI and OKAS) shows that this conductor has reached the industrial stage ${ }^{11}$.

Niobium Tin by the internal tin process still has significant potential both in cost and performance but to achieve this potential, the process has to be optimized for High Energy Physics future needs.

The internal tin concept, as first practiced by Hashimoto, was not readily scaleable. Zeitlin et al adapted the concept utilizing the Luvata Waterbury (formally IGC-AS) $60 \mathrm{~m}$ draw bench to cold clad the individual sub-elements composed of a copper niobium composite with a core of pure tin 9 . The stabilizer tube is formed of copper and tantalum. The tantalum serves as the diffusion barrier preventing the poisoning of the copper by the tin. Niobium, sometimes used in combination with tantalum as well as by itself, has the disadvantage of forming a continuous layer of $\mathrm{Nb}_{3} \mathrm{Sn}$ hence increasing the electrical losses. An illustration of that process is shown in Figure 1.

Initial deliveries were made to LBNL and BNL in long lengths from a $180 \mathrm{~kg}$ billet in $1983^{12}$. Since that time much of the development has focused on Magnetic Fusion requirements epitomized by the ITER program. This had lower field, loss and current density specifications. Work by Gregory et al has made excellent progress in adapting conductors developed for Magnetic Fusion to HEP goals ${ }^{13,14 \& 15}$. The $\mathrm{J}_{\mathrm{c}}$ 's were raised to $2550 \mathrm{amps} / \mathrm{mm}^{2}$ at $12 \mathrm{~T}$ in the non- $\mathrm{Cu}^{15}$. The increase in current density was mainly due to increasing the volume fraction of niobium and tin.

The last stage of the Internal Tin Process (ITP) is the cold cladding of the array with copper and tantalum stabilizer. The larger the number of conductor elements the greater the surface area. This leads to increased difficulties in establishing the bond for reasons possibly related to the condition of the conductor before it is drawn and the pressure distribution as well as pressure intensity on the inner elements. Also the greater surface leads to a higher probability that inclusions will be introduced. All of these factors result in lower yield through greater breakage.

A new improved internal tin process named the "Mono Element Internal Tin" (MEIT), shown schematically in Figure 2, has been developed under the DOE SBIR program contract DEFG0299ERE82899. The process takes the single element multifilament and draws the element to an intermediate size where it is then clad with a diffusion barrier and copper. It is then drawn to a fine size and incorporated into a cable with pure copper elements ${ }^{16}$. The process promises to be scalable to large scale utilizing $450 \mathrm{~kg}$ billets at costs below $\$ 1.5 /$ kiloampere meter $(\mathrm{kAm})$. Wire in continuous lengths of over 30,000 meters has been drawn to $0.14 \mathrm{~mm}$. Figure 3 shows an un-reacted cross section of a MEIT conductor. Figure 4 shows a conductor at $0.142 \mathrm{~mm}$ diameter. The fins composed of $\mathrm{NbTa}$ have been incorporated to separate the filaments which bridge after the formation of $\mathrm{Nb}_{3} \mathrm{Sn}$. Additional fins can be introduced to further reduce the magnetization 


\section{Figure 1.}

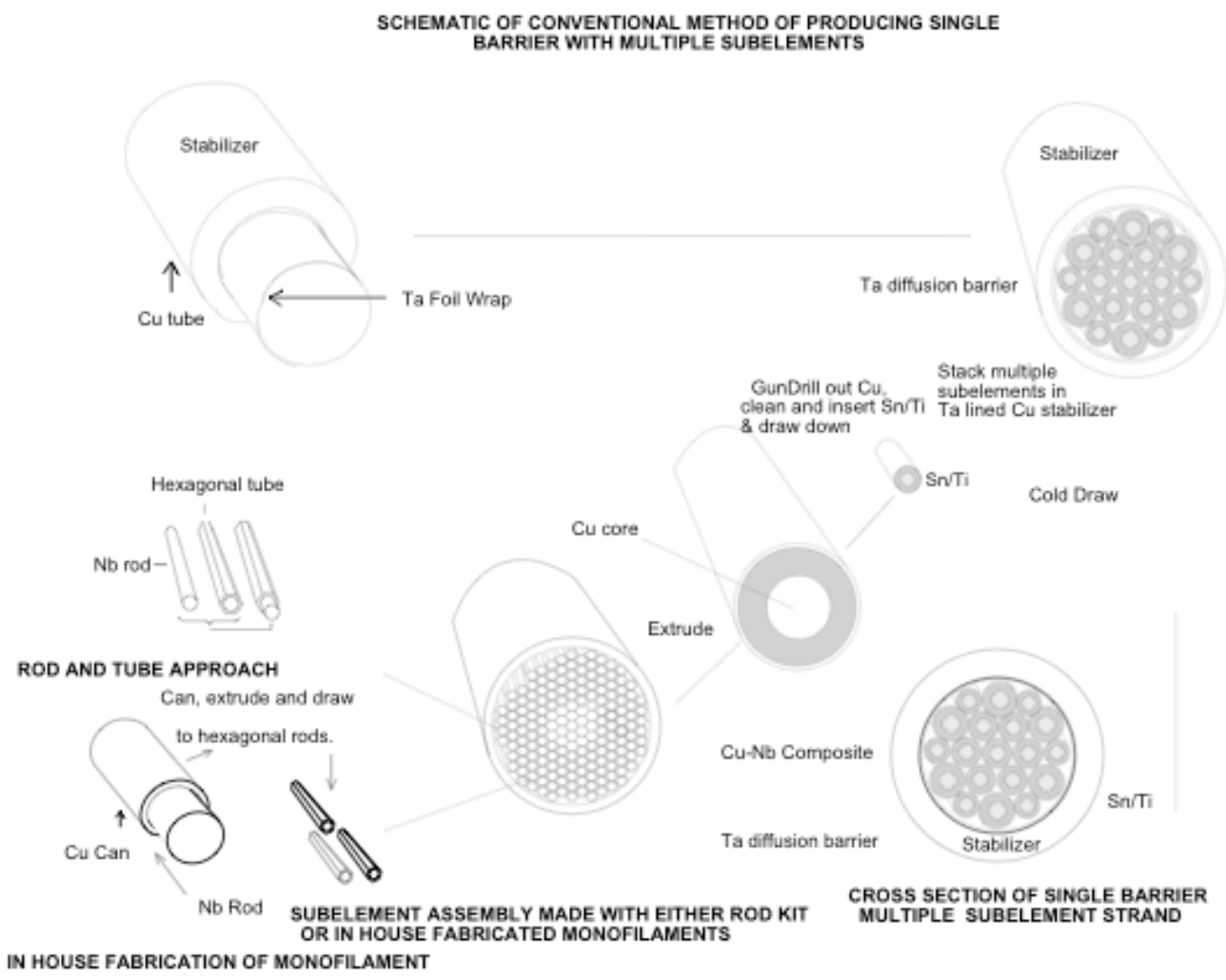


Figure 2.

SCHEMATIC OF CONVENTIONAL METHOD OF PRODUCING SINGLE UNSPLIT SUBELEMENT FOR THE MEIT PROCESS
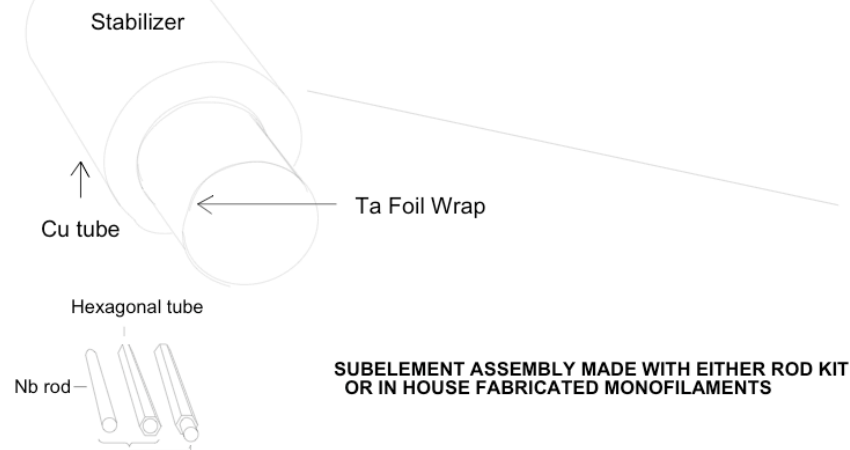

ROD AND TUBE APPROACH Can, extrude and draw

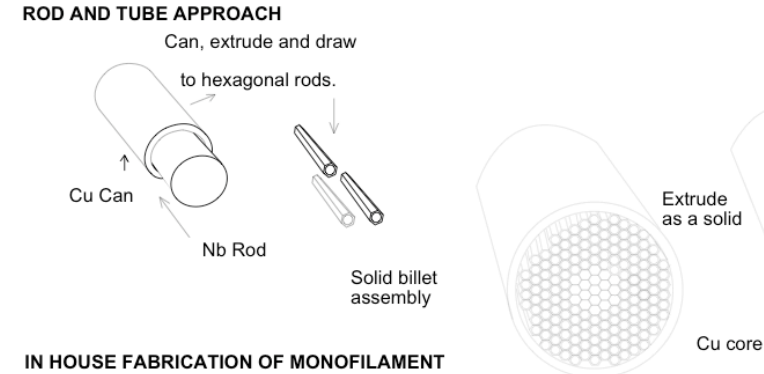

IN HOUSE FABRICATION OF MONOFILAMENT

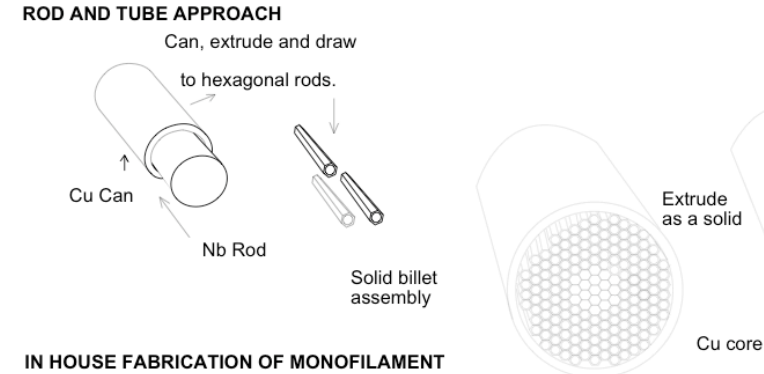

GunDrill out $\mathrm{Cu}$

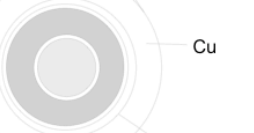

Ta/Nb Barrie 


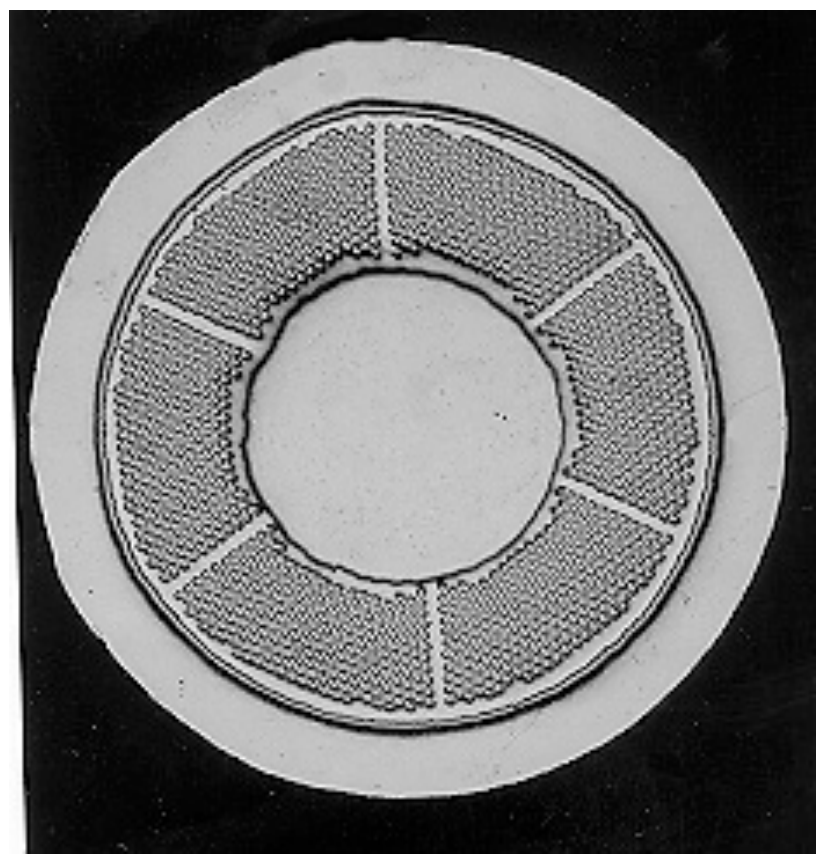

Figure 3., MEIT conductor (25x)

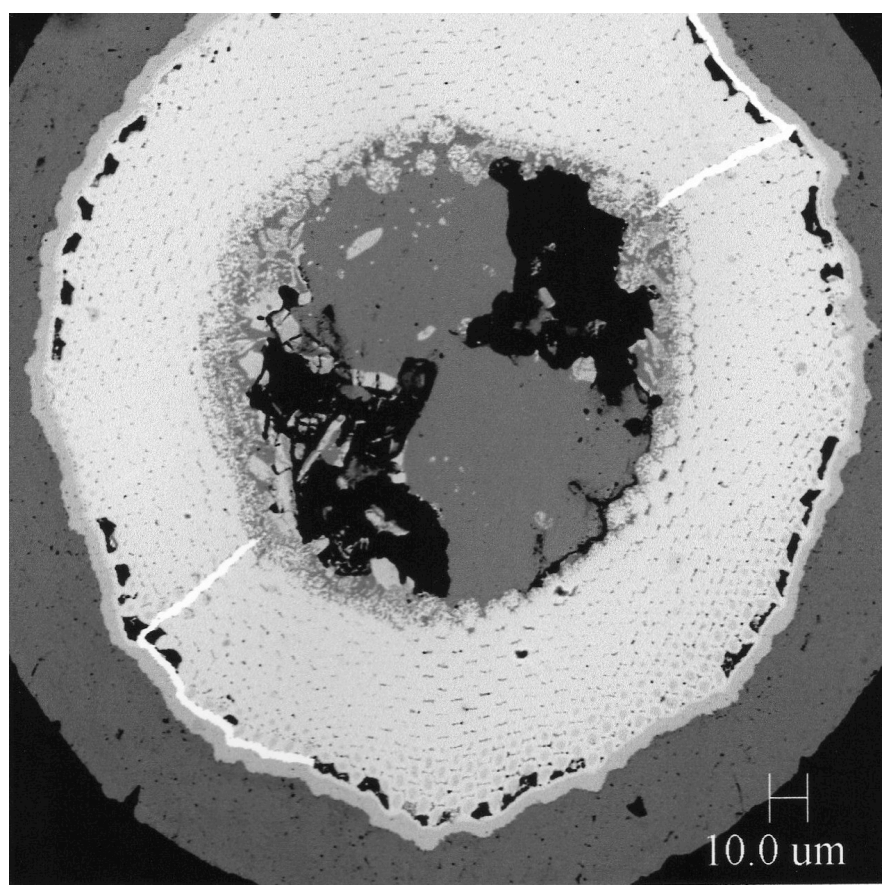

Figure 4., BAZ8 MEIT conductor at $0.142 \mathrm{~mm}$ with Ta fins.

Conductor (BAZ7) produced with 2.5-micron filaments in contract \# DEFG0299ERE82899 had a current density (in the $\mathrm{Nb}_{3} \mathrm{Sn}$ layer normalized to the niobium) of $6365 \mathrm{~A} / \mathrm{mm}^{2}$ and $4579 \mathrm{~A} / \mathrm{mm}^{2}$ in the $\mathrm{Nb}_{3} \mathrm{Sn}$ layer at 12 Tesla with a non- 
optimized heat treatment. Tantalum fins were also introduced successfully for the first time to reduce the magnetization/effective filaments size of the conductor.

To achieve the $3000 \mathrm{~A} / \mathrm{mm}^{2}$ in the non- $\mathrm{Cu}$ at $12 \mathrm{~T}$ a large volume fraction of niobium and the appropriate ratio of tin are needed. In practice this requires that the copper be reduced to a minimum. At a local area ratio of $.66 / 1(\mathrm{Cu} / \mathrm{Nb})$ all filaments within a segment are expected to bridge as the $\mathrm{Nb}_{3} \mathrm{Sn}$ layer leads to an approximate $37 \%$ expansion of the filament volume. Increasing the local ratio of $\mathrm{Nb}$ to $\mathrm{Cu}$ beyond that may reduce and or slow reaction, as the tin must diffuse through $\mathrm{Nb}_{3} \mathrm{Sn}$. The highest $\mathrm{Nb}_{3} \mathrm{Sn}$ layer current density reported in commercial conductors when normalized to the starting niobium is $5500 \mathrm{~A} / \mathrm{mm}^{16}$. To achieve $3000 \mathrm{~A} / \mathrm{mm}^{2}$ in the non-Cu requires about $55 \% \mathrm{Nb}$ by area and $25 \% \mathrm{Sn}$ by area. This is difficult to achieve without improving the current density in the layer and this is one of the primary objectives of the research effort.

\section{Layer current density}

The inherent current density in the layer depends on the grain size, stoichiometry and impurities ${ }^{17}$. Titanium, as well as tantalum, is used commercially to significantly increase the high field performance by increasing the critical field and, in the case of titanium, speeding up the reaction kinetics ${ }^{18}$. Titanium is often introduced by alloying with the tin core. The highest current density is found in equiaxed grains, those initially formed $^{19}$. To produce fine equiaxed grains a number of techniques have been explored. Phase II of the SBIR on the MEIT process yielded a current density of $3000 \mathrm{~A} / \mathrm{mm} 2$ at $12 \mathrm{~T}$ and $1800 \mathrm{~A} / \mathrm{mm} 2$ at $15 \mathrm{~T}$ with 2.5 micron $\mathrm{Nb} 7.5 \mathrm{Ta}$ filaments and $\mathrm{Ti}$ in the $\mathrm{Sn}$ core. Fine filaments produce higher current densities as the reaction layer is composed of a larger volume fraction of equiaxed fine grains. Magnesium in the form of an oxide has also been used as a grain size inhibitor with limited success ${ }^{20}$.

The early $\mathrm{Nb}_{3} \mathrm{Sn}$ tape process as developed by $\mathrm{GE}$ and later practiced by Intermagnetics General, utilized a $\mathrm{Nb} 1 \% \mathrm{Zr}$ tape as the substrate which was then anodized to introduce oxygen. The tape was then dipped in liquid tin/copper alloy and reacted. The process yielded 0.5 to 1 micron grains of $\mathrm{Nb}_{3} \mathrm{Sn}$ at reaction temperatures above $930^{\circ} \mathrm{C}^{21}$. Later work raised the reaction temperatures to $1050^{\circ} \mathrm{C}$ and reduced the grain size to 0.3 microns $(300 \mathrm{~nm})$. They also found that the current density was directly proportional to grain size ${ }^{22}$. This result confirms some early work done by Scanlan et. al. $^{23}$

Work by Dietderich et $\mathrm{al}^{24,25}$ using thin film deposition techniques showed that a film of $\mathrm{Nb}$ with $\mathrm{Sc}$ and $\mathrm{Al}_{2} \mathrm{O}_{3}$ and $\mathrm{Sn}$ resulted in a very high layer current density of $10,000 \mathrm{~A} / \mathrm{mm}^{2}$ at $12 \mathrm{~T}$ normalized to the starting $\mathrm{Nb}$ with a 20 to $25 \mathrm{~nm}$ grain size after 8 hrs at $700^{\circ} \mathrm{C}$. In comparison a non-doped sample heat treated 60 minutes at $700^{\circ} \mathrm{C}$ had a $\mathrm{J}_{\mathrm{c}}$ of $3500 \mathrm{~A} / \mathrm{mm}^{2}$ and a grain size in excess of $100 \mathrm{~nm}$. Current densities in titaniumdoped materials had a lower bound value of $7000 \mathrm{~A} / \mathrm{mm}^{2}$ at $12 \mathrm{~T}$ without any grain growth inhibitors. Work by P.J. Lee, et. al. ${ }^{26}$, analyzed conductors made for the ITER program as well as others. The best conductors with Ti additions had grain sizes of approximately $110 \mathrm{~nm}$ with a layer current density of $3800 \mathrm{~A} / \mathrm{mm}^{2}$ at $12 \mathrm{~T}$. This is equivalent to $5200 \mathrm{~A} / \mathrm{mm}^{2}$ when normalized to the starting $\mathrm{Nb}$. The potential for 
significant current density improvement has been demonstrated. Improvements in current density without affecting the fabrication process significantly has the most leverage to improve the key measure of conductor performance, dollars/kilo amp meter $(\$ / \mathrm{kAm})$.

The key to further improve the performance cost of $\mathrm{Nb}_{3} \mathrm{Sn}$ beyond what is envisioned with the MEIT process as well as any other internal tin process that can be fabricated in large billets is to improve the inherent current density in the layer. To do this we proposed to incorporate a demonstrated $\mathrm{Nb}_{3} \mathrm{Sn}$ grain refiner Zirconium (Zr) and Oxygen into the Niobium.

At the High Field Materials-LTSW workshop on November 1-3 1999, Mark Benz and Judson Marte presented a work in progress to refine the grain size in a bronze processed $\mathrm{Nb}_{3} \mathrm{Sn}$. They utilized a $\mathrm{Nb} 1 \% \mathrm{Zr}$ filament with the required oxygen incorporated in the initial melting process. They successfully fabricated a $54 \mathrm{~mm}$ diameter billet with seven filaments in a bronze matrix and processed it to a $1.73 \mathrm{~mm}$ wire to yield a $0.17 \mathrm{~mm}$ filament ${ }^{27}$. A cross section of the conductor is shown in Figure 5. The outer filament shape is distorted and irregular possibly as a result of incorporating uncropped swaged ends in the extrusion. In addition the rods were machined from an "as cast" ingot by "Electro-Discharge Machining" (EDM) resulting in a coarse grain structure in the rod prior to extrusion.

Earlier work designed to speed reaction times in GE tape without loss of current density showed full reaction in $1 / 15$ of the time with grain sizes about $1 / 5$ of the size $\mathrm{e}^{22}$. Figures 6 and 7 illustrated the dramatic effect of $\mathrm{ZrO}_{2}$ on the kinetics and grain growth. Also demonstrated was the mechanism of grain refinement, a dissolution re-precipitation process that slowed the grain growth.

If $\mathrm{ZrO}_{2}$ can be as effective in controlling grain size in a solid state reaction as

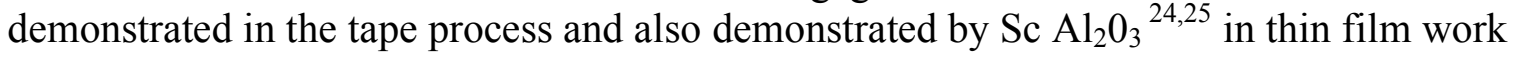
by Deitderich, then grain size could be reduced by a factor of two or more. All other things being equal this could well result in a doubling or more in the current density above the best materials in development today.

An alloy containing $1(\mathrm{at} \%) \mathrm{Zr}$ was used throughout with the oxygen introduced in two different ways:

1. 2 (at.\%) $\mathrm{O}_{2}$ was introduced during the casting of the alloy.

2. The $\mathrm{O}_{2}$ was introduced in the later stages of the fabrication by diffusion from a $\mathrm{SnO}$ powder incorporated into the tin core.

In Phase I the $\mathrm{NbZr}$ alloy containing oxygen prepared in the manner described in 1. above, did not extrude successfully in a $\mathrm{Cu}$ matrix at the same temperature $\left(800^{\circ} \mathrm{C}\right)$ as that used for fabricating regular $\mathrm{Nb}-\mathrm{Cu}$ composites. Although extrusion took place there appeared to be a very uneven reduction of the two components, $\mathrm{Cu}$ and $\mathrm{Nb}$ (1at.\%) $\mathrm{Zr}$ containing oxygen. One reason for this appears to be a considerable difference between 


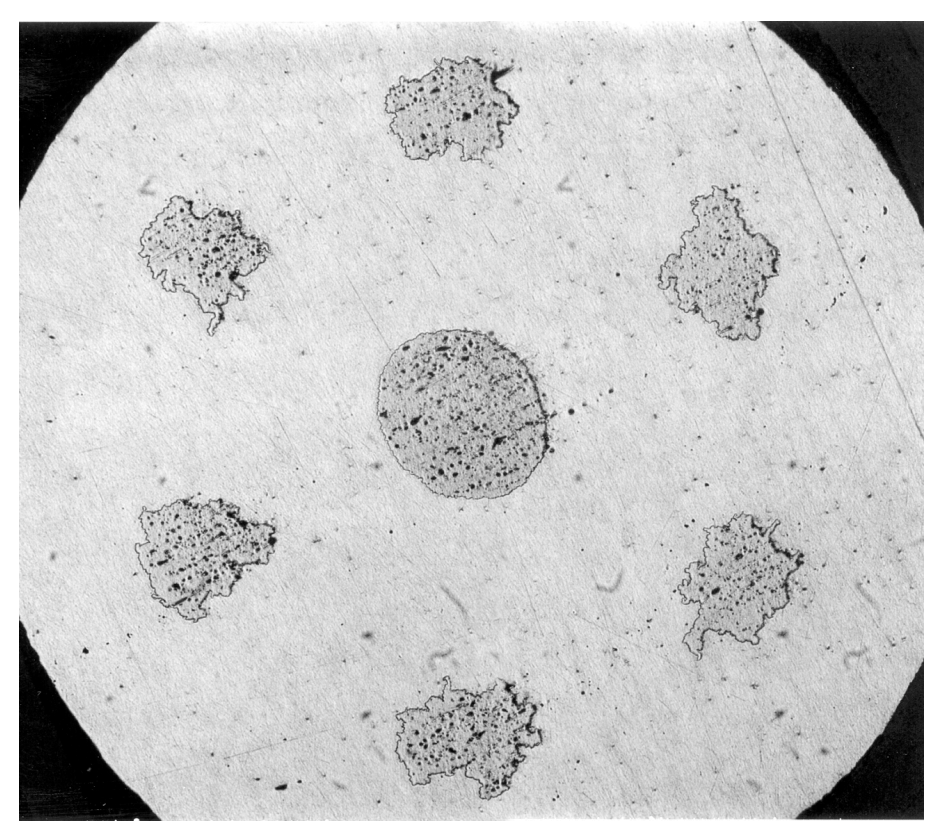

Figure 5, A cross section of 6 outer $\mathrm{NbZrO}_{2}$ filaments and one inner $\mathrm{Nb}$ filaments at $2.5 \mathrm{~mm}$ in a bronze matrix.

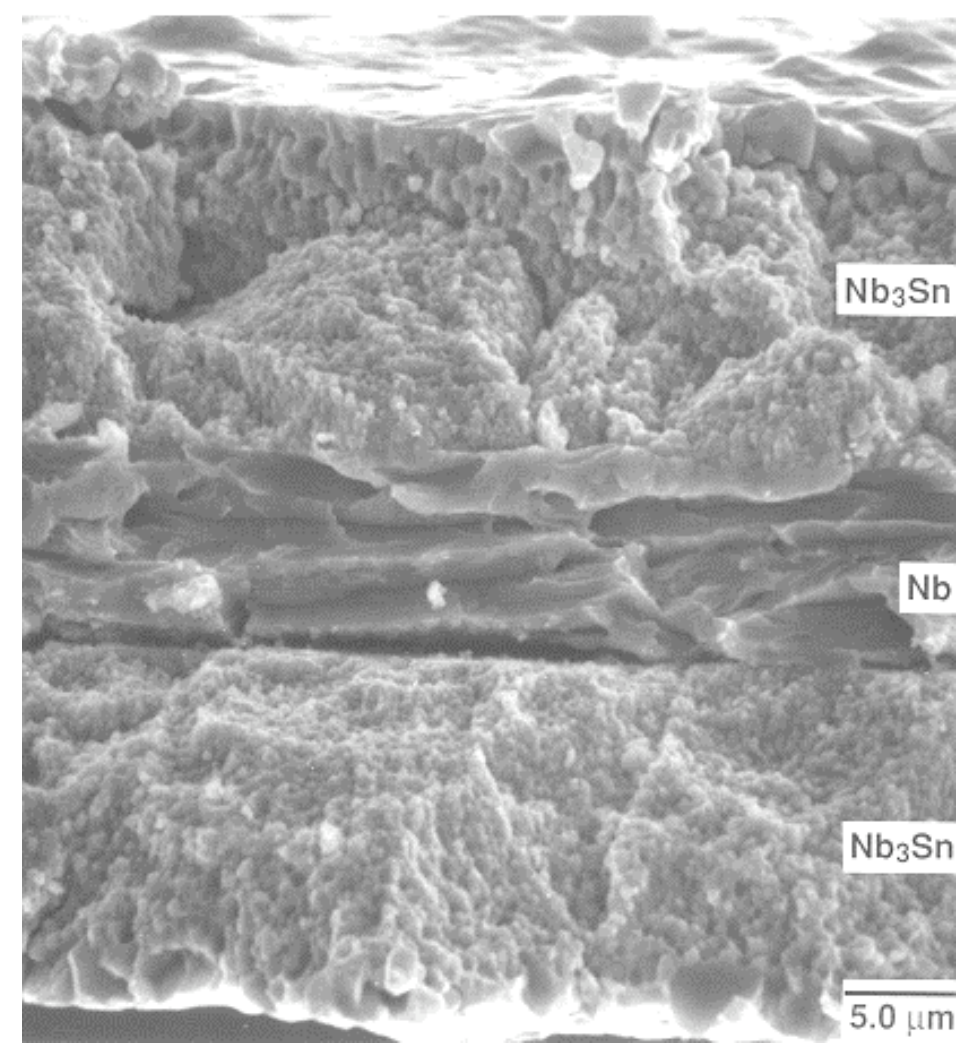

Figure $6, \mathrm{~A} \mathrm{NbZrO}_{2}$ tape $200 \mathrm{~s}$ at $1050^{\circ} \mathrm{C}$ showing fine equi-axed $\mathrm{Nb}_{3} \mathrm{Sn}$ grains. 


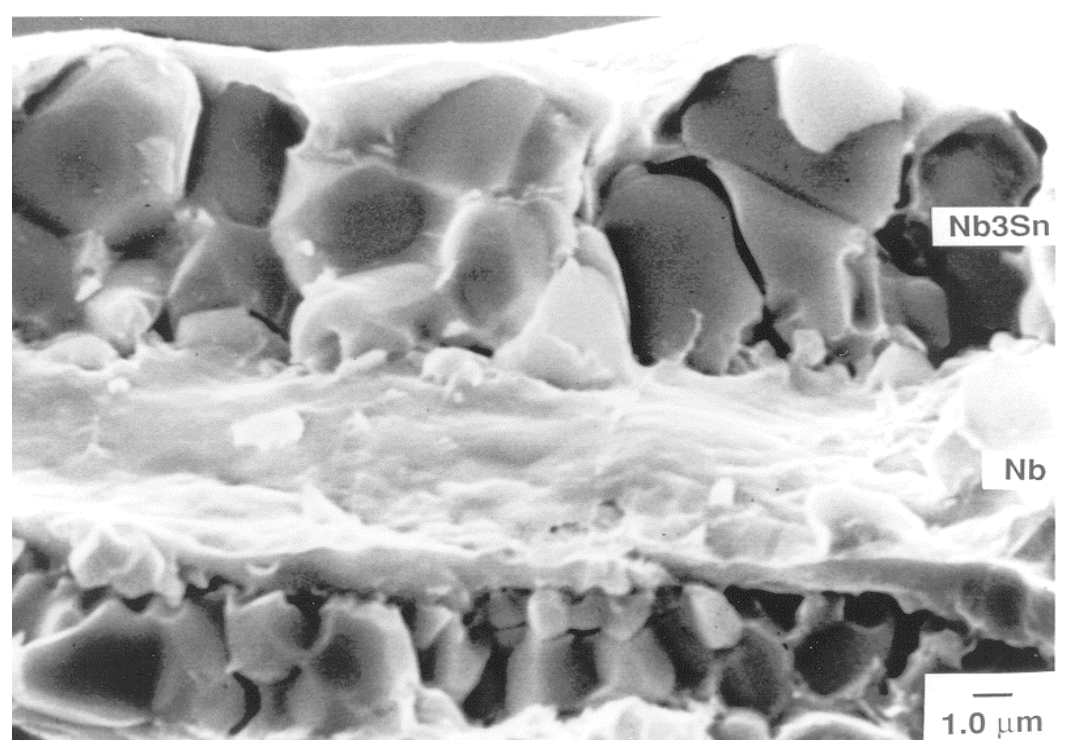

Figure 7, A Pure Niobium Tape with Large $\mathrm{Nb}_{3} \mathrm{Sn}$ Columnar Grains after 3000s at $1050^{\circ} \mathrm{C}$.

the strength of the Nb1at.\%Zr alloy and that of $\mathrm{Cu}$ at this temperature, compared with that between pure $\mathrm{Nb}$ and $\mathrm{Cu}$, (see Fig.8) Previous work carried out by General Electric on fully annealed material in a bronze matrix had shown that the same alloy could be extruded at $675^{\circ} \mathrm{C}$ and then drawn down at least to some degree. Presumably the bronze was significantly stronger than $\mathrm{Cu}$ in these extrusions. The data, shown in Fig. 8, for $\mathrm{Nb} 1$ at. $\% \mathrm{Zr}$ and $\mathrm{Nb}$ are taken from the literature ${ }^{28}$. The $\mathrm{Cu}$ data is taken from the Metals Handbook and all are materials with relatively low $\mathrm{O}_{2}$ contents. It is known however, that

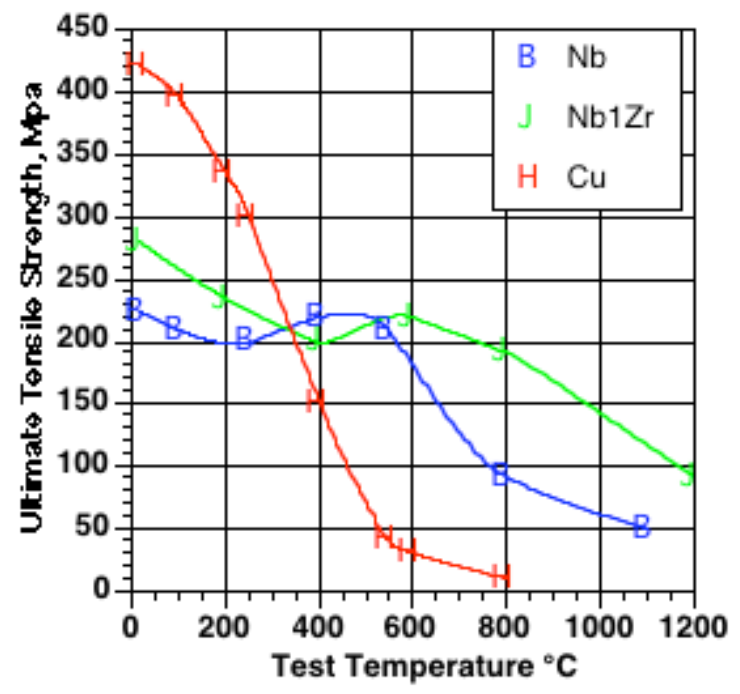

Figure 8. Comparative Tensile Properties of $\mathrm{Cu}, \mathrm{Nb}$, and low $\mathrm{O}_{2} \mathrm{Nb} 1 \mathrm{at} \% \mathrm{Zr}$. 
niobium zirconium alloys can be markedly increased in strength in the presence of low partial pressures of oxygen during vacuum annealing for long periods in the temperature range $700-1000^{\circ} \mathrm{C}{ }^{29}$. In strained alloys the temperature for maximum hardening was found to be $800^{\circ} \mathrm{C}$. The yield and ultimate tensile strengths of $\mathrm{NbZr}$ and $\mathrm{NbWZr}$ alloys at room temperature are reported by these authors ${ }^{29}$ to have been doubled by internal oxidation of $1 \mathrm{~mm}$ thick sheet at $800^{\circ} \mathrm{C}$ and $1200^{\circ} \mathrm{C}$ for $100 \mathrm{~h}$. The creep resistance was also greatly increased as a result of this treatment. The alloy that we attempted to extrude in Phase I, already contained a significant amount of oxygen and was somewhat cold worked. It can be expected that, in this material, strengthening could have taken place more rapidly, possibly during billet heating prior to extrusion. Assuming that the oxygen was present in the same solution condition in the rods that were extruded satisfactorily by G.E. previously, the strengthening effect may have been less at $675^{\circ} \mathrm{C}$, particularly as this material was in the annealed condition. In addition the bronze matrix is expected to have a significantly higher flow stress than the pure copper.

Lowering the temperature of extrusion and reducing the oxygen content was expected to facilitate homogeneous extrusion and this approach was explored in Phase I by extruding a billet containing commercial (relatively low $\mathrm{O}_{2}$ ) $\mathrm{Nb} 1 \mathrm{Zr}$ (at\%) alloy rods at $450^{\circ} \mathrm{C}$, a temperature shown in Fig. 8 to be one where the difference in tensile properties between $\mathrm{Nb}$ and $\mathrm{Nb} 1 \mathrm{Zr}$ is small and $\mathrm{Cu}$ is much stronger than at the higher temperatures. Unfortunately this low temperature extrusion resulted in the introduction of a large amount of cold work and breakage problems were encountered when the wire was reduced below 1 or $2 \mathrm{~mm}$ in diameter. A review of the Avitzur criteria, indicates that the drawing parameters used may have led to filament sausage and then failure in spite of the ductility of the components. A short anneal at $800^{\circ} \mathrm{C}$ after the extrusion has solved this $\mathrm{f}$ problem for processing this $\mathrm{Nb} 1 \mathrm{Zr}$ based composites. Alternatively it may not be necessary to extrude at such a low temperature and this was investigated in Phase II. From this preliminary work it appears that it would be desirable if most of the fabrication could be performed on a $\mathrm{Nb} 1 \mathrm{Zr}$ alloy that was low in oxygen. Ideally it would be best if the oxygen is introduced into the alloy when its dimensions are as close to the final one as possible. This is our second approach.

In an effort to fabricate the $\mathrm{Nb1}(\mathrm{at} \%) \mathrm{Zr}$ into fine filaments in a $\mathrm{Cu}$ matrix and still produce additional pinning sites based on some form of $\mathrm{ZrO}_{2}$, we explored the following approaches;

We first tested the fabricability of the Nb1Zr alloy as it is available commercially and determined if it shows a finer grain size of $\mathrm{Nb}_{3} \mathrm{Sn}$ than that made from $\mathrm{Nb}$.

It has been shown previously by LBNL that the grain size of an as cast $\mathrm{Nb} 1 \% \mathrm{Zr}$ a $34.9 \mathrm{~mm}$ (9.5") billet from Reference Metals Corporation (RMC) was measurably smaller than that of a similarly processed $\mathrm{Nb}$ billet. Comparing Figs. 9 and 10 shows this. 
The indications from the work carried out in Phase I of this contract are, that if we choose the extrusion conditions carefully, this material can be successfully extruded and although some problems were encountered while reducing the material to wire, it is expected that by modifying the fabricating conditions, these will be overcome. It remains to be shown how the grain size and properties of the $\mathrm{Nb}_{3} \mathrm{Sn}$ formed by reaction with $\mathrm{Sn}$ in this material differ from those when pure $\mathrm{Nb}$ is the filamentary material.

Since our initial Phase I work we are now cognizant of the increased high temperature strength of the $\mathrm{Nb} 1$ at $\% \mathrm{Zr}$ alloy (Fig. 8) and its sensitivity to internal oxidation. ${ }^{28}$ \& 29 Once we have determined how to process the regular alloy to fine wire we examined again the high oxygen alloy, its fabrication ability.

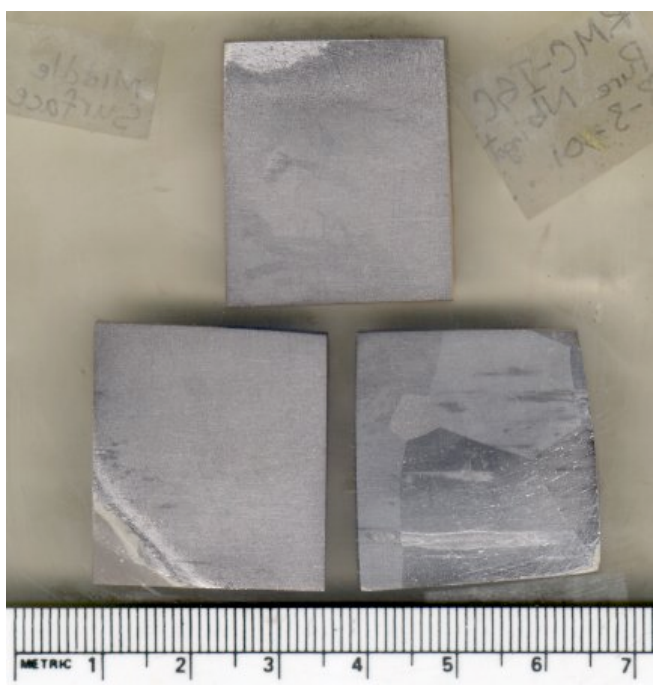

Figure 9. Polished and etched sections of the pure $\mathrm{Nb}$ "as cast" billet showing large grain size. Photograph courtesy of LBNL.

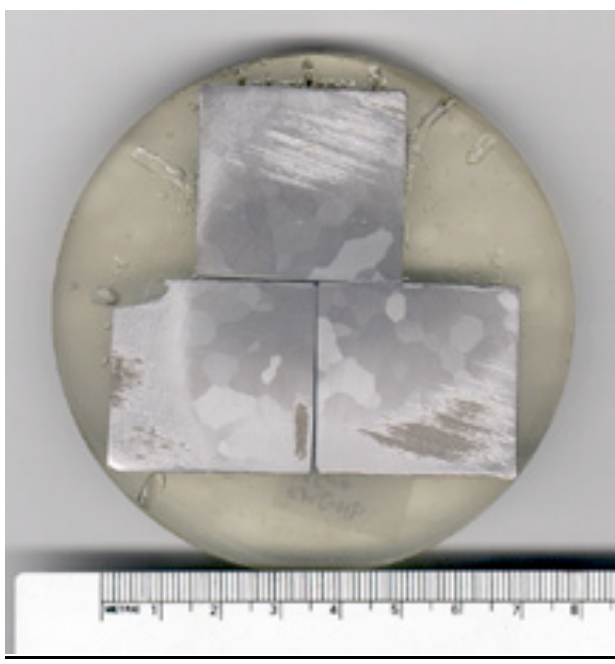

Figure 10. Polished and etched sections of $\mathrm{Nb} 1 \% \mathrm{Zr}$ "as cast" billet showing a grain size smaller than that in Figure 9. Photograph courtesy of LBNL. 
As expected this work shows a marked difference in the fabrication ability of the two alloys with different oxygen contents. Or second parallel approach introduces oxygen into the alloy at the final stage in the process, followed by an internal oxidization of the wire.

As has been mentioned above it is known that a marked increase in strength in this $\mathrm{Nb} 1 \% \mathrm{Zr}$ alloy can be achieved by annealing for long periods in a low partial pressure of oxygen during vacuum annealing on the temperature range $700^{\circ} \mathrm{C}$ to $1000^{\circ} \mathrm{C}$. $^{29}$ This is due to internal oxidation and we will review this phenomenon briefly and show that it can be used to effect the objectives outlined, i.e. to introduce oxygen at a late stage in the manufacturing process.

Internal Oxidation.

The conditions for the formation of a stable dispersion of a compound $\mathrm{BX}$ in a metal $\mathrm{A}$ by diffusing element $\mathrm{X}$ into a solid solution of $\mathrm{A}$ and $\mathrm{B}$ have been discussed by many authors in the past starting with Rhines ${ }^{30}$ and Meijering ${ }^{31}$ followed shortly afterwards by groups at the University of Cambridge, $\mathrm{UK}^{32 \& 33}$ and MIT. ${ }^{34}$

The ideal conditions are as follows:

1. $\mathrm{X}$ must diffuse more rapidly in solvent $\mathrm{A}$ than it does solute $\mathrm{B}$ otherwise a surface layer BX will be formed.

2. The free energy of formation of the compound BX must be much more negative than that of the compound AX.

When gases are soluble in metals they generally diffuse far more quickly than do metallic solute elements and therefore are ideally suited to the formation of a disperse phase by this method. In general noble metals alloyed with a small percentage of a metal having a high affinity for oxygen are very suitable for internal oxidation. Silver (top left corner of Fig. 11) is ideal as its oxide is unstable above $200^{\circ} \mathrm{C}^{35}$, thus a stable oxide scale can be eliminated.

Internal oxidation also takes place in copper alloys despite the fact that a surface layer of oxide also forms. The dissociation pressure of $\mathrm{Cu}_{2} \mathrm{O}$ at the heat treatment temperature governs the diffusion rate of the oxygen below this surface layer.

Ref. 29 reports that annealing at $800^{\circ} \mathrm{C}$ for $100 \mathrm{hr}$. at pressures close to $10^{-6}$ torr, produces an appreciable strength increase in re-crystallized $\mathrm{Nb} 1 \mathrm{~W} 1 \mathrm{Zr}$ alloys and suggests that a similar change takes place in the Nb1Zr alloy. Fig. 11 shows the free energy of formation of the oxides (where $\mathrm{X}=\mathrm{O}$ ). The larger the difference between the curves of the solvent, $(\mathrm{A}-\mathrm{Nb})$ and that of the oxide forming element $(\mathrm{B}-\mathrm{Zr})$, the smaller the precipitate and the more potent the hardening effect. The effect is obviously most significant in systems such as silver or copper with magnesium, aluminum or zirconium. There is however a significant separation between the $\mathrm{NbO}_{2}$ and $\mathrm{ZrO}_{2}$ curves [shown in red] confirming that strength increases can be expected by subjecting a niobium zirconium alloy to a low partial pressure of oxygen as has been reported. ${ }^{29}$ The curves also show that it can be expected that the $\mathrm{Nb}$ alloy will reduce $\mathrm{Cu}_{2} \mathrm{O}$ [also shown in red] and take up the oxygen from the $\mathrm{Cu}$.

In green we have shown the curves for $\mathrm{Sn}$ and $\mathrm{Ti}$. The $\mathrm{TiO}_{2}$, while not as stable as $\mathrm{ZrO}_{2}$ is similar to $\mathrm{NbO}_{2}$ and may compete for oxygen at various stages of the heat treatment. 
$\mathrm{SnO}_{2}$ may not be a problem as it is less stable than most of the other materials.

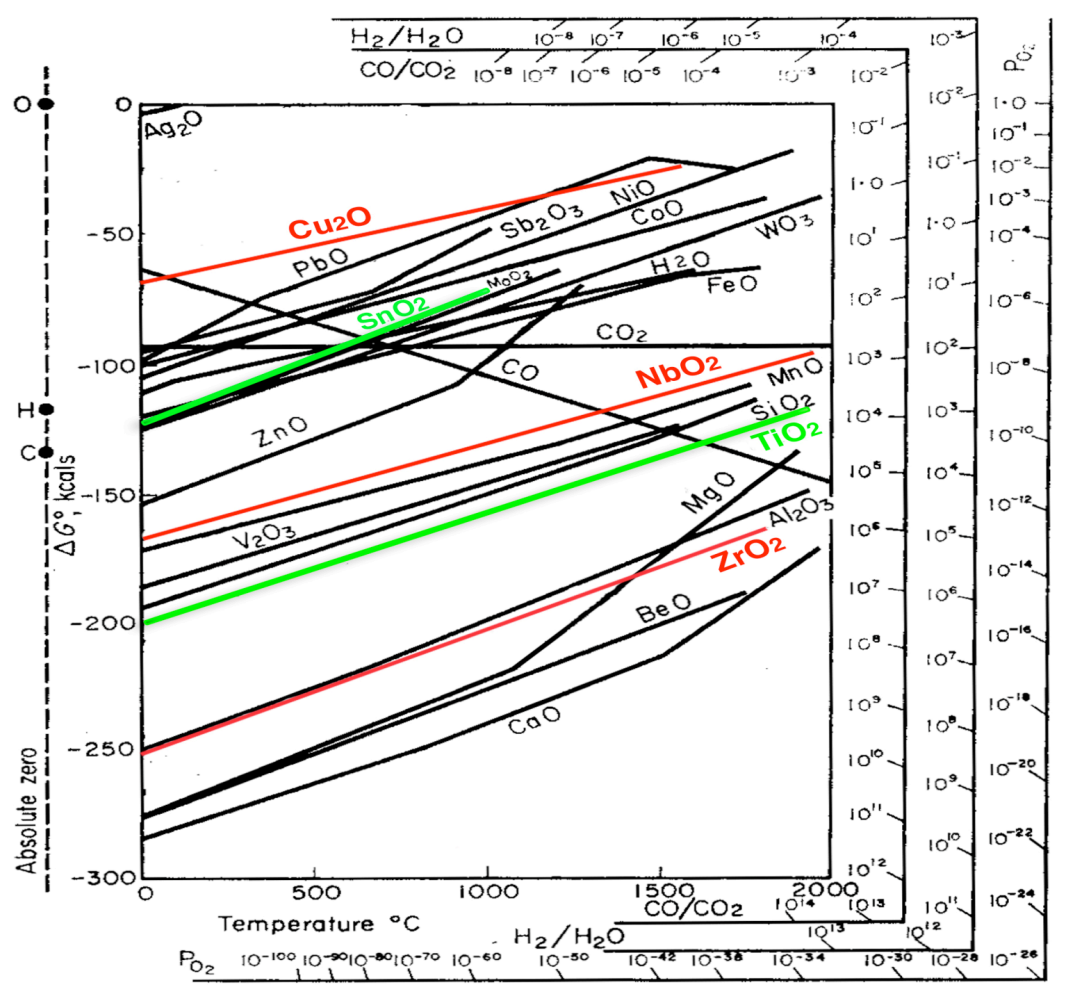

Fig. $11 \Delta G^{\circ}$ in free energy when one mole of gaseous oxygen at $1 \mathrm{~atm}$. pressure combines with a pure element to form an oxide.

The original objective was to load oxygen into the copper matrix by a number of means. This proved much more difficult than justified especially after development of introduction of oxygen through $\mathrm{SnO}_{2}$ introduced through mixing the oxide with $\mathrm{Sn}$ powder for the tin core

Oxygen diffuses through metals upward from a 1000 times as fast as any metals diffusing through other metals ${ }^{38}$ and so we anticipate having little trouble in getting the oxygen into and through the $\mathrm{Nb}$ to react with the $\mathrm{Zr}$ and form a fine dispersion of $\mathrm{ZrO}_{2}$ ahead of the formation of $\mathrm{Nb}_{3} \mathrm{Sn}$.

It is known that exposing $\mathrm{NbZr}$ alloys to a low partial pressure of oxygen at $800^{\circ} \mathrm{C}$ produces the highest hardness ${ }^{29}$ and this is presumably because it causes the best distribution of pinning sites for dislocations etc. to be created. Such distributions could also be ideal for pinning flux, reducing grain growth and thus for providing high $\mathrm{J}_{\mathrm{c}}$. A long time at $700^{\circ} \mathrm{C}$ or even $650^{\circ} \mathrm{C}$ the temperatures normally used to form $\mathrm{Nb}_{3} \mathrm{Sn}$, may also provide a satisfactory pinning array. 
Table I gives the diffusion constants for $\mathrm{O}_{2}$ in $\mathrm{Cu}, \mathrm{Nb}$ and $\mathrm{Ta}$ taken from a paper by R. Kirchheim. ${ }^{39}$ Values are calculated for $\mathrm{D}$ at both 700 and $500^{\circ} \mathrm{C}$. The lower temperature is presumed to be more appropriate to diffuse the $\mathrm{O}_{2}$ through the copper and into the $\mathrm{Nb} 1 \mathrm{Zr}$ prior to reaction of the $\mathrm{Nb}_{3} \mathrm{Sn}$. It is realized however, that at $500^{\circ} \mathrm{C}$ oxygen diffusion may occur preferentially along the grain boundaries. ${ }^{38}$

Table I Diffusion Parameters for Key Metals in Superconductor

\begin{tabular}{|l|r|r|r|r|}
\hline Element & \multicolumn{1}{c|}{$\mathrm{D}_{0} \mathrm{~m}^{2} / \mathrm{sec}$} & $\mathrm{Q} \mathrm{Kcal} / \mathrm{mole}$ & $\mathrm{D} \mathrm{m}^{2} / \mathrm{sect}$ at $500^{\circ} \mathrm{C}$ & $\mathrm{D} \mathrm{m}^{2} / \mathrm{sec}$ at $700^{\circ} \mathrm{C}$ \\
\hline $\mathrm{Cu}$ & $5.8 \mathrm{E}-07$ & 57.4 & $7.71 \mathrm{E}-11$ & $4.83 \mathrm{E}-10$ \\
\hline $\mathrm{Nb}$ & $1.7 \mathrm{E}-06$ & 108 & $8.66 \mathrm{E}-14$ & $2.73 \mathrm{E}-12$ \\
\hline $\mathrm{Ta}$ & $3.5 \mathrm{E}-07$ & 99.3 & & $1.65 \mathrm{E}-12$ \\
\hline
\end{tabular}

It has been shown in an infinite cylinder of radius $L$ that equilibrium with the diffusing gas at the center is established based on the formula ${ }^{40}$ :

$$
\mathrm{T}(\text { time })=.9^{2} * \mathrm{~L}^{2} / \mathrm{D}(\text { the diffusion constant })
$$

For a typical MEIT processed conductor, a likely wire size would be $0.25 \mathrm{~mm}$ diameter (1.27 E-4 m radius) with a Nb1Zr filament size of 1 micron $(1 \mathrm{E}-6 \mathrm{~m})$ radius. With these assumptions at $500^{\circ} \mathrm{C}$ Table II gives the time to establish equilibrium with the surface atmosphere. As it can be seen this is quite short compared to homogenization and reaction times. Since the $\mathrm{Zr}$ will absorb the oxygen from the $\mathrm{Nb}$ and precipitate the oxide, the system acts as a pump to adsorb the oxygen as $\mathrm{ZrO}_{2}$ until all is oxidized. Careful control of the oxygen through a partial pressure established in the vacuum system or provided by the $\mathrm{O}_{2}$ in the tin core can be established such that the sufficient moles of oxygen will be available to precipitate the moles of $\mathrm{Zr}$ incorporated into the strand.

As can be seen conductors of other configurations at substantially larger sizes should also present no problem to internal oxidation.

Table II. Time to establish equilibrium of Oxygen within MEIT Conductor Element

\begin{tabular}{|l|r|r|}
\hline Conductor Element & Temperature $^{\circ} \mathrm{C}$ & Time sec/min \\
\hline $\mathrm{Cu}, 1.27 \mathrm{E}-4$ radius & 500 & $4781 / 79$ \\
\hline $\mathrm{Nb}$ filament 1E-6 radius & 500 & $150 / 2.49$ \\
\hline
\end{tabular}

\section{c. Technical Approach}

There are two general approaches in which to make a cost effective superconductor for this application: -

1. Improve the current carrying capability of the superconductor.

2. Change the manufacturing process so that it is more efficient and less costly.

In contract \# DEFG0299ER82899 we have concentrated on approach 2 by developing the MEIT process. In this proposal we are attempting to significantly increase the current carrying capacity of the strand. Most of the work in recent years with this objective in 
mind has been to change the strand design so as to include the highest amount of $\mathrm{Nb}$ and $\mathrm{Sn} / \mathrm{Ti}$ possible. This approach has yielded $3000 \mathrm{~A} / \mathrm{mm}^{2}$ at $12 \mathrm{~T}$ as demonstrated by the MEIT approach and Oxford but the $\mathrm{d}_{\mathrm{eff}}$ of $40 \mu \mathrm{m}$ has not been achieved. This is difficult to achieve without improving the inherent current density in the filaments such that the amount of $\mathrm{Nb}$ could be reduced. With higher layer current density $\mathrm{d}_{\mathrm{eff}}$ could be reduced by a combination of fins and or greater spacing of the $\mathrm{Nb}$ elements.

The objectives of this work were originally to investigate the above through the following work:

1. Replace the niobium filaments used in much of the internal-tin work with regular Nb1at.\%Zr containing the standard amount of oxygen (i.e. $<250 \mathrm{ppm}$ usually $<100 \mathrm{ppm}$ ). Compare the grain size and the properties after reaction heat treatment with material without $\mathrm{Zr}$. This will help us to determine the effect of $\mathrm{Zr}$ with and without $\mathrm{Ti}$ additions and without intentional addition of oxygen.

2. As a result of our Phase I work, it is suspected that there may be some limitations to the extent to which the high oxygen $\mathrm{Nb} 1 \mathrm{Zr}$ can be made into the required superconducting strand. The second objective will therefore be to fabricate the low oxygen containing $\mathrm{Nb} 1 \mathrm{Zr}$ close to finished size before introducing the oxygen into the alloy.

3. Repeat the work attempted in Phase I with $\mathrm{Nb} 1 \mathrm{Zr}$ containing a significant amount of oxygen. (i.e. $2 \mathrm{at} \% \mathrm{O}_{2}$ ) Again compare the grain size and the properties after reaction heat treatment. This will give us a better idea of the extent to which such material can be made into fine filament strand now that we are more aware of some of the limits to the conditions that can be employed.

\subsection{Work on phase I material and oxidation experiments}

The detailed objectives were:

1. Gather as much information as possible from the material produced in Phase I.

2. Determine the best extrusion conditions and thermo-mechanical treatment to process the low oxygen $\mathrm{Nb} 1 \mathrm{at} . \% \mathrm{Zr}$ alloy.

3. Using a relatively simple billet assembly technique - rods and tubes in $89 \mathrm{~mm}(3.5$ ") $\varnothing$ billets- determine the effect of $\mathrm{Zr}$ and $\mathrm{O}_{2}$ on the grain size and properties of the $\mathrm{Nb}_{3} \mathrm{Sn}$ produced by reaction heat treatment. Compare them with those resulting from material without $\mathrm{Zr}$ and $\mathrm{O}_{2}$ in the $\mathrm{Nb}$.

4. To improve the overall $\mathrm{I}_{\mathrm{c}}$ by lowering the amount of $\mathrm{Cu}$ inside the barrier, repeat some of the above by using $\mathrm{Cu}$-clad rods in two conditions

Low oxygen in the Cu cladding

Higher oxygen in the $\mathrm{Cu}$ cladding

From the results of the work on 1 above, this objective has to be modified. 
5. Again attempt to determine the fabricability of the high $\mathrm{O}_{2} \mathrm{Nb} 1 \mathrm{at} . \% \mathrm{Zr}$ by processing a $50.8 \mathrm{~mm}$ (2") $\varnothing$ drilled billet and comparing the results with a similar one made using annealed $\mathrm{Nb}$ rods.

6 Finally prove the commercial viability of the approach by making and testing a $203 \mathrm{~mm}\left(8^{\prime \prime}\right) \varnothing$ or two $177 \mathrm{~mm}$ (7') Ø billets using the techniques that have been shown to give the most promise in the preceding work.

The designs for the cans, noses and lids are shown in Figure 1. These have been made at Draher Machine Inc. in Waterbury CT and delivered to GE CRD. Oxide powders, $\mathrm{Cu}_{2} \mathrm{O}, \mathrm{Ag}_{2} \mathrm{O}$ and $\mathrm{SnO}_{2}$ were obtained by GE CRD.
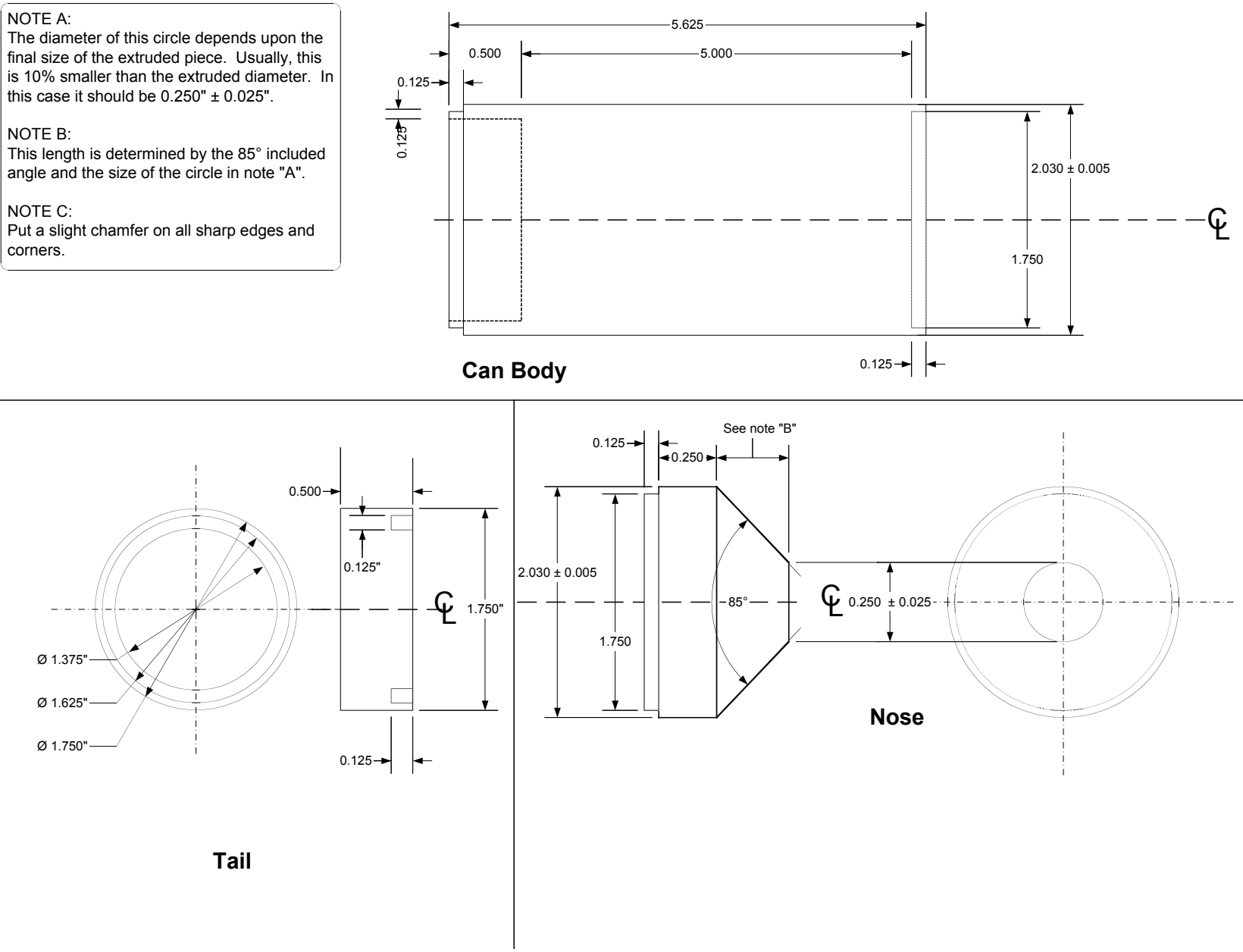

Figure 1.1. Design of the 2" $\varnothing$ can, nose and lid

Materials for fixtures to hold the samples to be heat treated in quartz tubes were purchased and the fixtures built. 
1. Examination and Testing of Phase I materials.

In Phase I, a billet was successfully extruded and $1000 \mathrm{~mm}$ of sound material at 21,3 $\mathrm{mm}$ diameter obtained. This was gun drilled with a $8.71 \mathrm{~mm}$ hole at Grover Gundrilling in Norway ME. The material was cut in half at Outokumpu Advanced Superconductors and pure $\mathrm{Sn}$ inserted into one rod (ZAB1B) and the usual $\mathrm{Sn} / \mathrm{Ti}$ inserted into the other (ZAB1A). This material, although its filaments were significantly "sausaged", was chosen for heat treatment and further analysis.

Table 1 summarizes the characteristics and the conditions under which the samples were treated. The samples were sealed in quartz ampoules and the heat treatment conditions were: ramp to $180^{\circ} \mathrm{C}$ at $10^{\circ} \mathrm{C} / \mathrm{h}$, hold for $24 \mathrm{hr}$, ramp to $340^{\circ} \mathrm{C}$ at $5^{\circ} \mathrm{C} / \mathrm{hr}$, hold for $24 \mathrm{hr}$, ramp to $700^{\circ} \mathrm{C}$ at $25^{\circ} \mathrm{C} / \mathrm{h}$, hold for $47 \mathrm{hr}$ and water quench.

Table 1

\begin{tabular}{|l|l|l|l|l|l|l|l|l|}
\hline Sample ID & Diameter & Length & Mass & & & & & \% wt of \\
\hline & in & in & grams & Powder & quantity & grams in & & sample \\
\hline & & & & & grams & ampoule & & \\
\hline ZAB 1A \#1 & $\mathbf{0 . 0 3 6 5}$ & $\mathbf{2 . 0 6 3}$ & $\mathbf{0 . 2 9}$ & none, control & & & & \\
\hline ZAB 1A \#2 & $\mathbf{0 . 0 3 6 5}$ & $\mathbf{2 . 0 6 3}$ & $\mathbf{0 . 3}$ & $\mathbf{C u}, \mathrm{Cu}_{2} \mathbf{O}, \mathrm{Al}_{2} \mathrm{O}_{3}$ & $\mathbf{0 . 2 9 2 4}$ & & & \\
\hline ZAB 1A \#3 & $\mathbf{0 . 0 3 6 5}$ & $\mathbf{2 . 1 2 5}$ & $\mathbf{0 . 3}$ & $\mathbf{A g O}$ & $\mathbf{0 . 0 1 5 9}$ & $\mathbf{0 . 0 1 5 9}$ & $\mathbf{2}$ At\% in sample & $\mathbf{5 . 3 0 \%}$ \\
\hline ZAB 1A \#4 & $\mathbf{0 . 0 3 6 5}$ & $\mathbf{1 . 8 1 2 5}$ & $\mathbf{0 . 2 6}$ & $\mathbf{A g O}$ & $\mathbf{0 . 0 3 0 5}$ & $\mathbf{0 . 0 3 0 5}$ & $\mathbf{4}$ At\% in sample & $\mathbf{1 1 . 7 3 \%}$ \\
\hline
\end{tabular}

\section{ZAB $1 \mathrm{~A} \# 1$}

There was no oxygen in this ampoule and, if we assume that some of the colors are due to actual compositional variations and are not artifacts, the tin has diffused to the outer row of filaments although they are more reacted on the surfaces closer to the center. Figures $1.2 \& 1.3$, the maximum reacted layer (on the inner ring) is $\sim 13 \mu \mathrm{m}$.

There are several unusual effects compared with what we normally see while processing $\mathrm{Nb}$ containing $\mathrm{Cu}$ with $\mathrm{Sn} / \mathrm{Ti}$. There appears to be another layer outside the reacted layer on the filaments on the side facing the tin, Figure 1.3. The central tin area has no $\mathrm{Sn} / \mathrm{Ti}$ inclusions although $\mathrm{Sn} / \mathrm{Ti}$ was supposed to have been inserted. There also appears a pink phase presumably due to the presence of $\mathrm{Cu}$. There is an outer layer of a different color and around the "black holes" in the center the pink is absent and the material looks to have polished as a harder material. The reacted layer (presumably $\mathrm{Nb}_{3} \mathrm{Sn}$ ) has a hardness of $503 \mathrm{HV}_{25}, 51 \mathrm{Rc}$ whereas the center of the filament is $164 \mathrm{HV}$ ${ }_{25}, 85 \mathrm{Rb}$ Figure 1.4. The sample was reported to have experienced a minor tin leak which may be the cause of central "black holes". 


\section{$\underline{Z A B} 1 \mathrm{~A} \mathrm{\# 2}$}

$\mathrm{Cu}_{2} \mathrm{O}$ appears to have had little effect on the amount of filament reaction, (Figures $5 \&$ 6). No double layer on the filaments is visible. No tin leak was reported and no central porosity but significant porosity in the inner row of filaments and the outer part of the central core has less of the $\mathrm{Cu}$ phase and appears harder.

\section{ZAB1A \#3}

This was heat treated with 0.0159 grams of Ag0, 2 At.\% in sample. Filaments still appear to have reacted to a similar extent as the first two samples. Still assuming the effects are not just artifact, there seems to be an asymmetry to the photograph. The inter-filamentary porosity on one side appears to be further into the filament array on one side. Also the core appears harder on one side than the other.

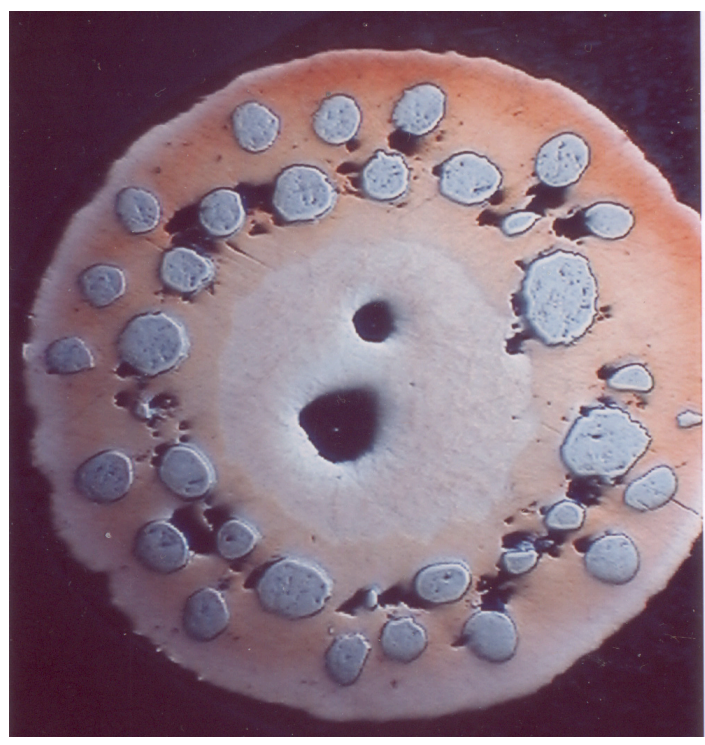

Figure 1.2. ZAB1A\#1

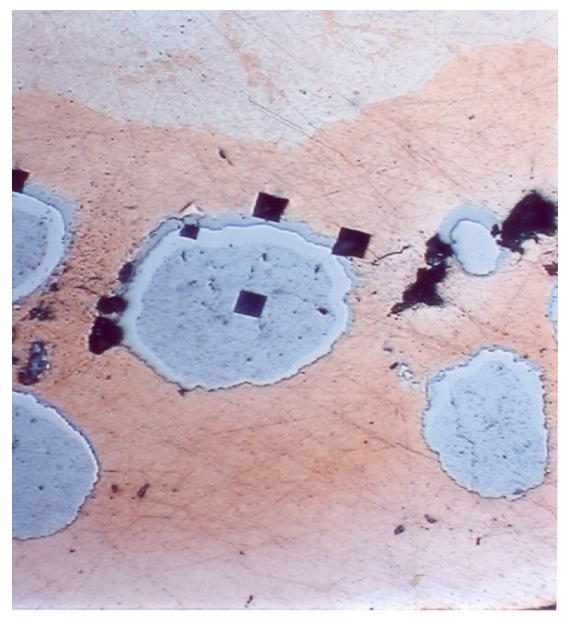

Fig.1.4 Hardness indentations ZAB1A X375

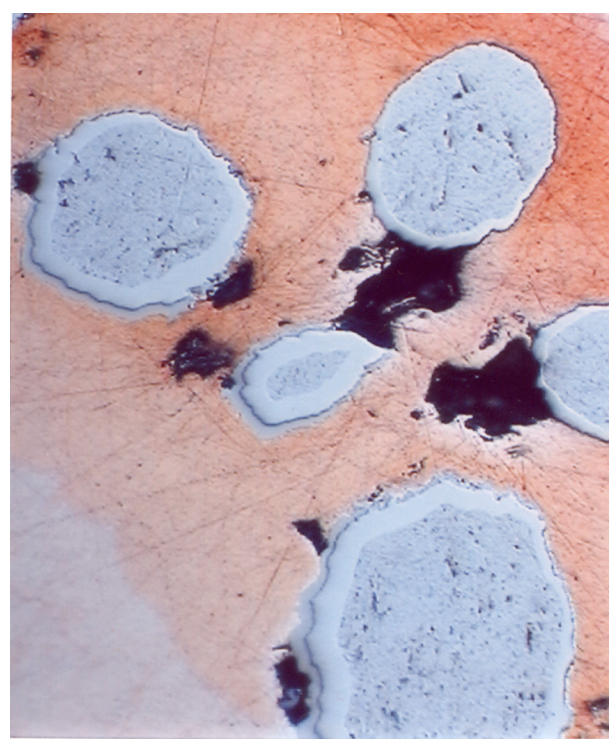

Figure 1.3. ZAB 1A\#1 375X

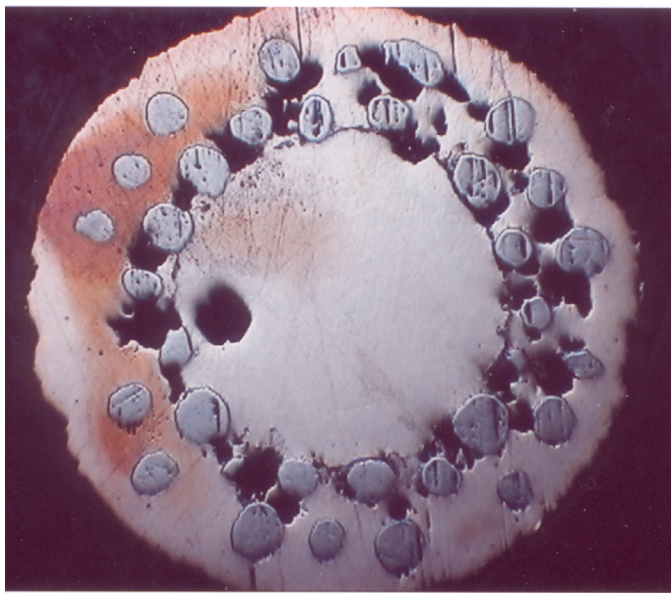

Fig. 1.5 ZAB 1A \#2 


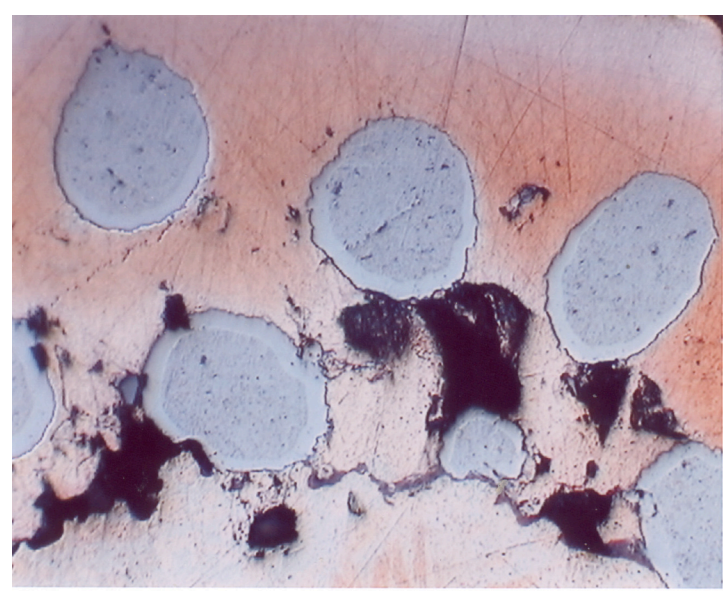

Fig.1.6 ZAB1A \#2 375X

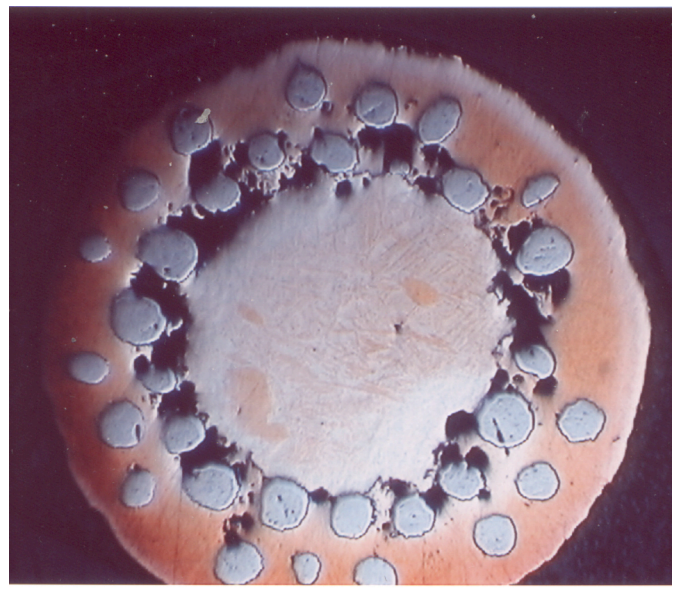

Fig. 1.7 ZAB 1A \#3

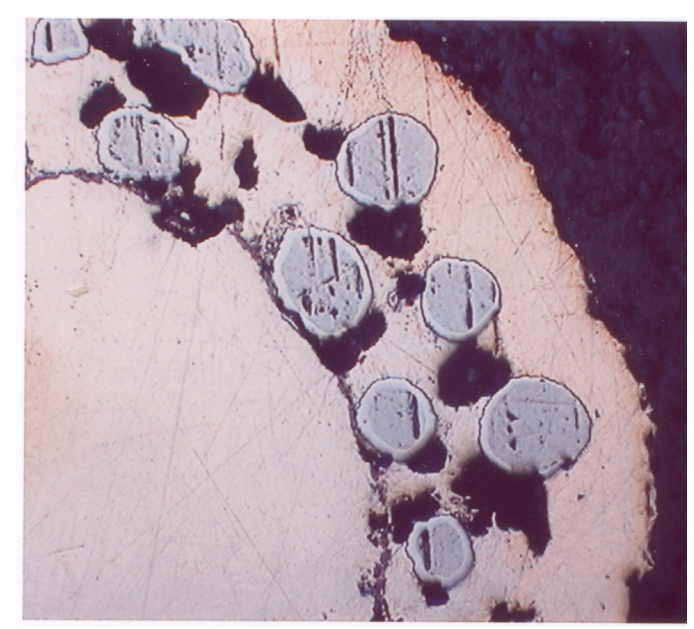

Fig. 1.8 ZAB1A \#3, 175

\section{ZAB1A \#4}

This was heat treated with 0.0305 grams Ag0, 4 At. \% in sample. The whole sample looks more symmetrical than in the case of \#3. The core and the filaments are hard and of one phase. The hardness indentations are shown in Fig.1.11 and both the central core and the filaments are $\mathrm{Rc} 52, \mathrm{HV}_{25}$ 572. The obvious questions are why the hard core and is the hardness for the filament due to oxygen or $\mathrm{Sn}$. 


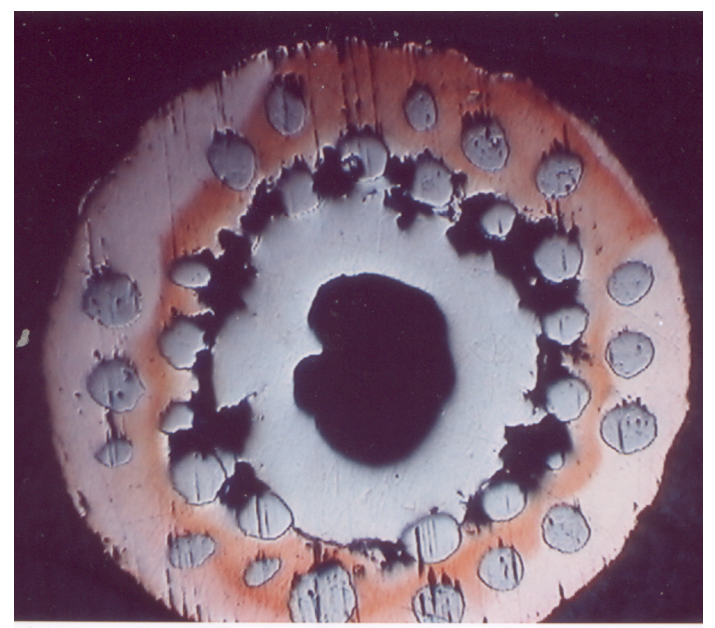

Fig. 1.9. ZAB1A \#4

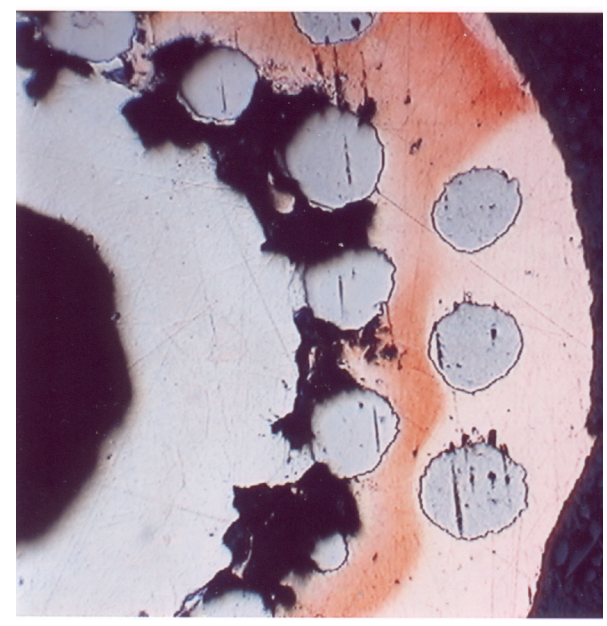

Fig. 1.10. ZAB1A \#4 $17 \mathrm{X}$

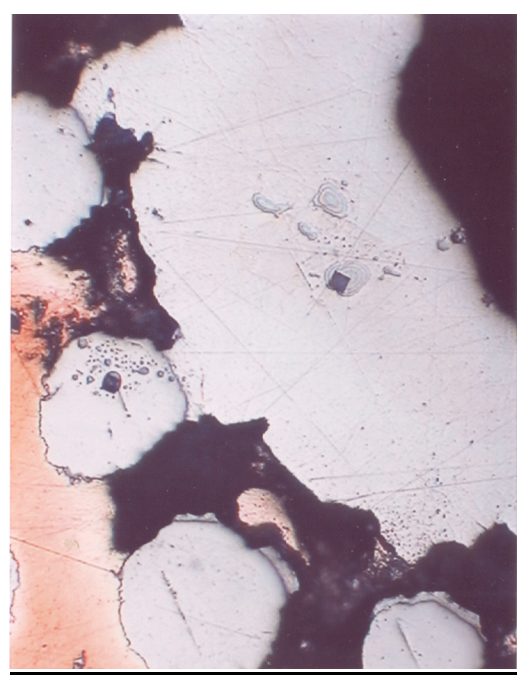

Fig. 1.11. Hardness indentations in ZAB1A \#4

\section{$\underline{\text { SEM Examination of ZAB1A\#1 and ZAB1A\#4 }}$}

\section{$\underline{\text { ZAB1A\#1 }}$}

Compositional traces of the three areas, $\mathrm{X}_{1}, \mathrm{X}_{2} \& \mathrm{X}_{3}$ in a filament are shown in Figs. 1.12 a, 1.12 b, 1.12 c \& 1.12 d

These show that under these conditions normal $\mathrm{Nb}_{3} \mathrm{Sn}$ formation is taking place but in addition an area with high ( $\sim 50 \mathrm{wt} . \%)$ Sn and containing 10wt.\% Cu in addition to $\mathrm{Nb}$ appears to have formed on the side of the filaments closest to the $\mathrm{Sn}$ source.

\section{ZAB1A\#4}

In order to determine the source of the hardness which appears in both the filaments and the core in this material, SEM and EDX analysis was carried out on 
two of the hard filaments, one of which showed a small surface area which appeared to have undergone reaction. The filament with no surface reaction, although hard, showed no evidence of Sn. The small surface area on the other did show some evidence of reaction.

The considerable difference between the results on ZAB1A \#4 and those on ZAB1A\#s 1-3 suggested that a serious tin leak had taken place, allowing oxidation to take place throughout the observed cross section. The opposite end of the same sample was examined and appeared to be similar.

It was decided to discontinue any further examination of these Phase I samples and to concentrate on oxidation experiments on $\mathrm{Nb}, \mathrm{Nb} 1 \mathrm{Zr}$ and OFHC and ETP $\mathrm{Cu}$, until new composites have been produced.

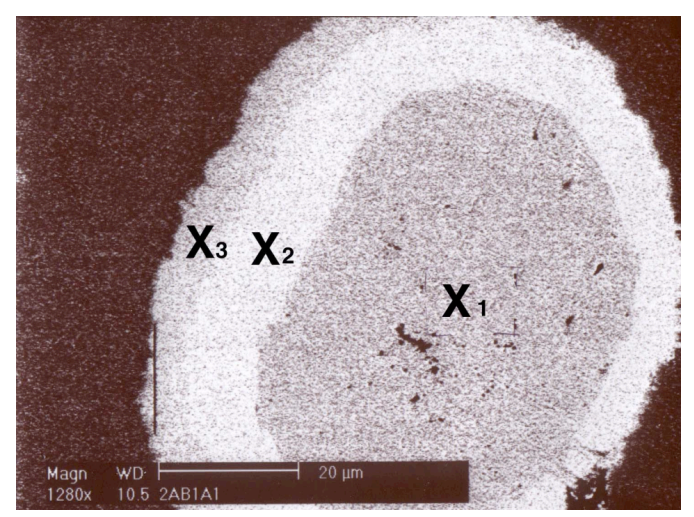

Fig. 1.12 a.

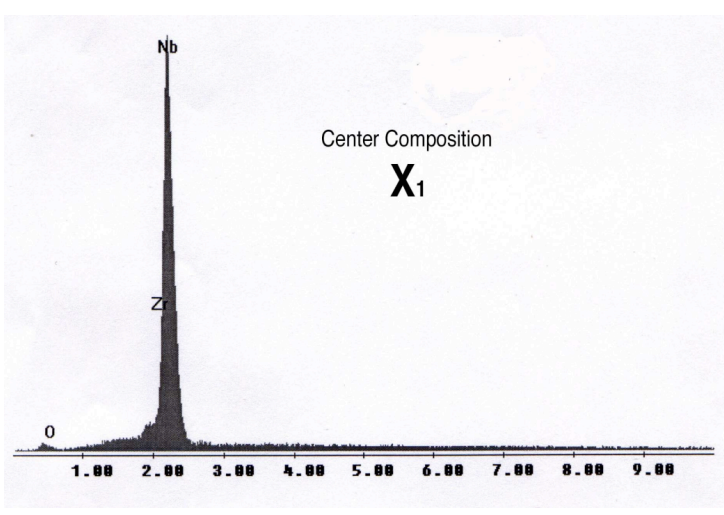

Fig. 1.12 b.

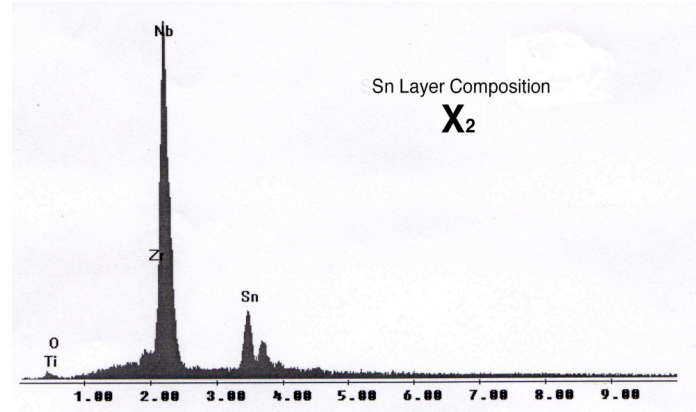

Fig. $1.12 \mathrm{c}$.

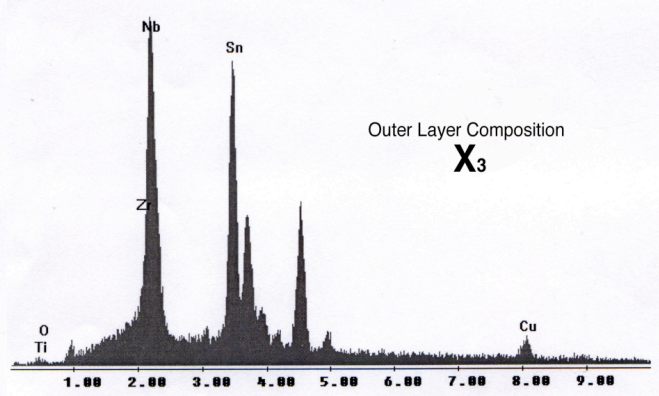

Fig. 1.12 d.

3. Methods of introducing $\mathrm{O}_{2}$ into the $\mathrm{Cu}, \mathrm{Nb}$ and $\mathrm{Nb} 1 \mathrm{Zr}$ explored.

It appeared from the work on the Phase I ZAB1A \#4 material that something, presumably oxygen, had significantly hardened the $\mathrm{Nb} 1 \mathrm{Zr}$ filaments and also the $\mathrm{Sn} / \mathrm{Ti}$ core. It was decided therefore to explore the direct exposure of $\mathrm{Nb}$ and $\mathrm{Nb} 1 \mathrm{Zr}$ 
to the same oxidizing environment that was used in the ZAB1A \#2 experiment. Table II shows the conditions. Again the samples were sealed in quartz ampoules and the heat treatment conditions were: ramp to $180^{\circ} \mathrm{C}$ at $10^{\circ} \mathrm{C} / \mathrm{h}$, hold for $24 \mathrm{~h}$, ramp to $340^{\circ} \mathrm{C}$ at $5^{\circ} \mathrm{C} / \mathrm{hr}$, hold for $24 \mathrm{~h}$, ramp to $700^{\circ} \mathrm{C}$ at $25^{\circ} \mathrm{C} / \mathrm{h}$, hold for $47 \mathrm{~h}$ and water quench.

In order to determine the extent to which oxygen could be introduced into OFHC and ETP $\mathrm{Cu}$ these samples were each heat treated under two different conditions: $450^{\circ} \mathrm{C}, 24 \mathrm{~h}$ and water quench, $800^{\circ} \mathrm{C}, 24 \mathrm{~h}$ and water quench (See Table III).

The copper samples developed a thick oxide composed of a black outer layer and a red-orange inner layer which increased in thickness with temperature. The oxide was removed using an abrasive tool prior to oxygen analysis being performed. The $\mathrm{Nb} 1 \mathrm{Zr}$ developed an outer layer which was visible as a more lustrous layer during the oxidizing treatment. It was also visible as an area in which the hardness was such that the abrasive $\mathrm{SiC}$ did not get imbedded during sample preparation Fig.1.13. This suggests a considerable penetration of $\mathrm{O}_{2}$.

Oxygen analysis was carried out on all these samples both before and after the oxidizing treatment. Table IV shows the results.

Hardness tests were also carried out on the various samples at room temperature, $300^{\circ} \mathrm{C}, 400^{\circ} \mathrm{C}$ and $500^{\circ} \mathrm{C}$. The results are shown in Figs 1.14-1.23. Fig. 1.14 shows the location of the region in which the hardness measurements were taken. Most readings were a long distance from the surface of the rods.

Table II

Sample ID DiameterLength Mass

in in grams Powder quantity grams in

grams

ampoule

$\begin{array}{llrrccr}\mathrm{d} & \mathrm{Nb} \# 1 & 0.1 & 1.75 & 1.94 \text { none, control } & - & \\ \mathrm{e} & \mathrm{Nb} \# 2 & 0.1 & 1.875 & 2.1 \mathrm{Cu}, \mathrm{Cu}_{2} \mathrm{O}, \mathrm{Al}_{2} \mathrm{O}_{3} & 2.1 & 1.5 \\ & & & & & & \\ \mathrm{f} & \mathrm{Nb}-1 \mathrm{Zr} \# 1 & 0.238 & 1.938 & 11.6 \text { none, control }- & - & \\ \mathrm{g} & \mathrm{Nb}-1 \mathrm{Zr} \# 2 & 0.238 & 1.813 & 11.14 \mathrm{Cu}, \mathrm{Cu}_{2} \mathrm{O}, \mathrm{Al}_{2} \mathrm{O}_{3} & 8.1 & 8.1\end{array}$


Table III

\begin{tabular}{ccccc} 
Sample ID & $\begin{array}{c}\text { Diameter } \\
\text { in }\end{array}$ & $\begin{array}{c}\text { Length } \\
\text { in }\end{array}$ & \multicolumn{2}{c}{ Mass } \\
& & & & Conditions \\
ETP Cu & 0.25 & 1.75 & 12.53 & air \\
OFHC Cu & 0.25 & 1.75 & 12.53 & air \\
ETP Cu\#2 & 0.25 & 1.875 & 13.36 & air \\
OFHC Cu \#2 & 0.25 & 1.875 & 13.35 & air
\end{tabular}

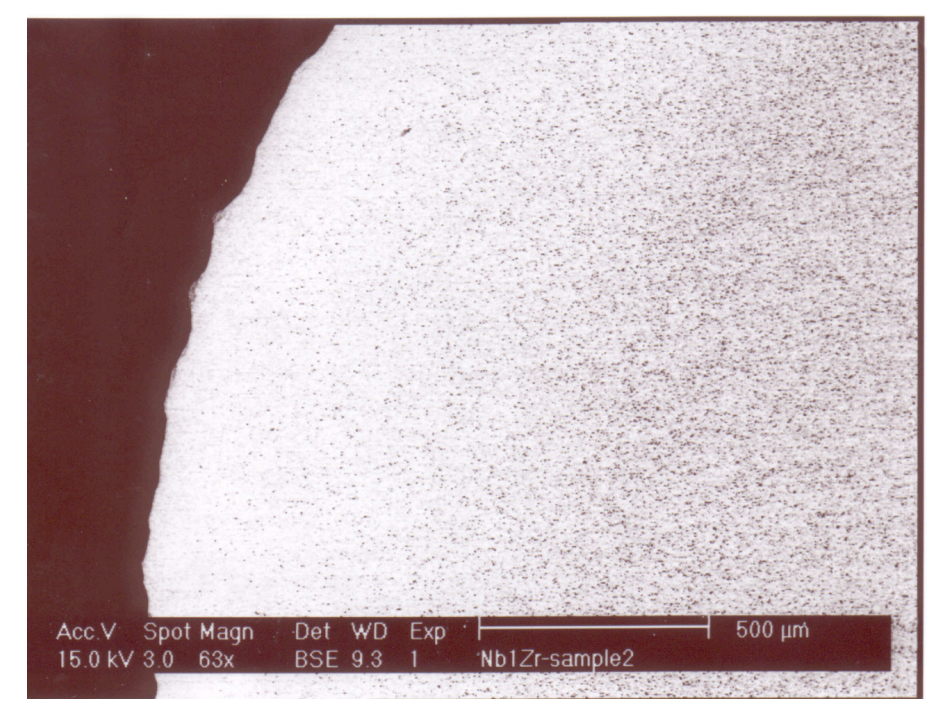

Fig. 1.13 $\mathrm{Nb} 1 \mathrm{Zr}$ after oxidizing treatment showing different amounts of embedded $\mathrm{SiC}$,

Table IV

\begin{tabular}{lllr} 
As received & \multicolumn{2}{c}{} \\
Heat treated & \multicolumn{2}{c}{ O Oxygen } & Mean \\
ETP Cu & 0.0264 & 0.0260 & 0.0262 \\
ETP Cu, 450C + air & 0.0271 & & 0.0271 \\
ETP Cu, 800C + air & 0.0270 & & 0.0270 \\
& & & 0.0002 \\
OFHC Cu & 0.0001 & 0.0002 & 0.0005 \\
OFHC Cu, 450C + air & 0.0005 & & 0.0005 \\
OFHC Cu, 800C + air & 0.0005 & & 0.0309 \\
& & & 0.0324 \\
$\mathrm{Nb}$ & 0.0309 & 0.0308 & 0.1115 \\
$\mathrm{Nb}$, vacuum & 0.0319 & 0.0328 & \\
$\mathrm{Nb}$, oxidized & 0.1090 & 0.1140 & 0.0040 \\
$\mathrm{Nb}-1 \mathrm{Zr}$ & & & 0.0060 \\
$\mathrm{Nb}-1 \mathrm{Zr}$ - vacuum & 0.0047 & 0.0032 & \\
$\mathrm{Nb}-1 \mathrm{Zr}$, oxidized & 0.1140 & 0.0861 & 0.0831 \\
\end{tabular}


They do not cover the area which shows the lustrous condition in Fig.1.13. Fig.1.14 below shows how hardness traces at room temperature were obtained. A square sample was cut from the cylinder and polished. The first indention was taken at $0.305 \mathrm{~mm}$ from the edge of the square. The resulting traces are shown below.

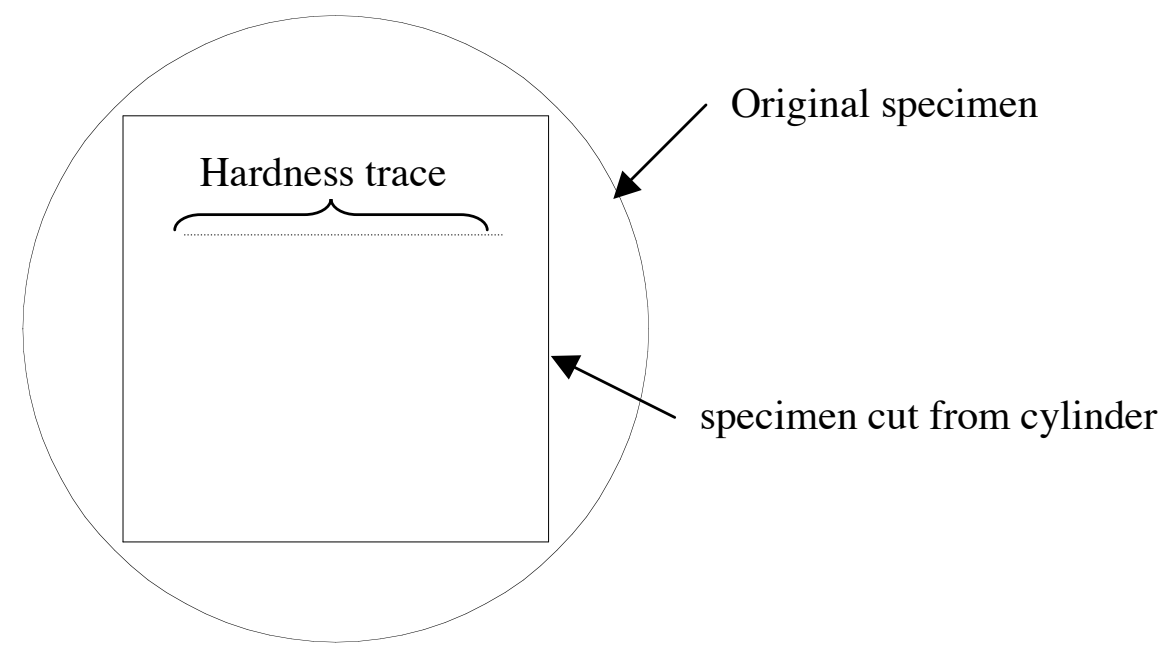

Fig.1.14. Locations of hardness traces 


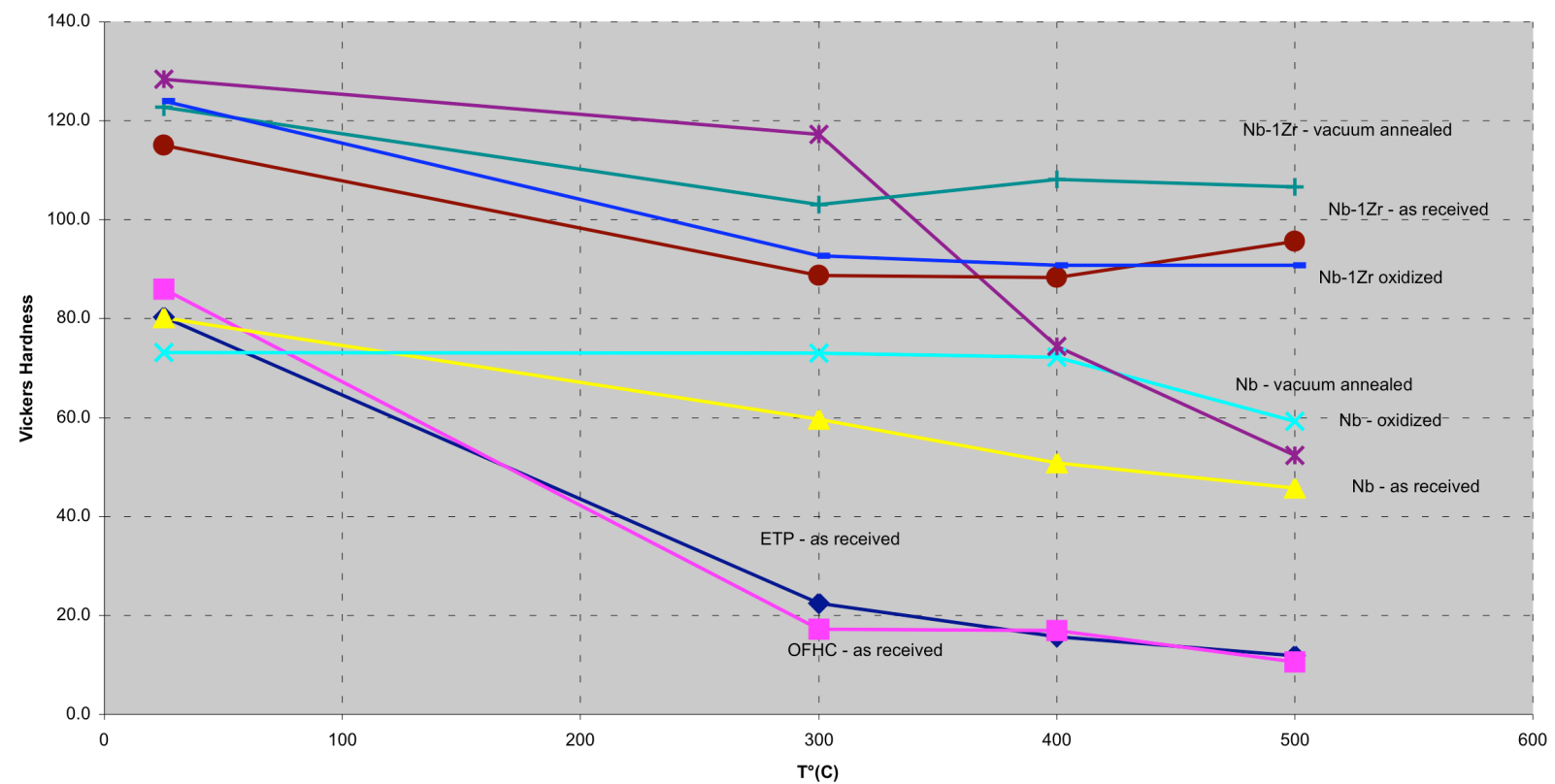

Fig. 1.15. Average Vickers hardness values and variation with temperature. The tests were conducted in a vacuum (order of $10^{-5}$ torr) using a load of 200 grams.

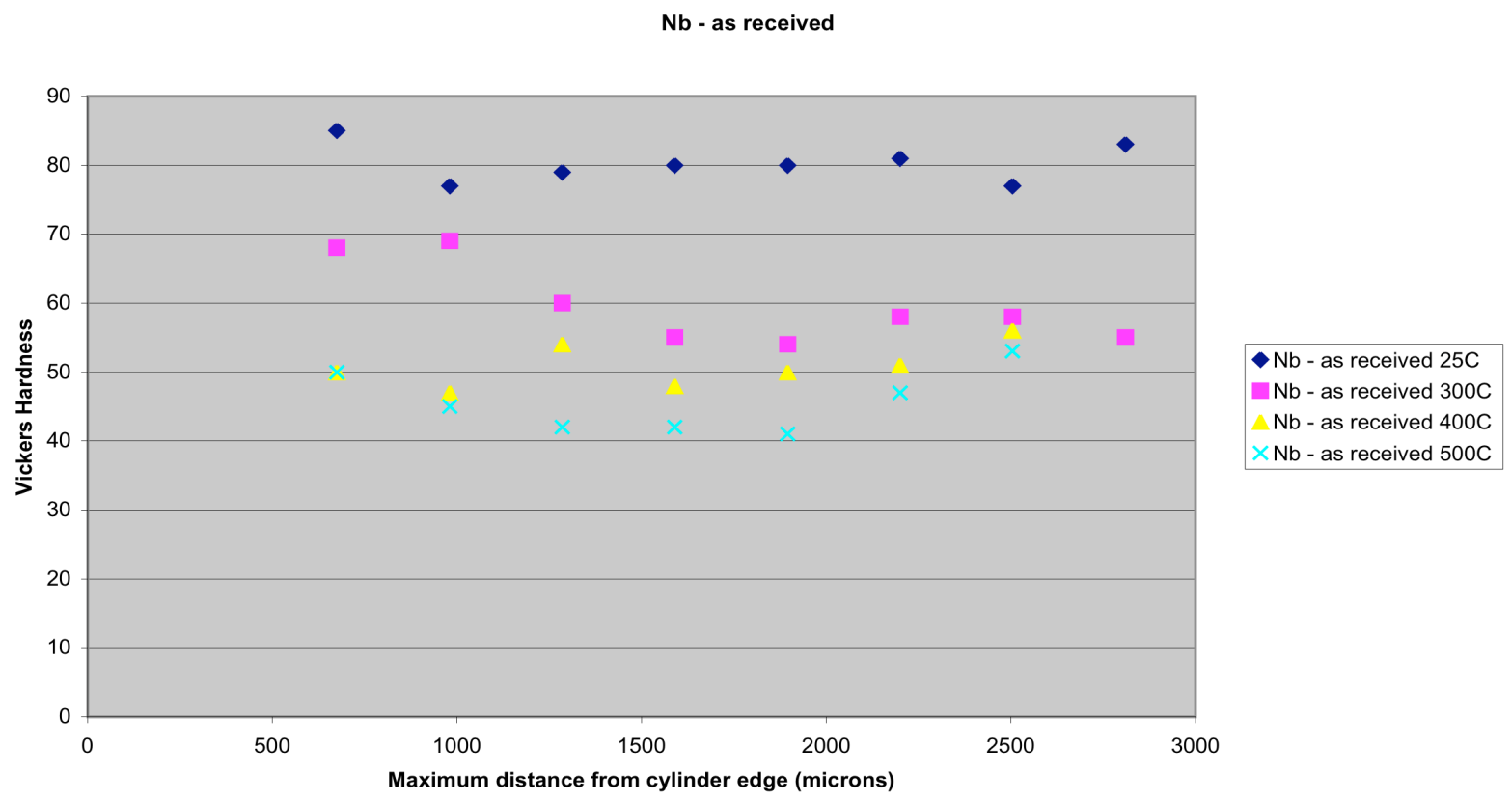

Fig. 1.16. Average Vickers harness starting $\mathrm{Nb}$ 
$\mathrm{Nb}$ - vacuum annealed

Fig.1.17

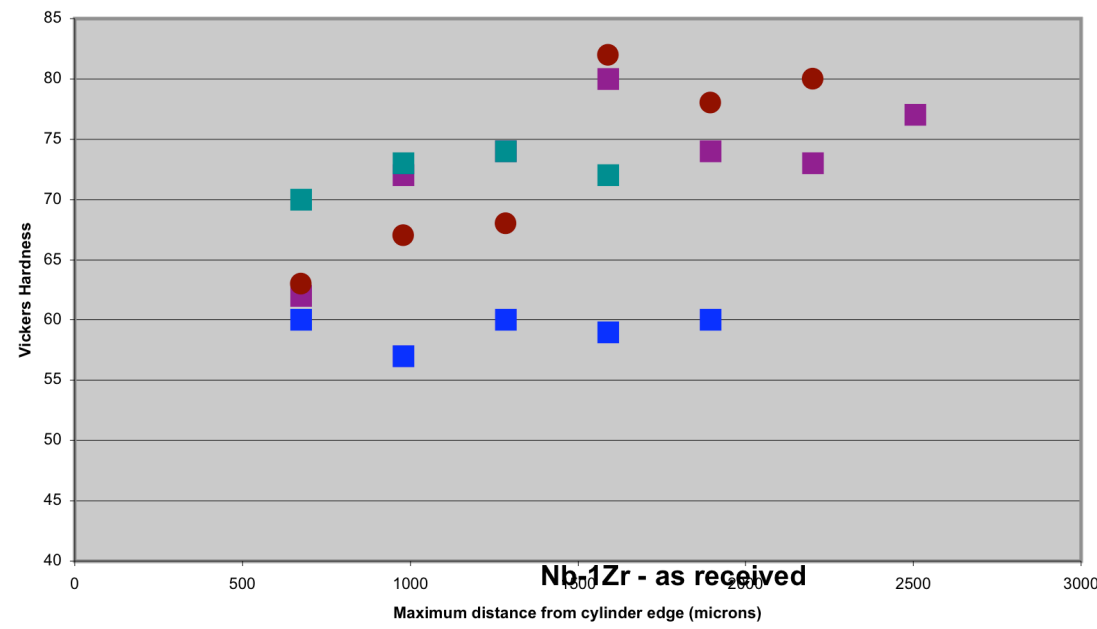

$\mathrm{Nb}$ - vacuum $25 \mathrm{C}$

Nb - vacuum $300 \mathrm{C}$

Nb - vacuum $400 \mathrm{C}$

Nb - vacuum $500 \mathrm{C}$

Fig. 1.18

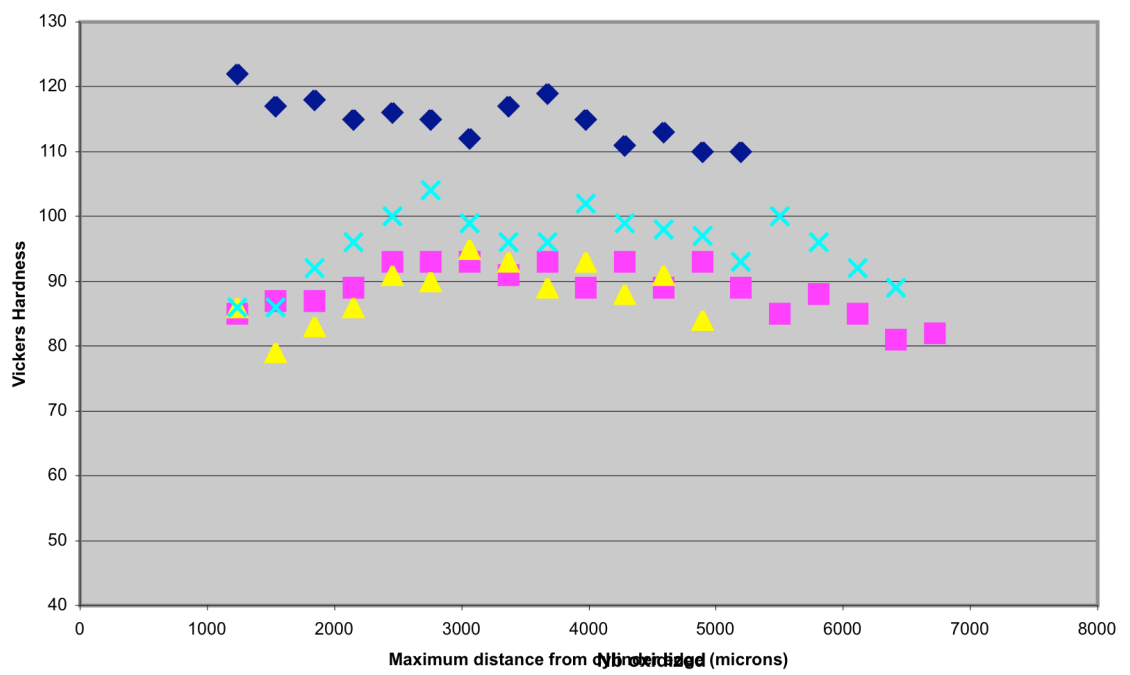

$\mathrm{Nb}-1 \mathrm{Zr}$ - as received $25 \mathrm{C}$

$\mathrm{Nb}-1 \mathrm{Zr}$ - as received $300 \mathrm{C}$

$\mathrm{Nb}-1 \mathrm{Zr}$ - as received $400 \mathrm{C}$

$\mathrm{X} \mathrm{Nb}-1 \mathrm{Zr}$ - as received $500 \mathrm{C}$

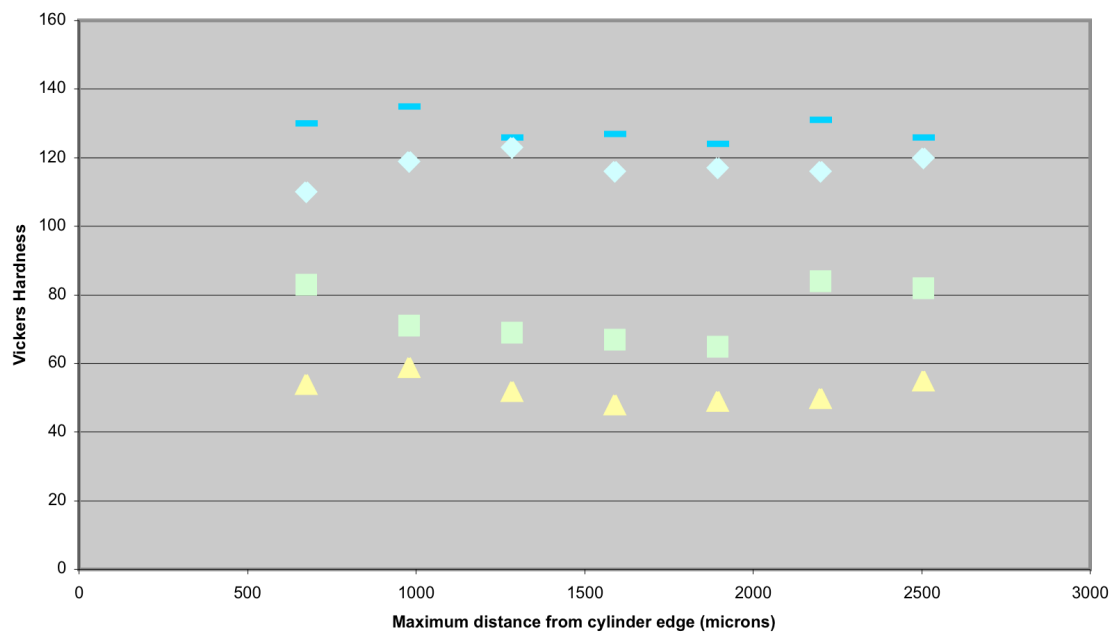

-Nb - oxidized 25C

$\mathrm{Nb}$ - oxidized $300 \mathrm{C}$

$\mathrm{Nb}$ - oxidized $400 \mathrm{C}$

$\mathrm{Nb}$ - oxidized $500 \mathrm{C}$ 
$\mathrm{Nb}-1 \mathrm{Zr}$ - vacuum annealed

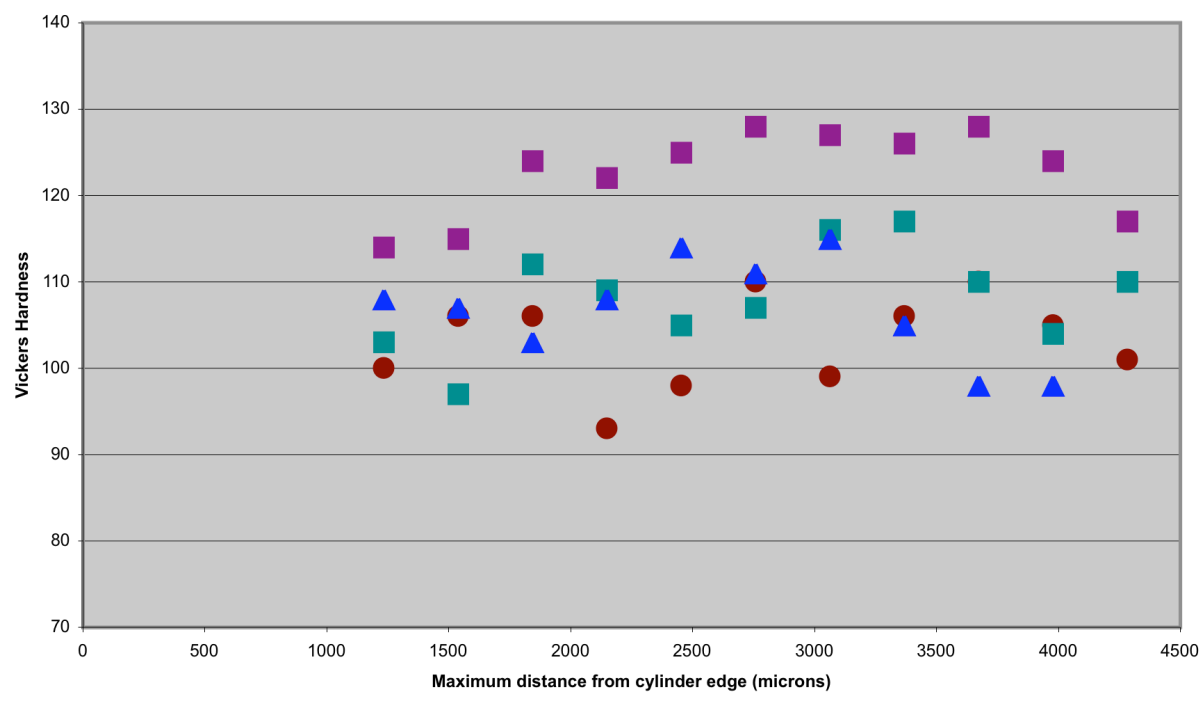

Nb-1Zr vacuum 25C - Nb-1Zr - vacuum 300C $\mathrm{Nb}-1 \mathrm{Zr}$ - vacuum $400 \mathrm{C}$ $\Delta \mathrm{Nb}-1 \mathrm{Zr}$ - vacuum $500 \mathrm{C}$

Fig.1.20

\section{$\mathrm{Nb}-1 \mathrm{Zr}$ - oxidized}

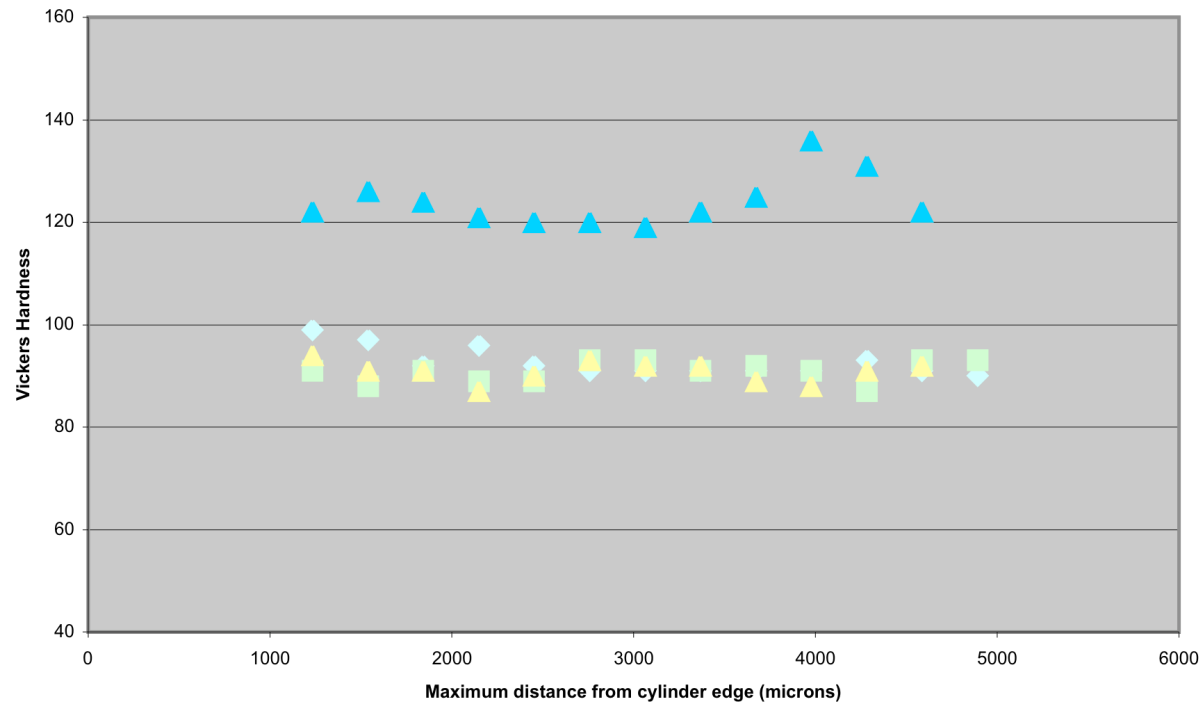

Fig.1.21 


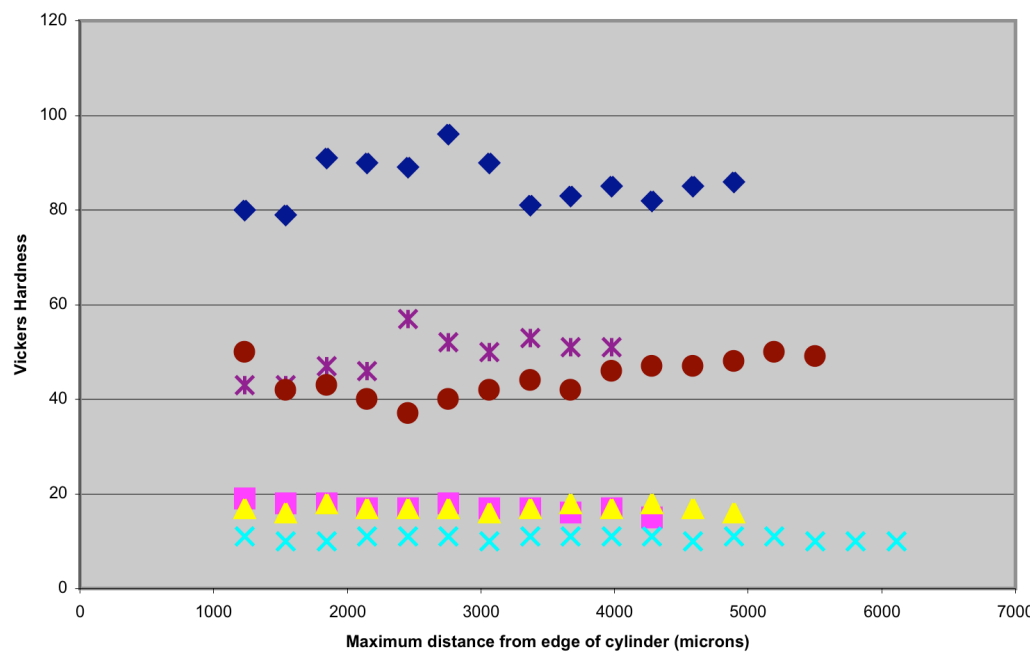

$\checkmark \mathrm{OHC} \mathrm{Cu}$ - as received $25 \mathrm{C}$ OFHC $\mathrm{Cu}$ - as received $300 \mathrm{C}$

OFHC Cu - as rceived $400 \mathrm{C}$ $\times \mathrm{OFHC} \mathrm{Cu}$ - as received $500 \mathrm{C}$ XOFHC Cu - $(450 \mathrm{C}$ air) $25 \mathrm{C}$ OFHC Cu -(800C air) $25 \mathrm{C}$

Fig.1.22

ETP

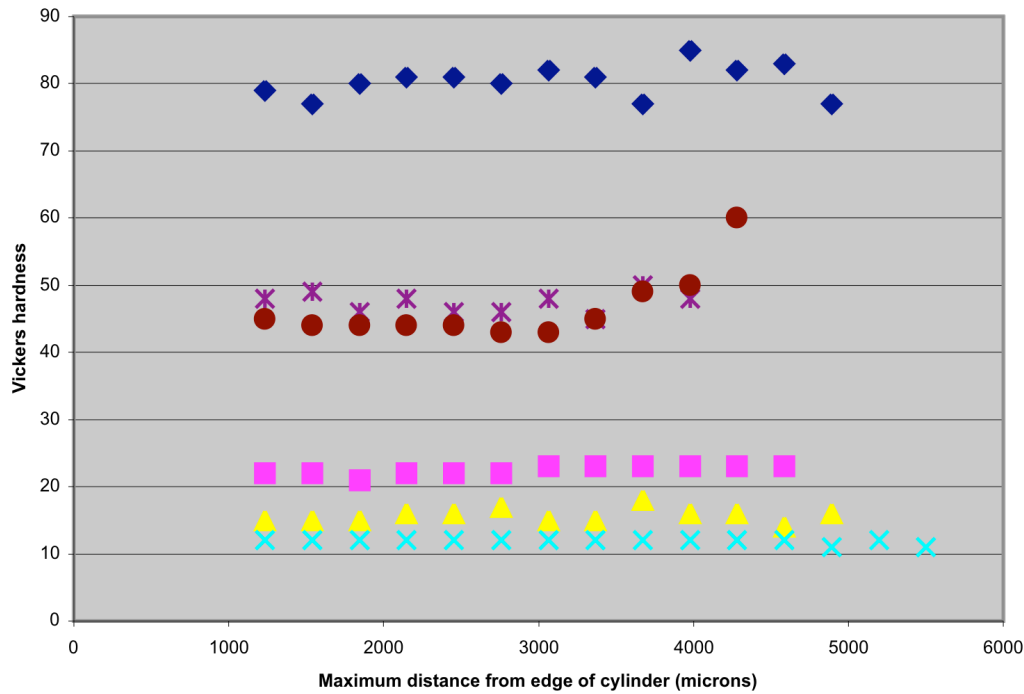

-ETP Cu - as received 25C ETP Cu - as received $300 \mathrm{C}$ ETP CU - as received $400 \mathrm{C}$ XETP CU - as received $500 \mathrm{C}$ ЖETP (450C air) $25 \mathrm{C}$ OETP Cu (800C air) 25C

Fig.1.23

It was apparent from Fig. 1.13 that significant oxygen penetration had taken place in the $\mathrm{Nb} 1 \mathrm{Zr}$ and this was not revealed in Fig. 1.21 as the hardness readings were not close enough to the surface of the rod.

A series of hardness traces were made at OSU taking readings closer to the surface on the cross sections of both the $\mathrm{Nb} 1 \mathrm{Zr}$ and the $\mathrm{Nb}$. These traces of the $\mathrm{Nb} 1 \mathrm{Zr}$ are shown in Figs. 1.24-1.26. The "as received" material was harder in the center than at the outside. This was only slightly lowered by the vacuum anneal and the distribution was 
maintained. After the oxidation treatment the surface hardness was markedly increased but this would not have been detected in the work carried out at GE.

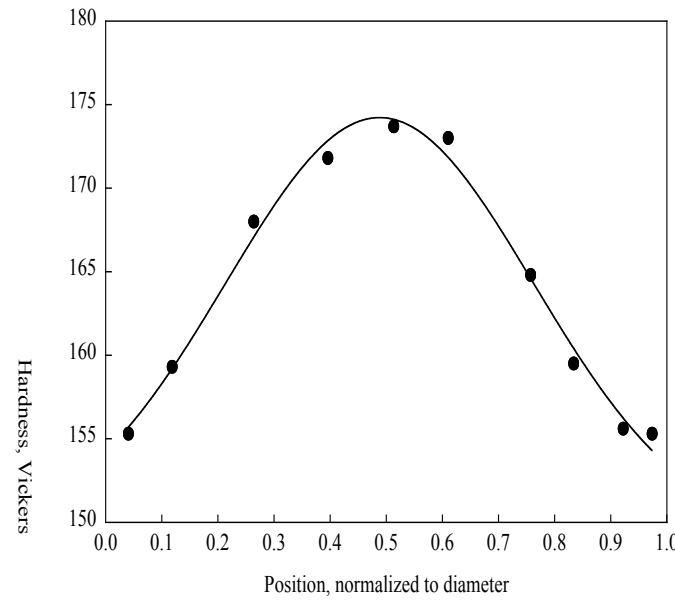

Hardness vs position for Sample A

Fig. 1.24 As received $\mathrm{Nb} 1 \mathrm{Zr}$

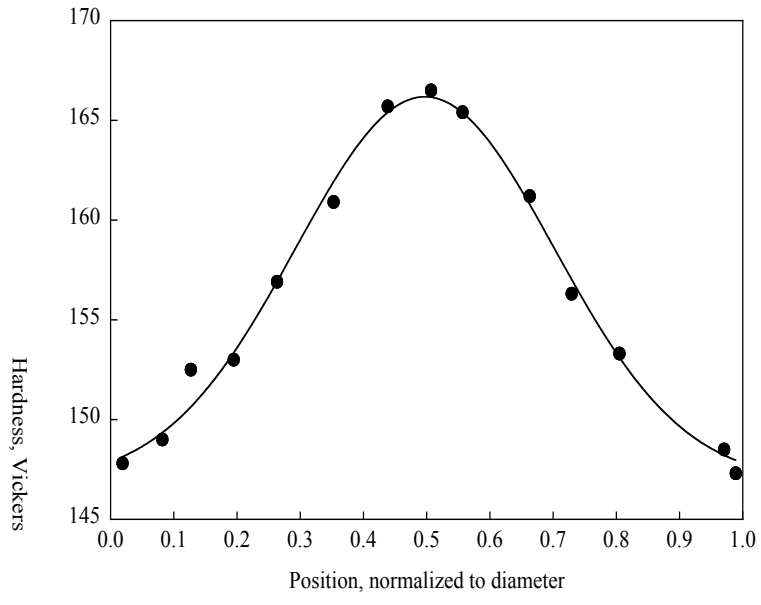

Hardness vs position for Sample 1

Fig. 1.25 Vacuum Annealed Nb1Zr

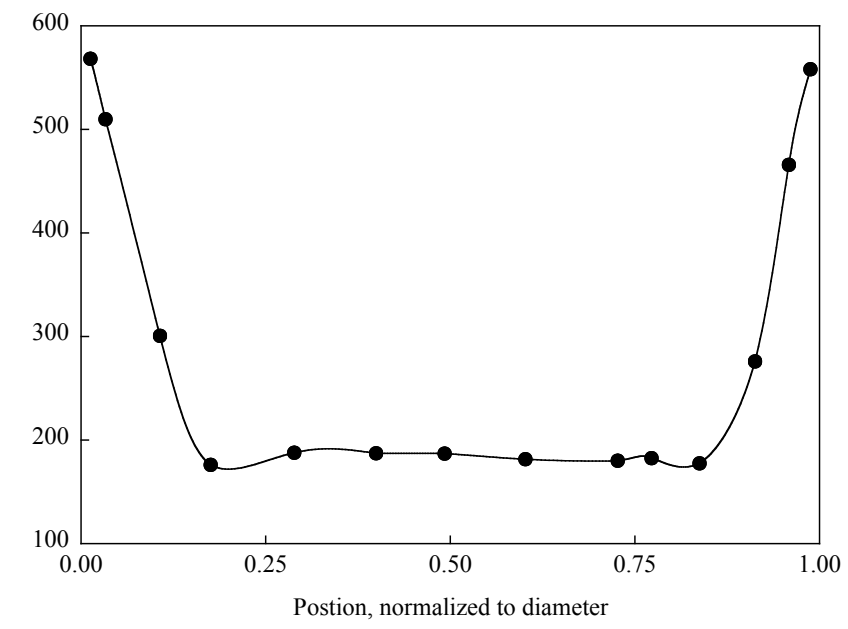

Hardness vs position for Sample 2

Fig.1.26 Oxidized $\mathrm{Nb} 1 \mathrm{Zr}$

Fig. 1.27 Shows the corresponding traces for Nb. Sample A is for the "as received " material. Sample 1 is the vacuum annealed material and Sample 2 is the oxidized sample. 
Sample A

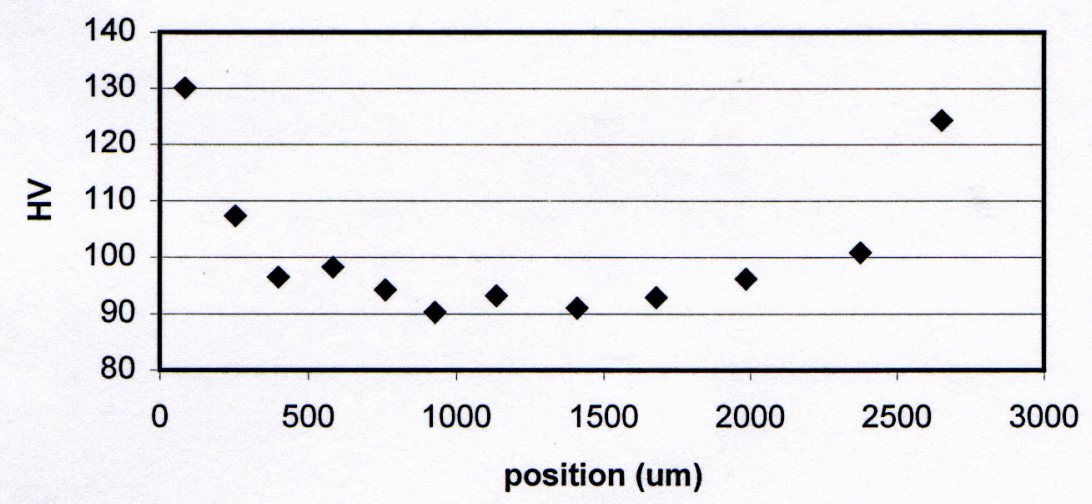

Sample 1

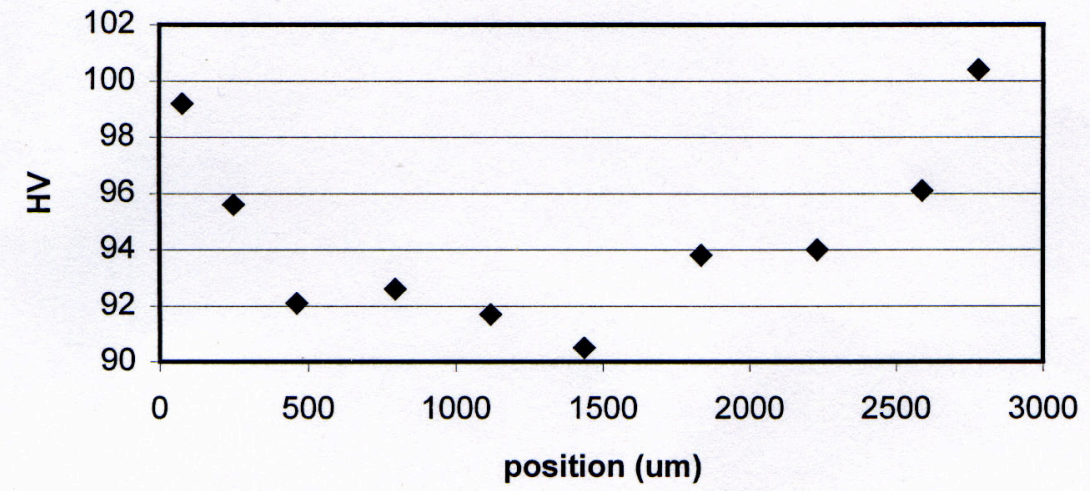

Sample 2

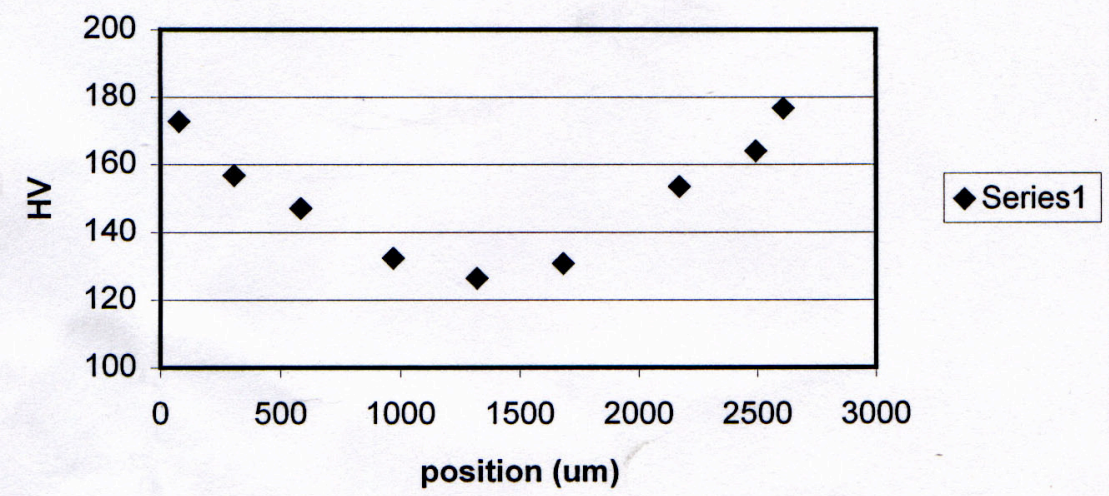

Fig. 1.27 
The "as received" material has a higher surface hardness while a vacuum anneal reduces this somewhat but heat treatment in oxygen raises the overall hardness. Not to the extent though found in $\mathrm{Nb} 1 \mathrm{Zr}$. This presumably is due to the fact that in the $\mathrm{Nb}$ the interstitial oxygen is increased whereas in the case of the $\mathrm{Nb} 1 \mathrm{Zr}, \mathrm{ZrO}_{2}$ dispersion is formed.

Fig.1.28 shows a cross section of the vacuum treated material and Fig. 1.29 one of the oxidized material. Fig.1.30 shows the latter at a higher magnification. These surface oxides were of course removed before the hardness traces in Fig.1.27 were taken.

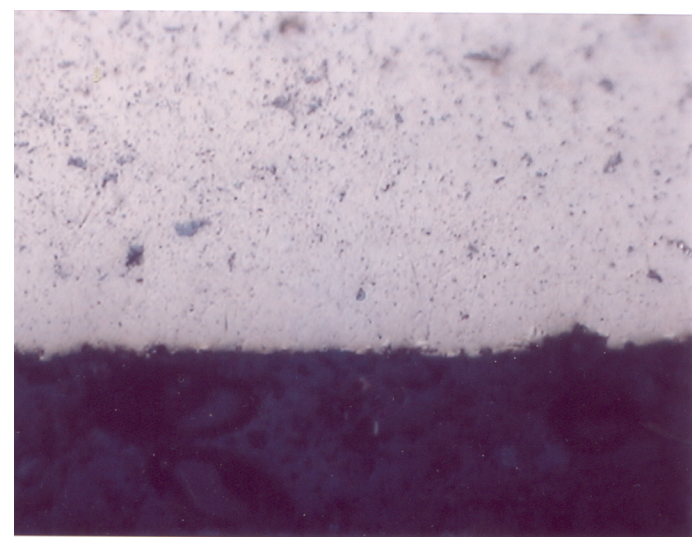

Fig. 1.28 C. S. Vacuum treated Nb X 925.

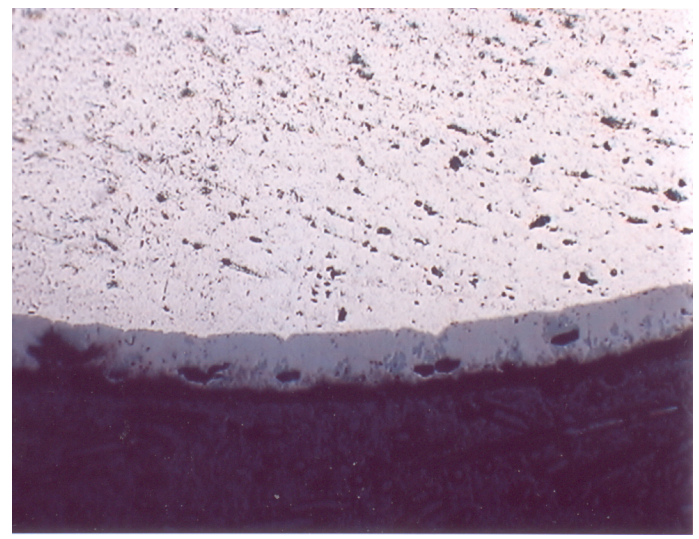

Fig. 1.29 C. S. of oxidized Nb X 175.

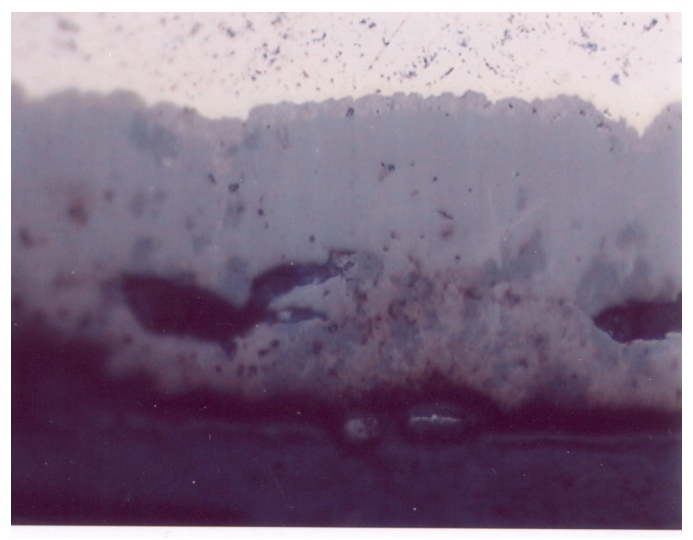

Fig. 1.30 Cross Section of oxidized Nb showing several different oxides X925.

\section{Oxygen in the Copper}

The results in Figs. 1.22 and 1.23 show that both the OFHC and ETP coppers showed no evidence from the hardness of oxygen penetration below the surface oxide that had been removed before taking the measurements. Since these measurements were also taken some distance from the surface, the samples after oxidation were carefully examined by optical metallography, SEM and EDX from close to the surface and inwards. No evidence of oxygen penetration was observed. It was concluded that storing 
enough oxygen in the copper to internally oxidize the $\mathrm{Nb} 1 \mathrm{Zr}$ in the later stages of the processing was not a viable option.

\section{Alternative methods of introducing oxygen}

A series of experiments were conducted designed to introduce oxygen through the $\mathrm{Sn} / \mathrm{Cu}$ alloy that is inserted into the subelement after extrusion. The first attempt was to extrude a powder mixture of $\mathrm{Sn}$ and either $\mathrm{Sn}$ oxide or $\mathrm{Cu}_{2} \mathrm{O}$.

We also intend to explore the possibility of introducing oxygen into the $\mathrm{Nb} 1 \mathrm{Zr}$ rods directly before extrusion. The aim is to get the oxygen into the alloy without hardening it to the point where it cannot be processed.

Two methods were tried and time and temperature variables explored:-

1. Heating the $\mathrm{Nb} 1 \mathrm{Zr}$ rods at three different temperatures $(700 \mathrm{~K}, 900 \mathrm{~K}$ and $1100 \mathrm{~K})$ in $\mathrm{Nb}_{2} \mathrm{O}_{5}$ for three different times. (This will provide the Oxygen at a slower rate)

2. Heating the $\mathrm{Nb} 1 \mathrm{Zr}$ rods at $700^{\circ} \mathrm{C}$ in $\mathrm{Cu}_{2} \mathrm{O}$ for three different times. (This is a faster rate process.)

Table V shows the matrix of conditions tried.

\section{$\underline{\text { Table V }}$}

Base comp Oxidizer comp Time (hours) Temp (K)

$\begin{array}{|llrr|}\mathrm{Nb}-1 \mathrm{Zr} & \mathrm{Cu} 2 \mathrm{O} & 0.5 & 700 \\ \mathrm{Nb}-1 \mathrm{Zr} & \mathrm{Cu} 2 \mathrm{O} & 5 & 700 \\ \mathrm{Nb}-1 \mathrm{Zr} & \mathrm{Cu} 2 \mathrm{O} & 50 & 700 \\ \mathrm{Nb}-1 \mathrm{Zr} & \mathrm{Nb} 2 \mathrm{O} 5 & 0.5 & 700 \\ \mathrm{Nb}-1 \mathrm{Zr} & \mathrm{Nb} 2 \mathrm{O} 5 & 0.5 & 900 \\ \mathrm{Nb}-1 \mathrm{Zr} & \mathrm{Nb} 2 \mathrm{O} 5 & 0.5 & 1100 \\ \mathrm{Nb}-1 \mathrm{Zr} & \mathrm{Nb} 2 \mathrm{O} 5 & 5 & 700 \\ \mathrm{Nb}-1 \mathrm{Zr} & \mathrm{Nb} 2 \mathrm{O} 5 & 5 & 900 \\ \mathrm{Nb}-1 \mathrm{Zr} & \mathrm{Nb} 2 \mathrm{O} 5 & 5 & 1100 \\ \mathrm{Nb}-1 \mathrm{Zr} & \mathrm{Nb} 2 \mathrm{O} 5 & 50 & 700 \\ \mathrm{Nb}-1 \mathrm{Zr} & \mathrm{Nb} 2 \mathrm{O} 5 & 50 & 900 \\ \mathrm{Nb}-1 \mathrm{Zr} & \mathrm{Nb} 2 \mathrm{O} 5 & 50 & 1100\end{array}$




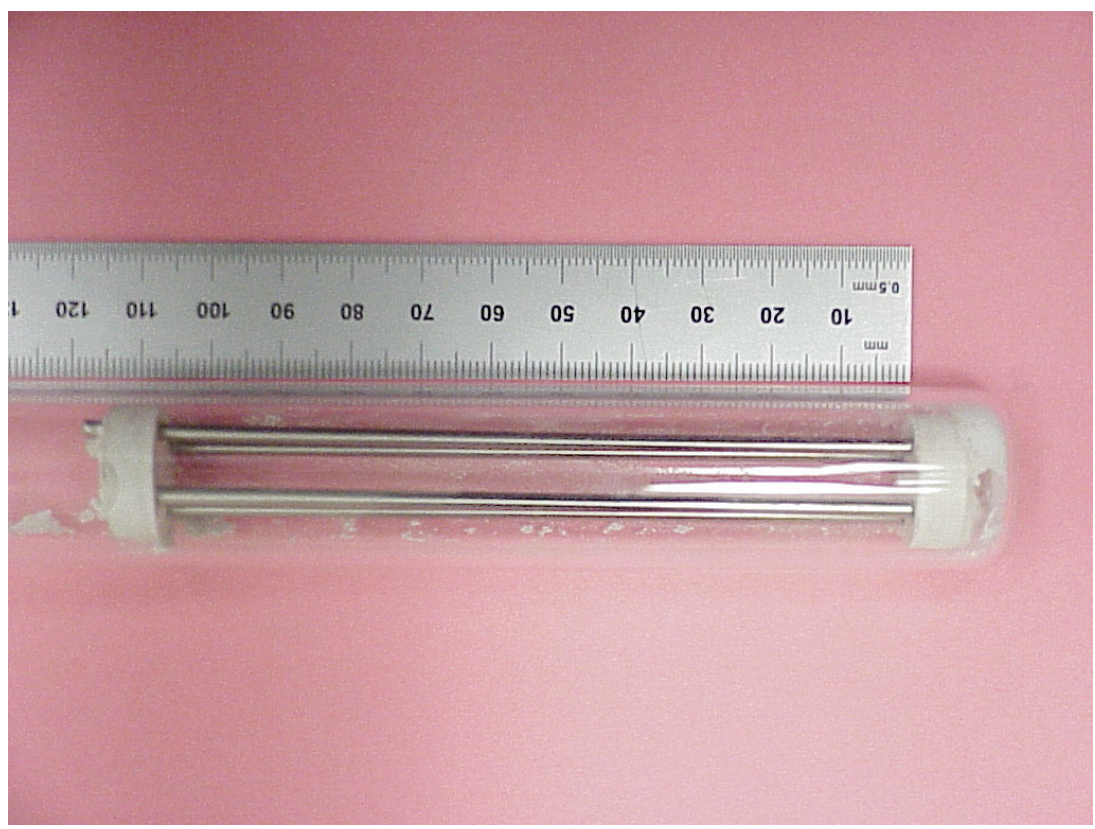

Fig 1.31 Ampoule with $\mathrm{Nb} 1 \mathrm{Zr}$ rods and rod holder

2. $50.8 \mathrm{~mm}(2 ") \varnothing$ billet preparation and extrusion.

In Phase I we successfully extruded at $450^{\circ} \mathrm{C}$, a drilled billet $88.9 \mathrm{~mm}$ (3.5”) $\varnothing$ to a bar $21.3 \mathrm{~mm}$ (0.84") in diameter. This billet contained 35 rods of $\mathrm{Nb} 1 \mathrm{Zr}$ in annealed and non-oxidized condition. Subsequent reduction by drawing resulted in badly "sausaged" filaments. Three conditions existed that may have caused part of the "sausaging" problem. We omitted to anneal the material after extrusion and, because the billet was drilled, the spacing between the filaments was too large to enable them to support one another, during the drawing process. In addition the die reduction schedule had to be adjusted to compensate for the large mismatch in yield strength of the materials.

After our successful extrusion Outokumpu tried to extrude two $203 \mathrm{~mm}$ (8") $\varnothing$ billets at higher temperatures and experienced problems similar to those we encountered when we tried to extrude at $800^{\circ} \mathrm{C}$. Their billets had $\mathrm{Cu}$ clad hexed rods $3.25 \mathrm{~mm}\left(0.128^{\prime \prime}\right)$ flatto-flat.

For our attempts to fabricate the non-oxidized material extruded one billet ahead of the rest to confirm the extrusion conditions. The billet had a diameter of $50.8 \mathrm{~mm}$ (2") and contained $\mathrm{Cu}$ tubes with a hex OD $3.25 \mathrm{~mm}$ (0.128") flat-to-flat and $2.44 \mathrm{~mm}(0.96 ") \varnothing$ $\mathrm{Nb} 1 \mathrm{Zr}$ rods. The design of the billet has been shown in Fig.1.1 and Fig. 1.32 shows the loaded billet before EB welding. 


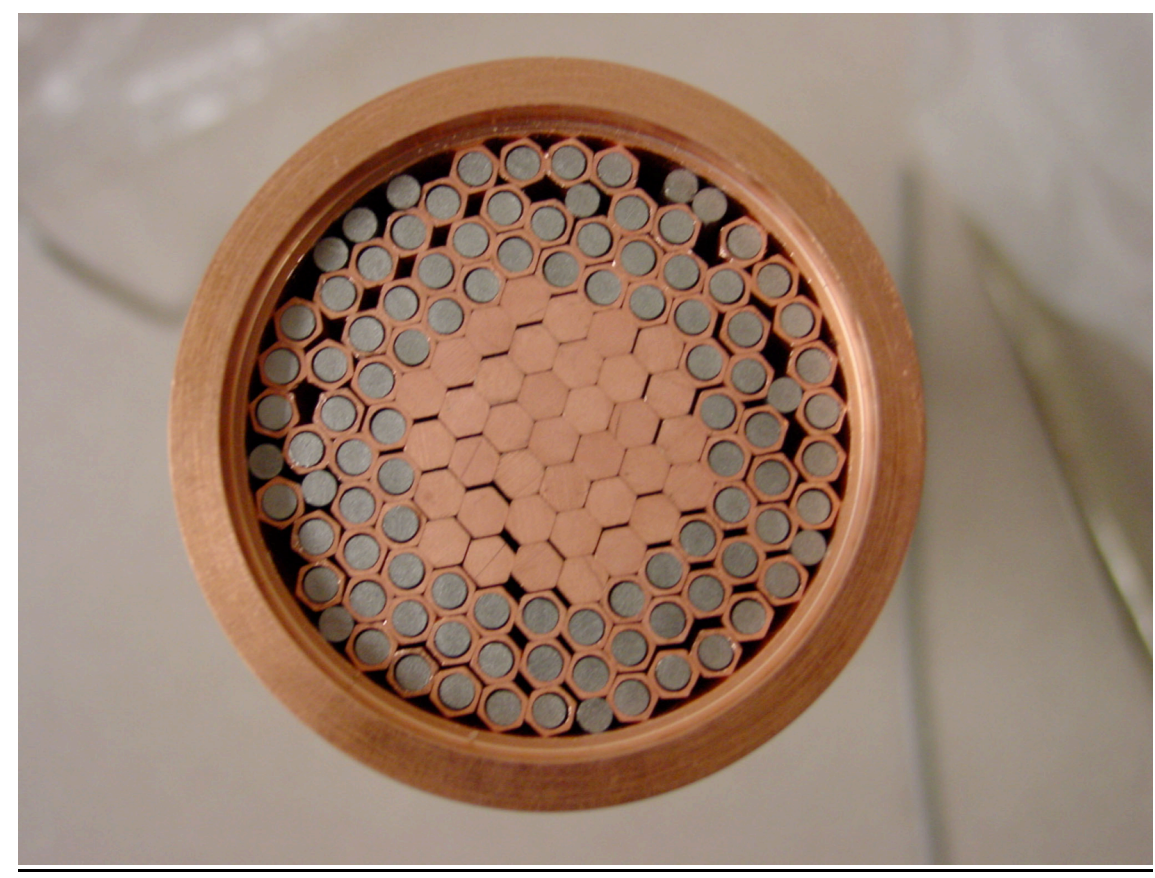

Fig. 1.32, 50.8mm (2”) Ø billet before EB welding.

$1100^{\circ} \mathrm{C}, \mathrm{Nb} 2 \mathrm{O} 5$

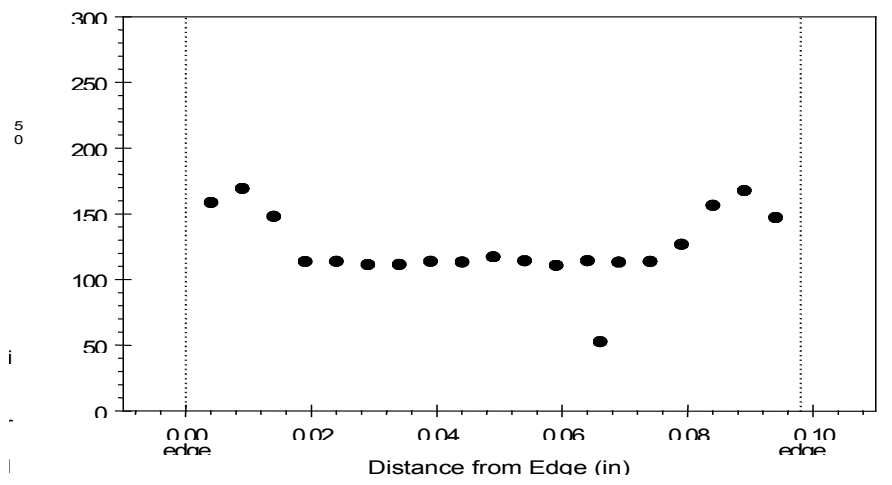

Fig. 1.33, Hardness across the Nb1Zr showing significant penetration of the oxygen 100 hrs. at $1100{ }^{\circ} \mathrm{C}$.

We have learned and practiced the introduction of oxygen to the $\mathrm{Nb} 1 \mathrm{Zr}$ starting rods by use of $\mathrm{Nb}_{2} \mathrm{O}_{5}$ powder as a source of oxygen at $1100{ }^{\circ} \mathrm{C}$. Figure 1.33 illustrates the hardness profile of a starting $\mathrm{Nb}$ rod of $2.438 \mathrm{~mm}$ diameter after $100 \mathrm{hrs}$ at $1100{ }^{\circ} \mathrm{C}$ with $\mathrm{Nb}_{2} \mathrm{O}_{5}$ powder as an oxidant. The y axis is the Vickers micro-hardness on the $\mathrm{HV}$ 500 scale. An average of $0.328 \mathrm{wt} \%$ of oxygen was introduced though mainly in the outer $30 \%$ of the area.

Summary

1. Sausaged filaments and tin leaks yielded inconclusive results on phase I material. Further efforts were focused on the new materials and billets. 
2. Use of copper as a carrier for oxygen is not practical. The solubility of Oxygen is too low when introduced by diffusion.

3. Oxygen introduced into the composite by adding Tin Oxide powder to the usual tin core and co-processing as per the MEIT process is a superior solution.

4. We have learned and practiced the introduction of oxygen to the $\mathrm{Nb} 1 \mathrm{Zr}$ starting rods by use of $\mathrm{Nb}_{2} \mathrm{O}_{5}$ powder as a source of oxygen at $1100{ }^{\circ} \mathrm{C}$.

\subsection{Experiments to demonstrate the best extrusion and drawing conditions and produce material suitable for testing and evaluation.}

ZAB3, a $51 \mathrm{~mm}$ diameter billet was successfully extruded to yield sound product using a low $450{ }^{\circ} \mathrm{C}$ extrusion temperature with a $17.4 / 1$ extrusion ratio. A $1000{ }^{\circ} \mathrm{C}$ anneal was introduced after extrusion and the material was drawn with an initial draw schedule of $30 \%, 26 \%$ and then a standard $20.6 \%$ reduction. Final wire without breakage was produced at $0.254 \mathrm{~mm}$ with a $\mathrm{Sn}+\mathrm{SnO}_{2}$ core. Figure $2 \mathrm{a}$, and b shows the etched as extruded rod while Figure $3 \mathrm{a}$, and $\mathrm{b}$ show the cross section and etched filaments.

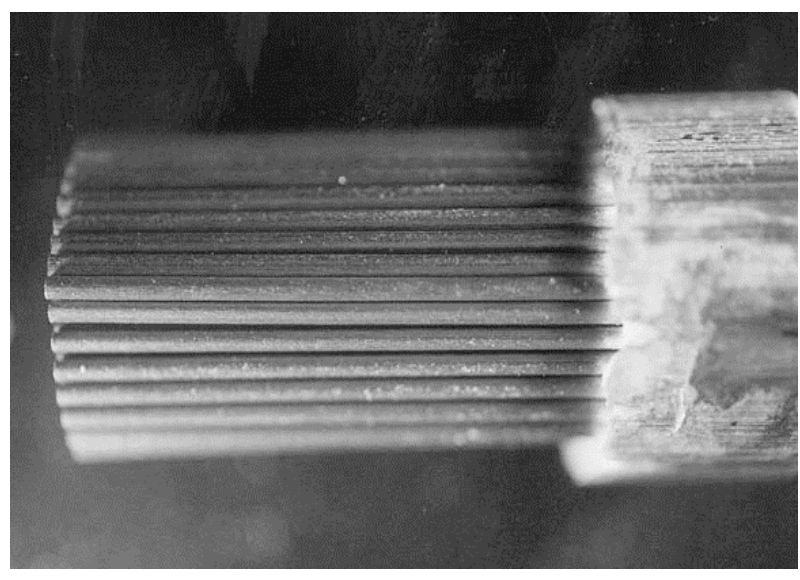

a.

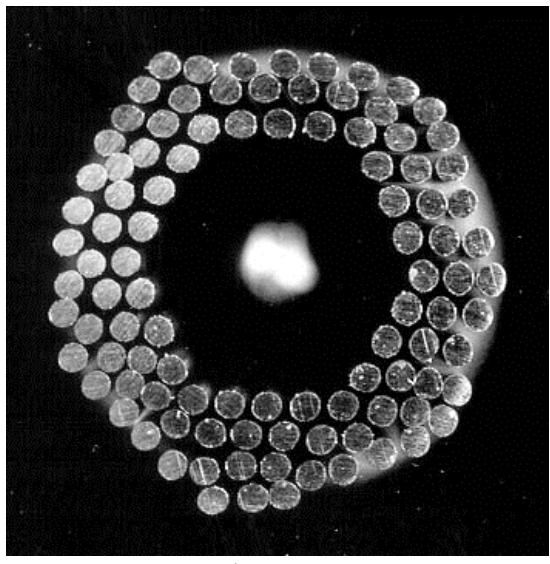

b

Figure 2. Filaments in the extruded condition - center section of the successful extrusion of $\mathrm{ZAB} 3$ 


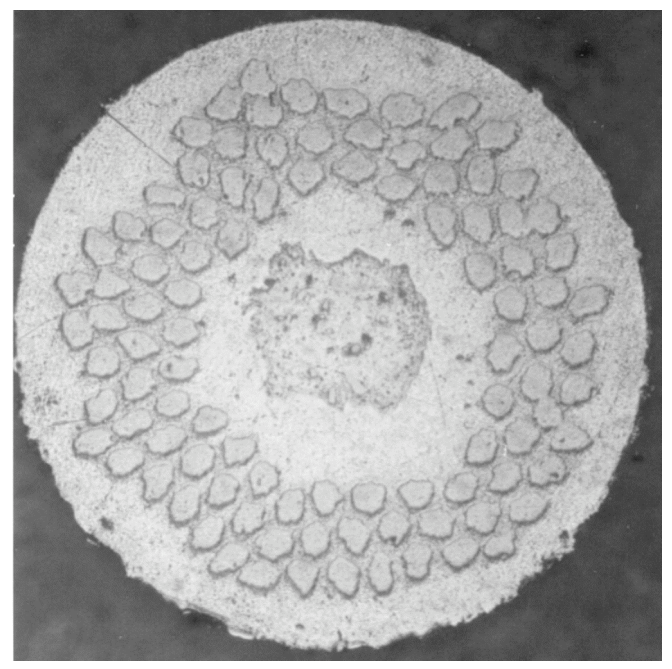

a.

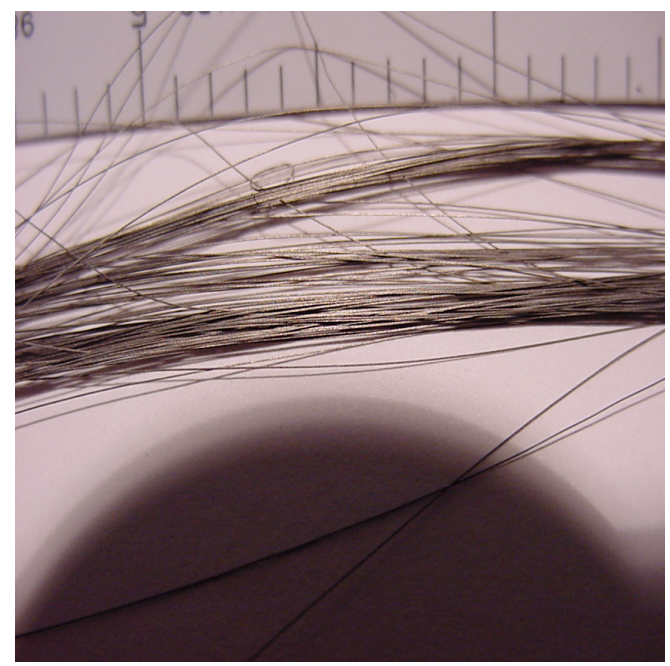

b.

Figure 3 (a) -ZAB3 at $0.381 \mathrm{~mm}$. Figure 3(b) - filaments of ZAB3 at $1.62 \mathrm{~mm}$

Samples of ZAB3 with a $\mathrm{Sn}+\mathrm{Ti}$ and $\mathrm{Sn}+\mathrm{SnO}_{2}$ core were heat treated for $24 \mathrm{hrs}$ at $185^{\circ} \mathrm{C}$, $24 \mathrm{hrs}$ at $375{ }^{\circ} \mathrm{C}$ and $48 \mathrm{hrs}$ at $700{ }^{\circ} \mathrm{C}$ using ramp rates of $10{ }^{\circ} \mathrm{C}, 10{ }^{\circ} \mathrm{C}$ and $50{ }^{\circ} \mathrm{C}$ per hour respectively. Three types of powder were added externally, $\mathrm{CuO}_{2}, \mathrm{Nb}_{2} \mathrm{O}_{5}$ and $\mathrm{Ag}_{2} \mathrm{O}$ as well as a control without additional powder. Table I gives the results of oxygen absorbed. The material with the $\mathrm{Sn}+\mathrm{SnO}_{2}$ core showed signs of cracking leading to leakage of the $\mathrm{Sn}$. The lack of a circumferential $\mathrm{Nb}$ barrier combined with the vapor pressure of the oxygen was thought to have contributed to the failure.

Table I

\begin{tabular}{|c|c|c|c|}
\hline Sample & Oxidizing powder & Oxygen content wt $\%$ & Observation \\
\hline$\# 2 . \mathrm{Sn}+\mathrm{SnO}_{2}$ core & None & 0.162 & burst \\
\hline \#4. $\mathrm{Sn}+\mathrm{SnO}_{2}$ core & $\mathrm{CuO}_{2}$ & 0.692 & burst \\
\hline \#6. $\mathrm{Sn}+\mathrm{SnO}_{2}$ core & $\mathrm{Nb}_{2} \mathrm{O}_{5}$ & 0.326 & burst \\
\hline \#8. $\mathrm{Sn}+\mathrm{SnO}_{2}$ core & $\mathrm{Ag}_{2} \mathrm{O}$ & 0.972 & burst \\
\hline$\# 1 . \mathrm{Sn}+\mathrm{Ti}$ core & None & 0.046 & sound \\
\hline \#3. $\mathrm{Sn}+\mathrm{Ti}$ core & $\mathrm{CuO}_{2}$ & 0.209 & sound \\
\hline \#5. Sn + Ti core & $\mathrm{Nb}_{2} \mathrm{O}_{5}$ & 0.101 & sound \\
\hline \#7. $\mathrm{Sn}+\mathrm{Ti}$ core & $\mathrm{Ag}_{2} \mathrm{O}$ & 0.965 & sound \\
\hline
\end{tabular}

Figure 4 a shows the reacted cross section of \#1 with a $\mathrm{Sn}+\mathrm{Ti}$ core. The Sn content of these billets was only 4.5 At \% giving a bronze of 5.6 At \% insufficient to fully react the filaments. Figure 4 b. shows \#2 with a $\mathrm{Sn}+\mathrm{SnO}_{2}$ core with cracks in the copper. This allowed the tin to leak out reducing the amount of reaction. The resulting difference in tin content makes comparison of the reaction amounts and grain size between the samples unsound. What can be seen though is that Oxygen was successfully introduced both through internal and or external means. 


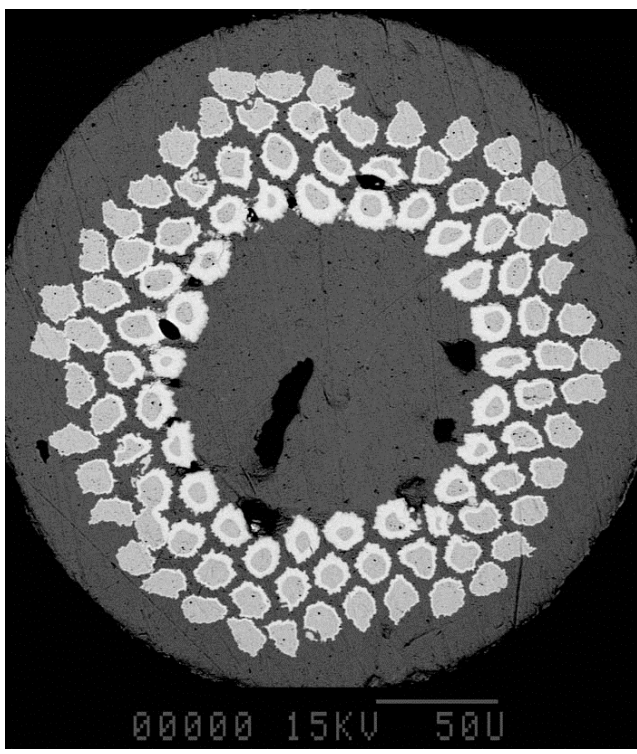

a.

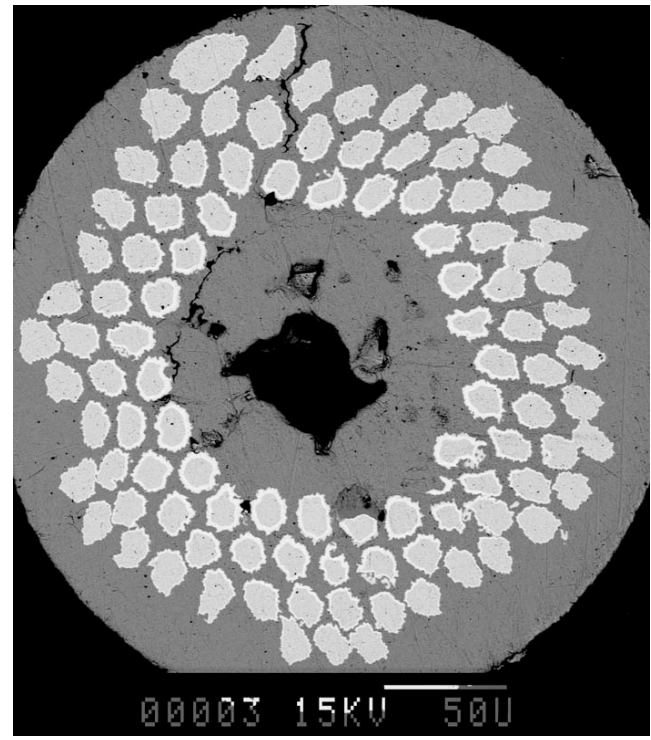

b.

Figure 4 (a) \#1 ZAB3 wire reacted and (b) \#2 reacted showing crack and less reaction due to tin leakage

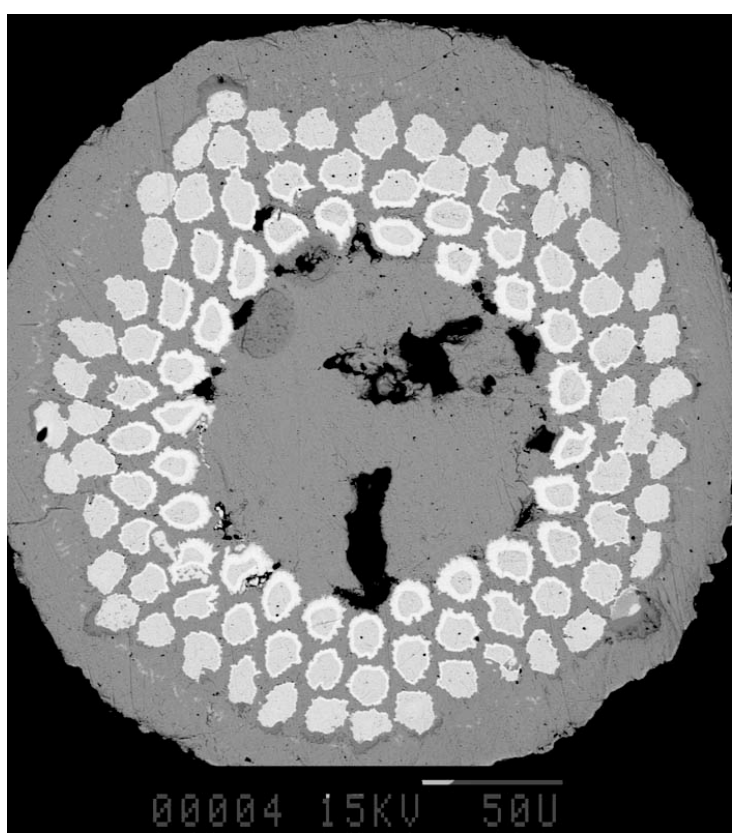

a.

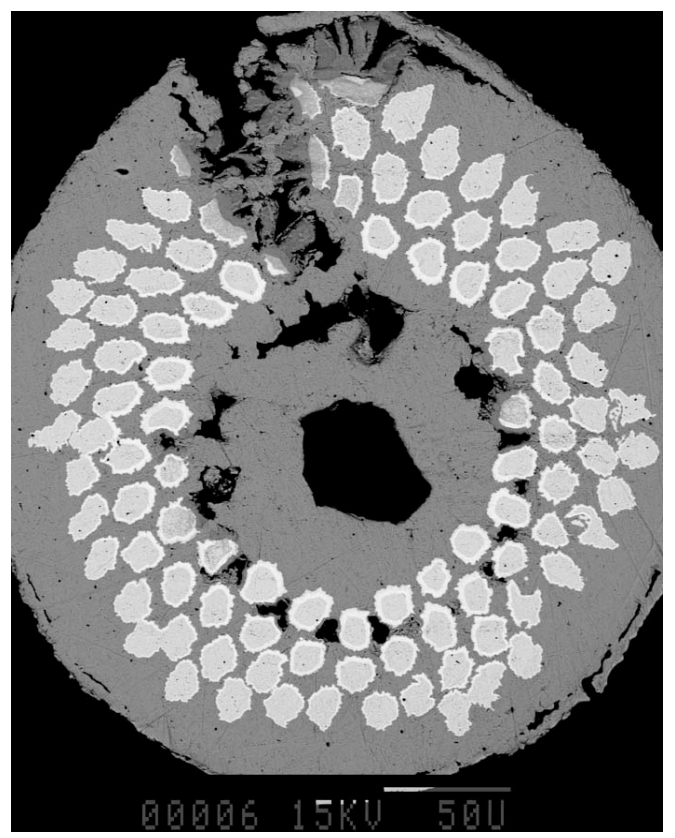

b.

Figure 5 (a) \#7 ZAB3 wire reacted and figure 5 (b) \#8 ZAB3 reacted showing a large burst area.

SEMs of the samples were obtained of the fractured surface to see if there was a difference in grain size. Figure 6(a). and 6(b). are typical but do not indicate much difference if any between the various samples. 


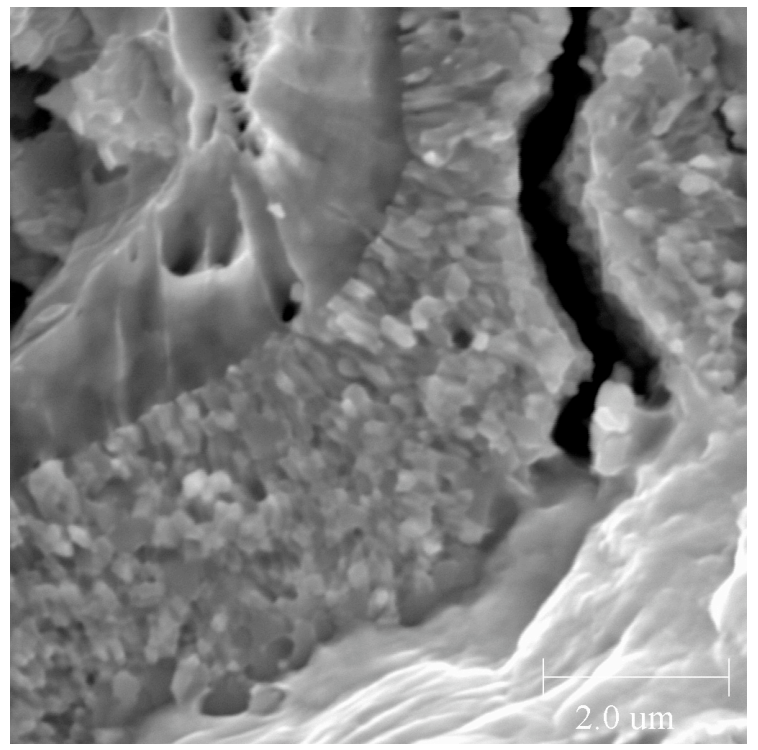

a.

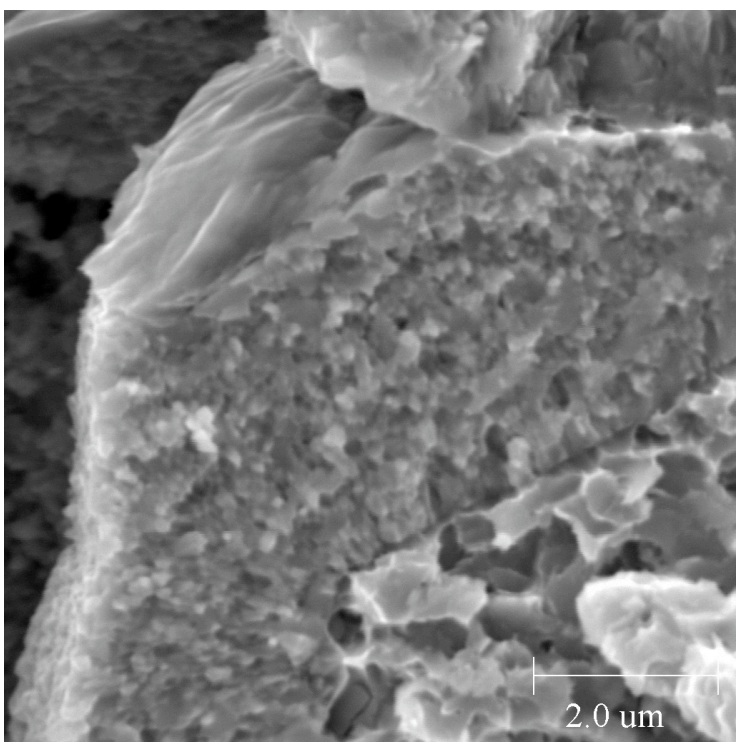

b.

Figure 6 (a) SEM at 14KX of \#7 ZAB3 Nb3Sn grains, (b )is \#8 ZAB3 with same parameters

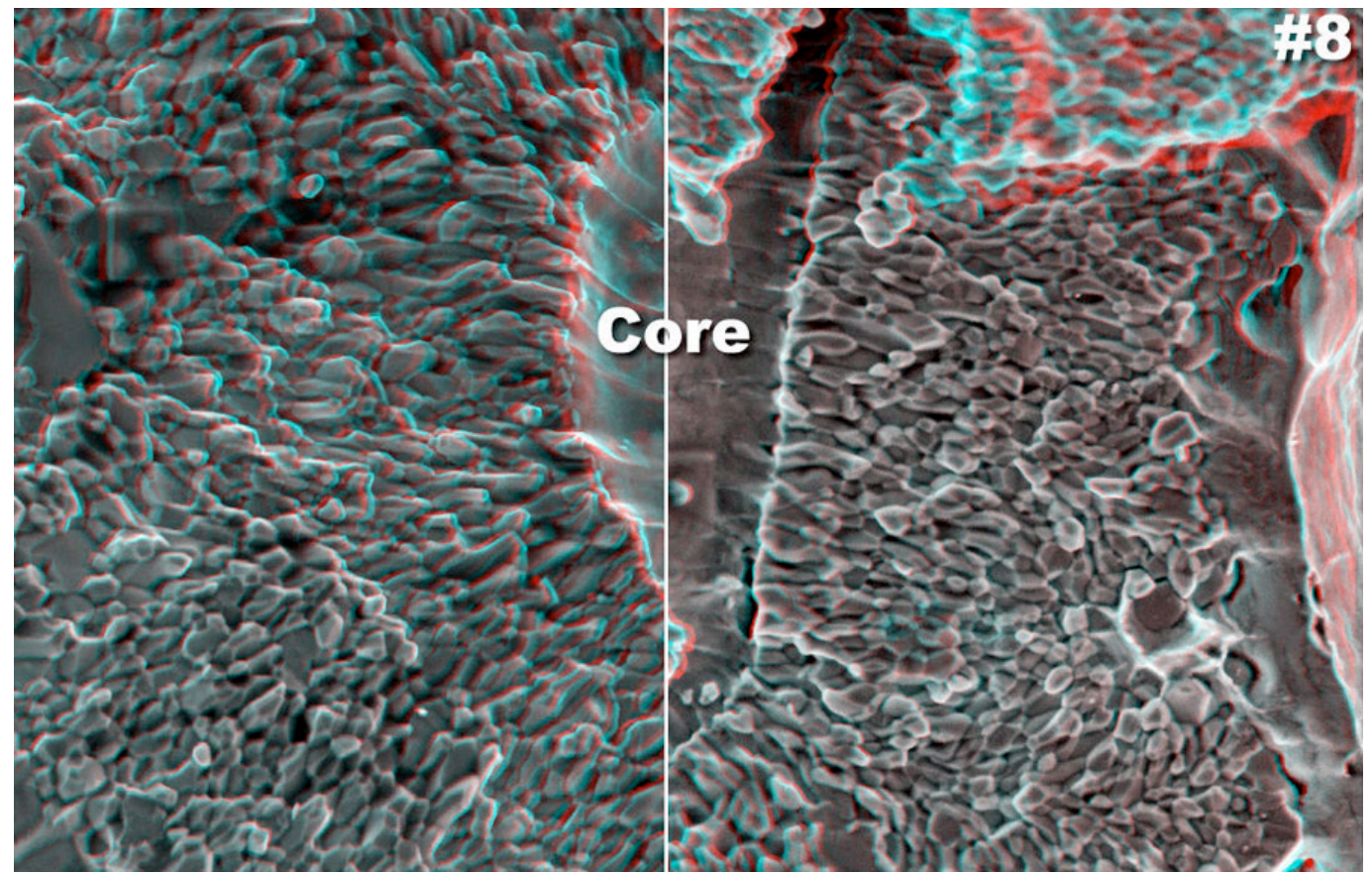

Figure 7, Steroscopic SEM courtesy of P. Lee of University of Wisconsin of \#8 ZAB3and \#2 ZAB3 with no oxygen (left).

Figure 7 is a view provided by P. Lee of the University of Wisconsin. Because of the low tin content as well as position of the filaments and their varying degree of reaction we can not draw any conclusions from the SEMs. 
ZAB4, a billet which incorporates a diffusion barrier, was used to evaluate the effect of oxygen not only through SEM analysis but also through critical current measurements. ZAB4, an $88.9 \mathrm{~mm}$ diameter billet, was assembled with 258 filaments of $\mathrm{Nb} 1 \mathrm{Zr}$, extruded to $22.22 \mathrm{~mm}$, annealed at $975{ }^{\circ} \mathrm{C}$ for one hour, gun drilled with a $8.255 \mathrm{~mm}$ diameter hole, tin core inserted and drawn to $0.254 \mathrm{~mm}$ diameter wire. The initial draw schedule was $17.4 \%, 30 \%, 30 \%$, and then a standard $20.6 \%$ reduction. The as extruded rod had to be turned more than usual to allow gun drilling. Copper stabilizer was $17.3 \%$. Three tin cores, pure $\mathrm{Sn}, \mathrm{Sn}+\mathrm{Ti}$, and $\mathrm{Sn}+\mathrm{AgO}_{2}$ were inserted. Some breakage was encountered with the $\mathrm{AgO}_{2}$ core. Figure 8 is $\mathrm{ZAB} 4$ with a $\mathrm{Sn}+\mathrm{AgO}_{2}$ core at $3.25 \mathrm{~mm}$. The array looks quite good.

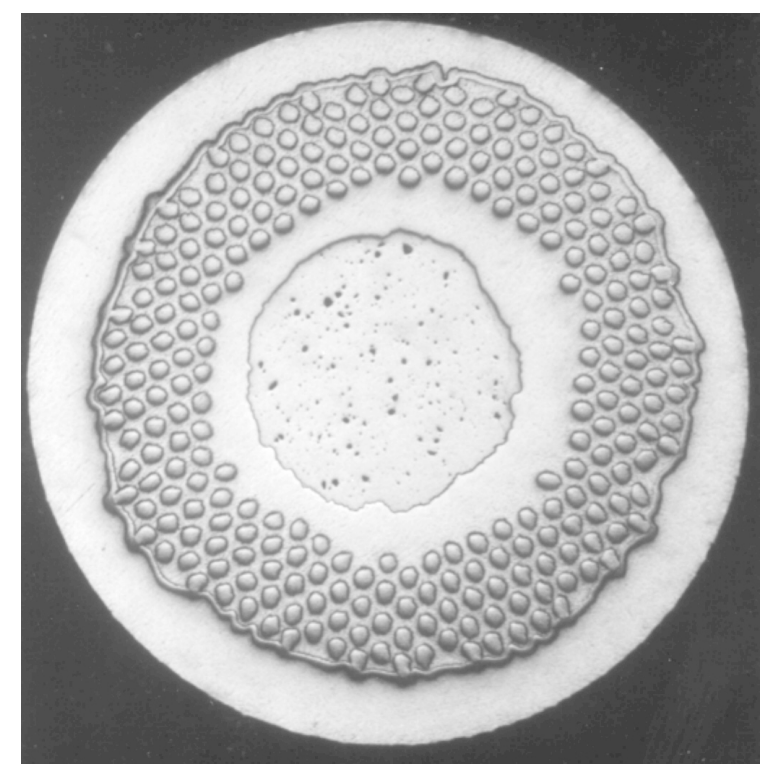

Figure 8. $\mathrm{ZAB} 4$ at $3.25 \mathrm{~mm}$ diameter with a $\mathrm{Sn}+\mathrm{AgO}_{2}$ core and diffusion barrier

Samples of ZAB4 wire at $0.254 \mathrm{~mm}$ wire were prepared with three cores composed of $\mathrm{SnCu}, \mathrm{Sn}+1 \% \mathrm{Ti}$, and a $\mathrm{Sn}+2.5 \mathrm{wt} \% \mathrm{SnO}_{2}$. The $\mathrm{SnO}_{2}$ is sufficient to react all the $\mathrm{Zr}$ in the $\mathrm{Nb} 1 \mathrm{Zr}$ rod. The heat treatment matrix is shown in table II. Samples were homogenized for $24 \mathrm{hrs}$. at $185{ }^{\circ} \mathrm{C}$ with a $10{ }^{\circ} \mathrm{C} / \mathrm{hr}$ ramp rate then followed by $24 \mathrm{hrs}$ at $375{ }^{\circ} \mathrm{C}$ with a $10{ }^{\circ} \mathrm{C}$ ramp rate and then ramped to the respective temperature at $50{ }^{\circ} \mathrm{C} / \mathrm{hr}$. A variety of times and temperatures were chosen to help build a model for grain size growth to compare with the original work done on $\mathrm{Nb}_{3} \mathrm{Sn}$ tape by $\mathrm{M}$. Benz et al.

Table II

ZAB4 Heat Treatment Matrix for Wire at $0.254 \mathrm{~mm}$

\begin{tabular}{|c|c|c|c|c|}
\hline Sample Core & $700{ }^{\circ} \mathrm{C}$ & $775{ }^{\circ} \mathrm{C}$ & $850{ }^{\circ} \mathrm{C}$ & $1000{ }^{\circ} \mathrm{C}$ \\
\hline $\mathrm{Sn}+\mathrm{Ti}$ & $1,10,100 \mathrm{hrs}$ & $3 \mathrm{hrs}$ & $1,10 \mathrm{hrs}$ & $1 \mathrm{hr}$ \\
\hline $\mathrm{Sn}+\mathrm{Cu}$ & $1,10,100 \mathrm{hrs}$ & $3 \mathrm{hrs}$ & $1,10 \mathrm{hrs}$ & $1 \mathrm{hr}$ \\
\hline $\mathrm{Sn}+\mathrm{SnO}_{2}$ & $1,10,100 \mathrm{hrs}$ & $3 \mathrm{hrs}$ & $1,10 \mathrm{hrs}$ & $1 \mathrm{hr}$ \\
\hline
\end{tabular}


The reacted samples of $\mathrm{Sn}+\mathrm{Cu}$ and $\mathrm{Sn}+\mathrm{Ti}$ looked very similar for all temperatures so comparison pictures will not be included except at $1000^{\circ} \mathrm{C}$ where there was significant difference. Figure 9 and 10 show significant difference at $1000^{\circ} \mathrm{C}$ between the samples with Oxygen vs. those without. It appears in figure 9 that the filaments have lost most of their identity presumably because of the large grain size. Figure 10, the sample with oxygen, on the other hand maintains it's filament identity showing the impact of the oxygen on reaction. For lower temperatures the oxygen appears to slow the reaction kinetics. The Sn+Ti sample at $850{ }^{\circ} \mathrm{C}$ for $1 \mathrm{hr}$. is fully reacted as seen in figure 11 . The $\mathrm{Sn}+\mathrm{SnO}_{2}$ shows less reaction as seen in figure 12 . At $700{ }^{\circ} \mathrm{C}$ for $10 \mathrm{hrs}$ comparison between the samples figures 13 and 14 again show that reaction is slower with oxygen than without. There is similar amount of $\mathrm{Sn}$ in all samples and as can be seen in figure 10 sufficient to fully react the sample with $\mathrm{Sn}+\mathrm{SnO}_{2}$.

All of the samples were analyzed at GE CR\&D for filament diameter, unreacted core diameter, and average reaction layer thickness. About 50 filaments were used for most of the analysis. It is interesting that for the $700^{\circ} \mathrm{C}$ Ti does not appear to influence the growth rate as compared to $\mathrm{Sn}+\mathrm{Cu}$. Table III, ZAB4 Reaction Area, presents the data used to calculate actual current density in the layer. Fully reacted samples have no core diameter data in the table.

The above samples were taken to Smartech for fractographs to allow grain size analysis. Figures 15,16 and 17 respectively show the significant differences between the grain size of the samples at $1000^{\circ} \mathrm{C}$ for $1 \mathrm{hr}$. The Ti sample has the largest grain size while the Oxygen sample is significantly smaller. In contrast, at 700,775 and $850^{\circ} \mathrm{C}$ there is little if any statistical difference. Table IV, Grain Size of ZAB4, presents the grain size data measured on one filament. Grain size analysis was done by GE and measures both radial and transverse direction. What is interesting though as can be seen from the table is that at $700^{\circ} \mathrm{C}$ for $10 \mathrm{hrs}$ grain size is between 85 and $101 \mathrm{~nm}$, relatively small as gleaned from the literature. This could be a result of the effect of the $\mathrm{Zr}$ addition which may have some $\mathrm{ZrO}_{2}$ already precipitated from the residual oxygen in the starting rods. We do not know how much $\mathrm{ZrO}_{2}$ is necessary to refine the grain. 


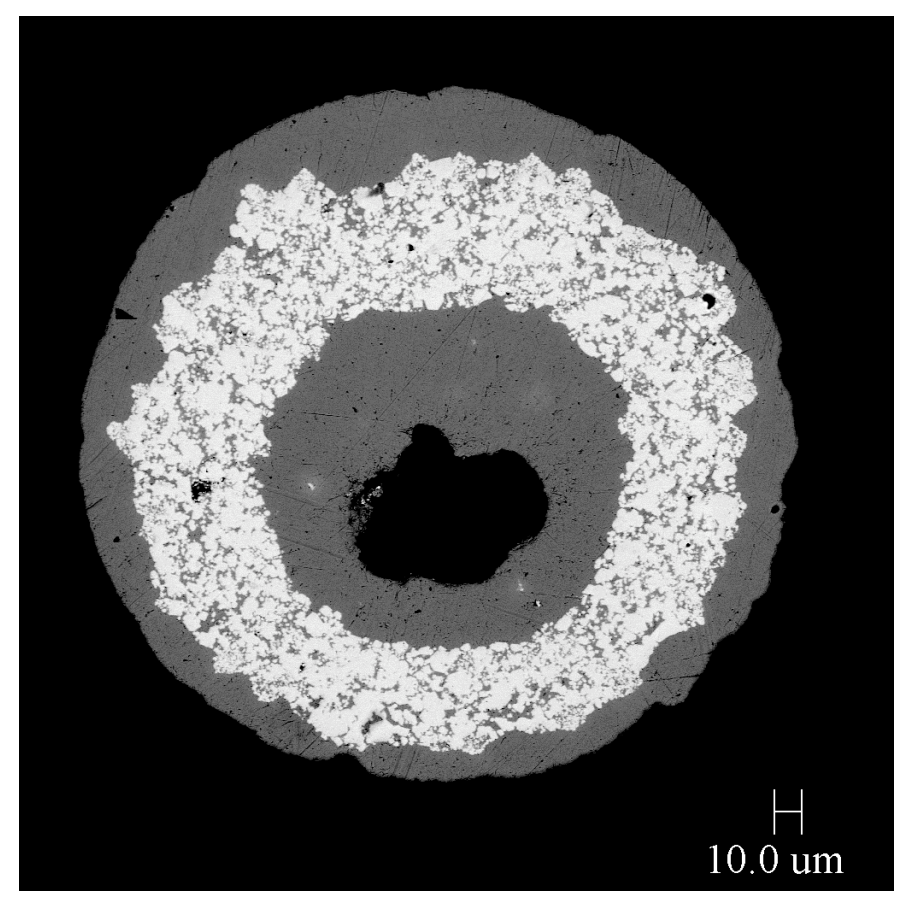

Fig. 9. ZAB4 CuSn core $1 \mathrm{hr}-1000^{\circ} \mathrm{C}(350 \mathrm{x})$

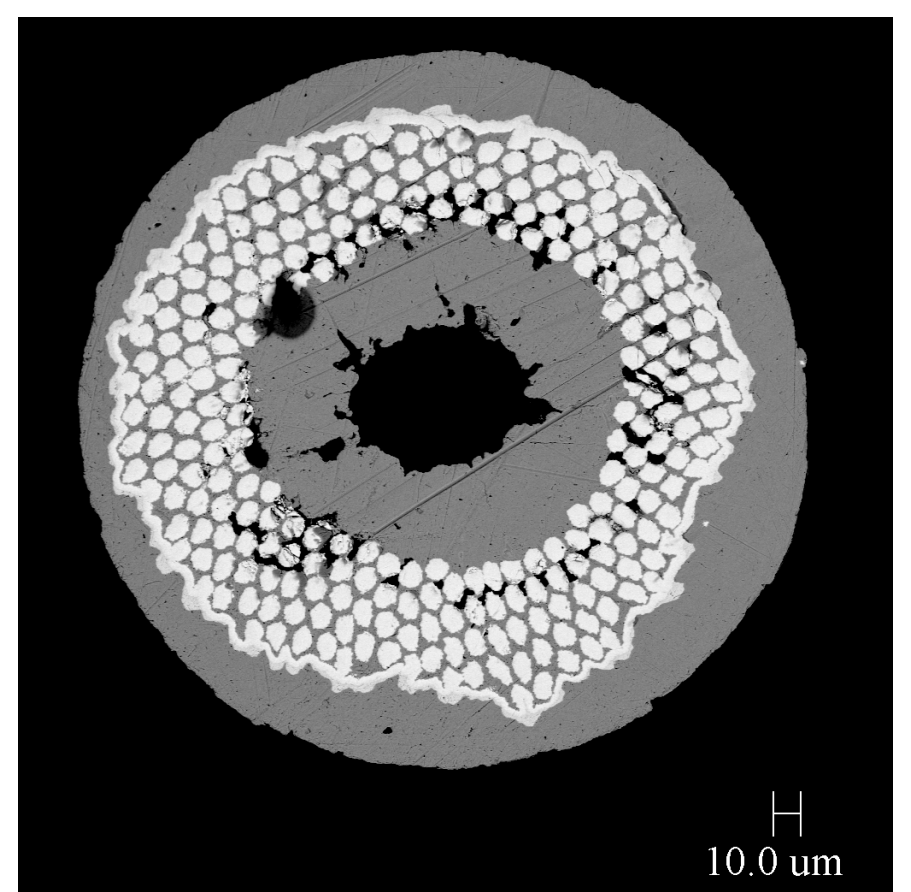

Fig 10. ZAB4 $\mathrm{Sn}+\mathrm{SnO}_{2}$ core $1 \mathrm{hr} 1000^{\circ} \mathrm{C}(350 \mathrm{x})$ 


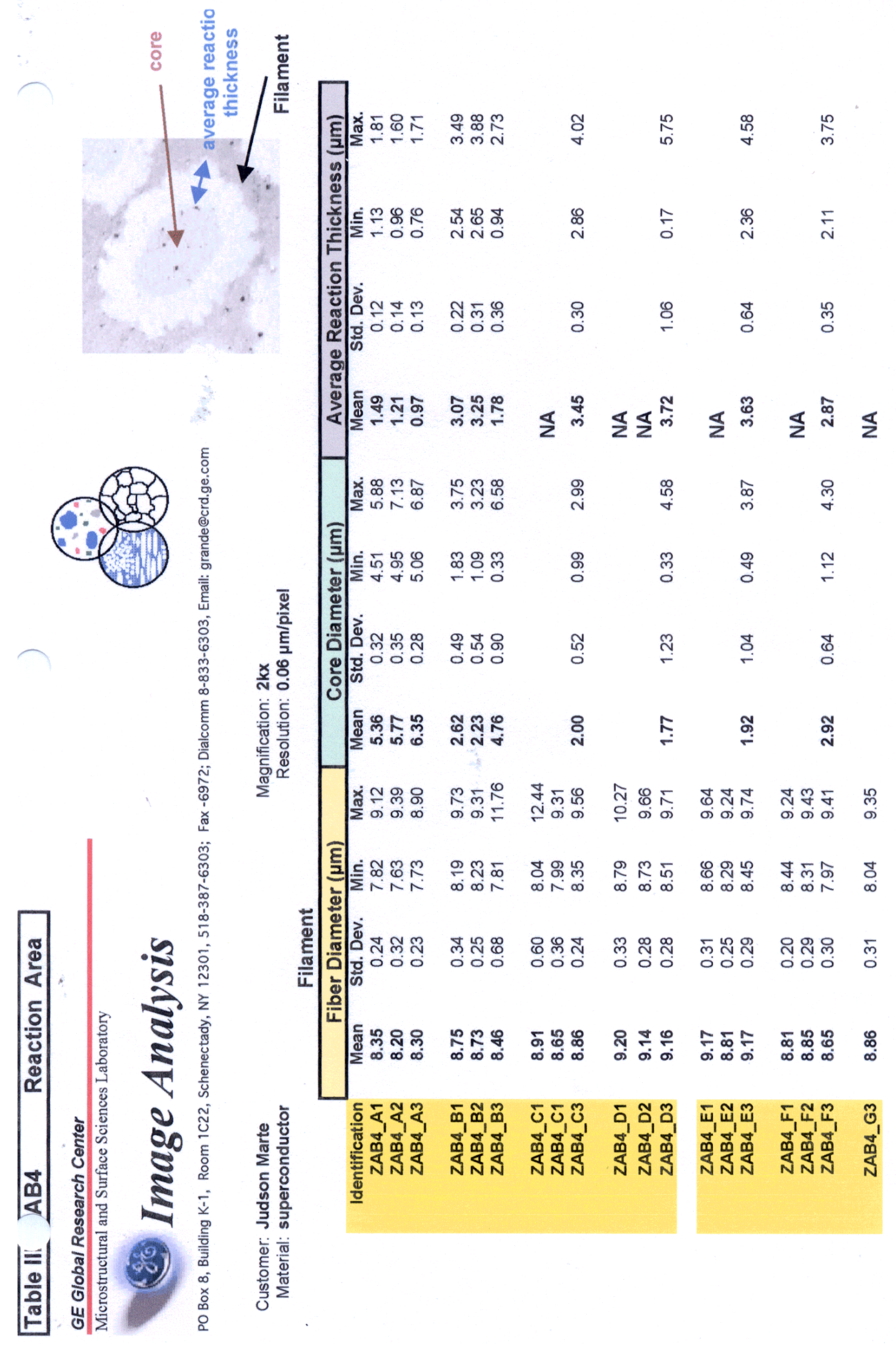




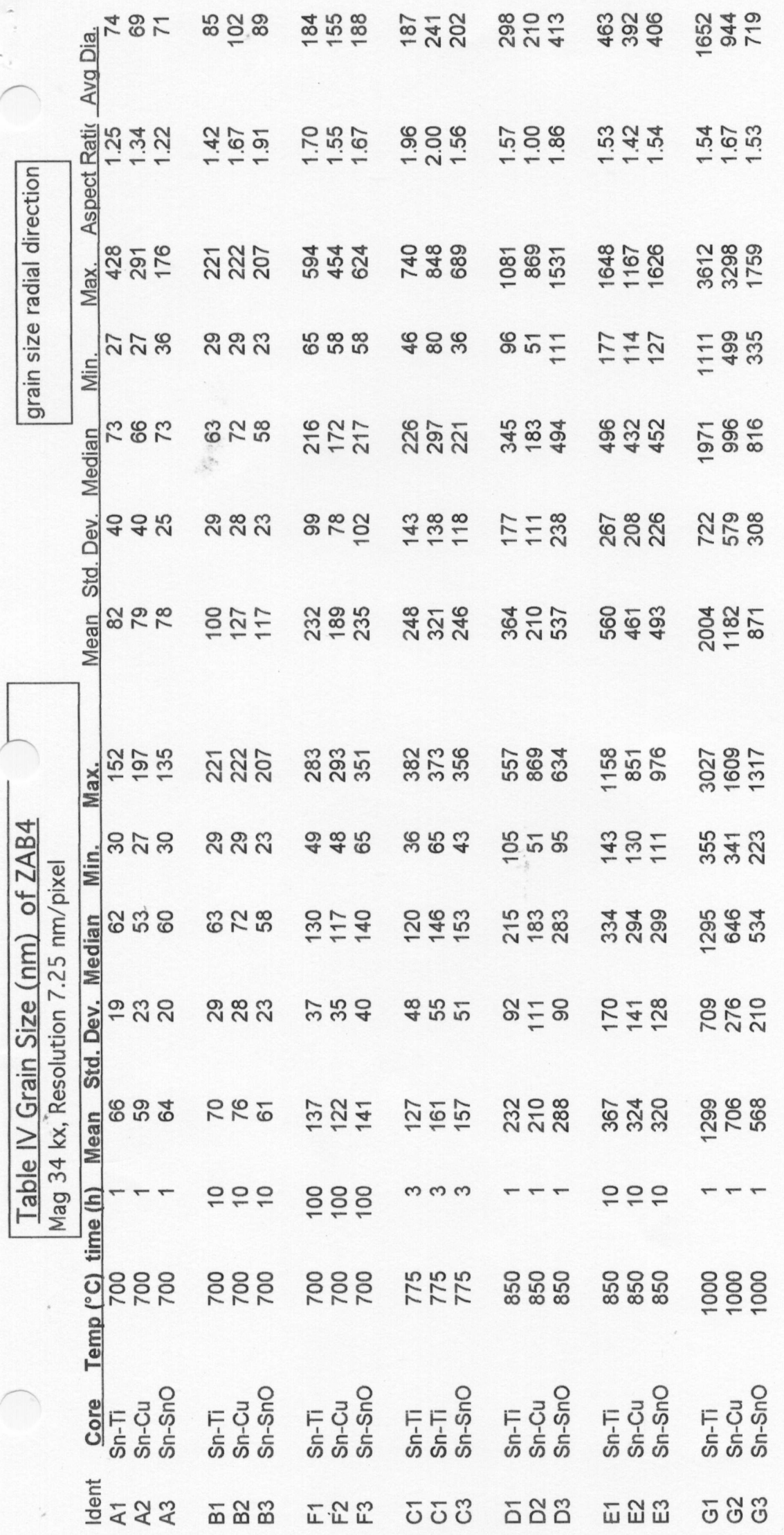




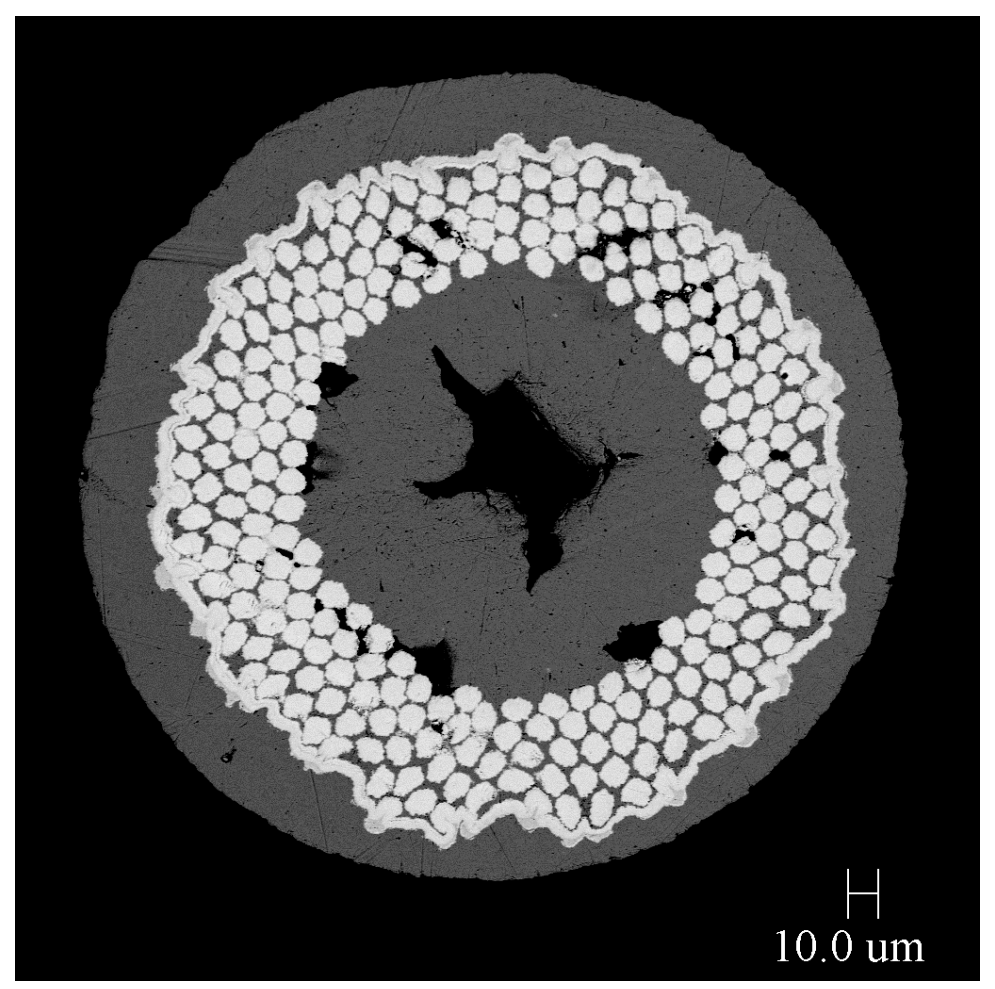

Fig. 11 Fully reacted $\mathrm{Sn}+\mathrm{Ti}$ core $850^{\circ} \mathrm{C} 1 \mathrm{hr}$. (350x)

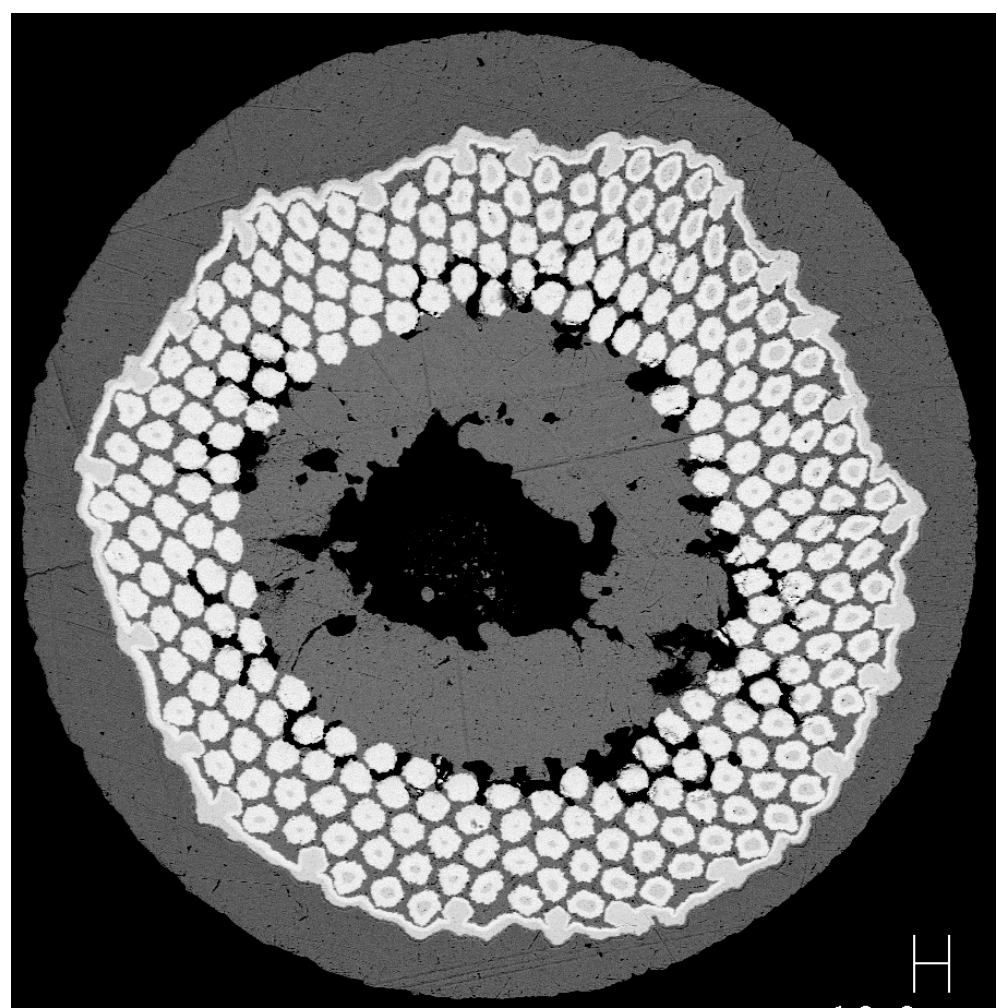

Fig.12 Partially reacted $\mathrm{Sn}+\mathrm{SnO}_{2}$ core $1 \mathrm{hr} 850^{\circ} \mathrm{C}(350 \mathrm{x})$ 


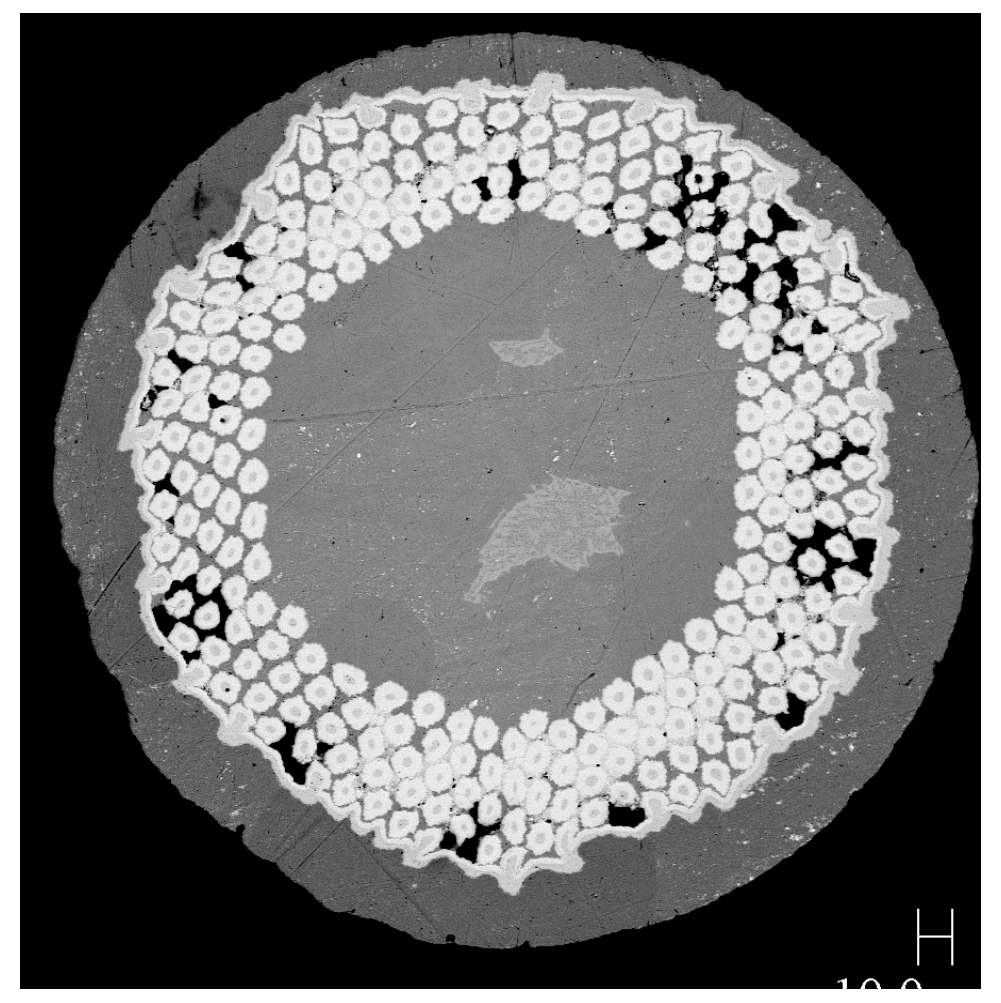

Fig.13 ZAB4 Sn+Ti core partially reacted $10 \mathrm{hr} 700^{\circ} \mathrm{C}(350 \mathrm{x})$

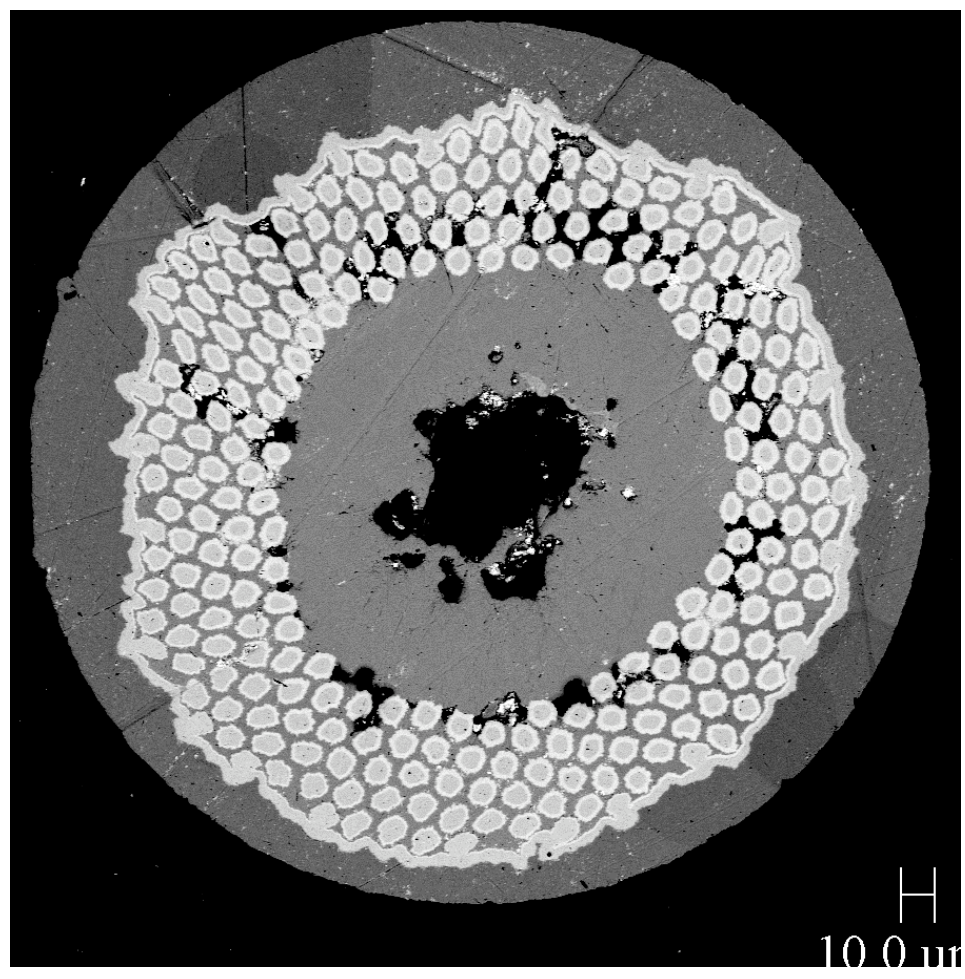

Fig.14 ZAB4 partially reacted $\mathrm{Sn}+\mathrm{SnO}_{2}$ core $10 \mathrm{hrs} 700^{\circ} \mathrm{C}(350 \mathrm{x})$ 


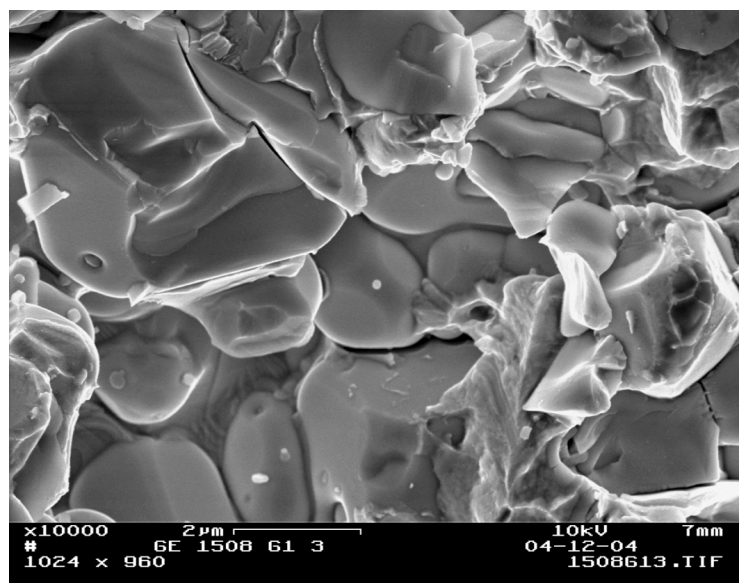

Fig.15. ZAB4 Sn+Ti core $1 \mathrm{hr} 1000^{\circ} \mathrm{C}$

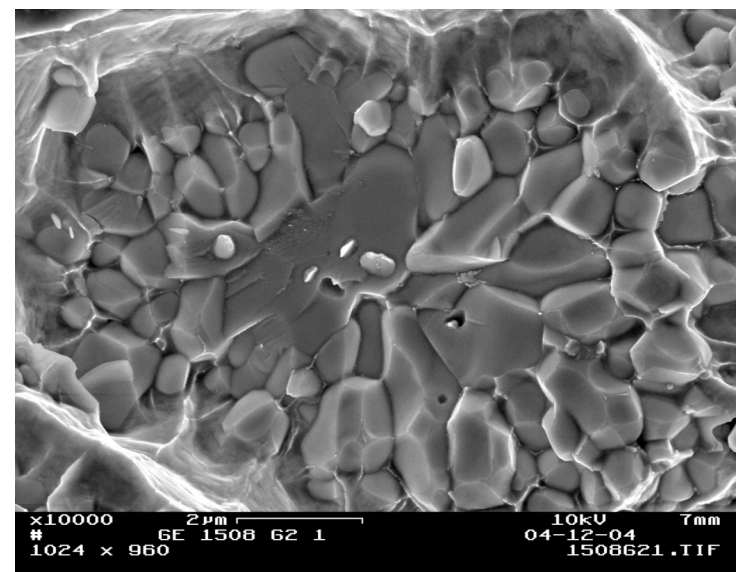

Fig. 16. $\mathrm{ZAB} 4 \mathrm{Sn}+\mathrm{Cu}$ core $1 \mathrm{hr} 1000^{\circ} \mathrm{C}$

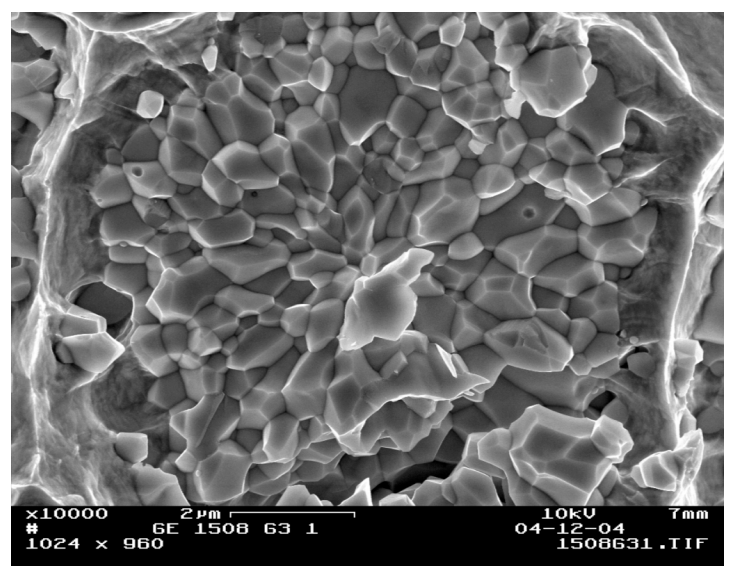

Fig. 17. $\mathrm{ZAB} 4 \mathrm{Sn}+\mathrm{SnO}_{2}$ core $1 \mathrm{hr} 1000^{\circ} \mathrm{C}$

The samples of ZAB4 with the heat treatments as listed in table II were tested at LBL by the P.I. and Dr. Dan Dietderich from 10 to 15 T on a holder designed to test short straight lengths. Some quenching was encountered especially in the higher current density samples. Table $\mathrm{V}$ presents the billet design parameters from which the overall current density was computed. Table VI takes the SEM data and summarizes the reaction area and grain size used in computing the layer current densities derived from the LBL measurements. Figure 18 presents the $\mathrm{J}_{\mathrm{c}}$ vs. $\mathrm{H}$ for the $\mathrm{Sn}+\mathrm{Ti}$ samples and the $\mathrm{Sn}+\mathrm{O}$ samples for the times and temperatures as given in table II. Figure 19 presents $J_{c}$ vs. $H$ for the $\mathrm{Sn}+\mathrm{Cu}$ vs. the $\mathrm{Sn}+\mathrm{SnO}_{2}$ samples.

Table V

Billet Design Parameters for ZAB4

\begin{tabular}{|l|l|l|l|l|}
\hline Billet & $\mathrm{Nb}$ at\% & $\mathrm{Sn}$ at\% & $\mathrm{Cu}$ at\% & $\mathrm{Nb} / \mathrm{Sn}$ \\
\hline $\mathrm{ZAB} 4 \# 258 \mathrm{Nb} 1 \mathrm{Zr}, \mathrm{Ti}$ and $\mathrm{Cu}+\mathrm{Sn}$ & 25.4 & 12.1 & 62.5 & $2.06 / 1$ \\
\hline $\mathrm{Sn}+\mathrm{SnO}{ }_{2}$ Core & 25.1 & 10.6 & 63.5 & $2.37 / 1$ \\
\hline
\end{tabular}




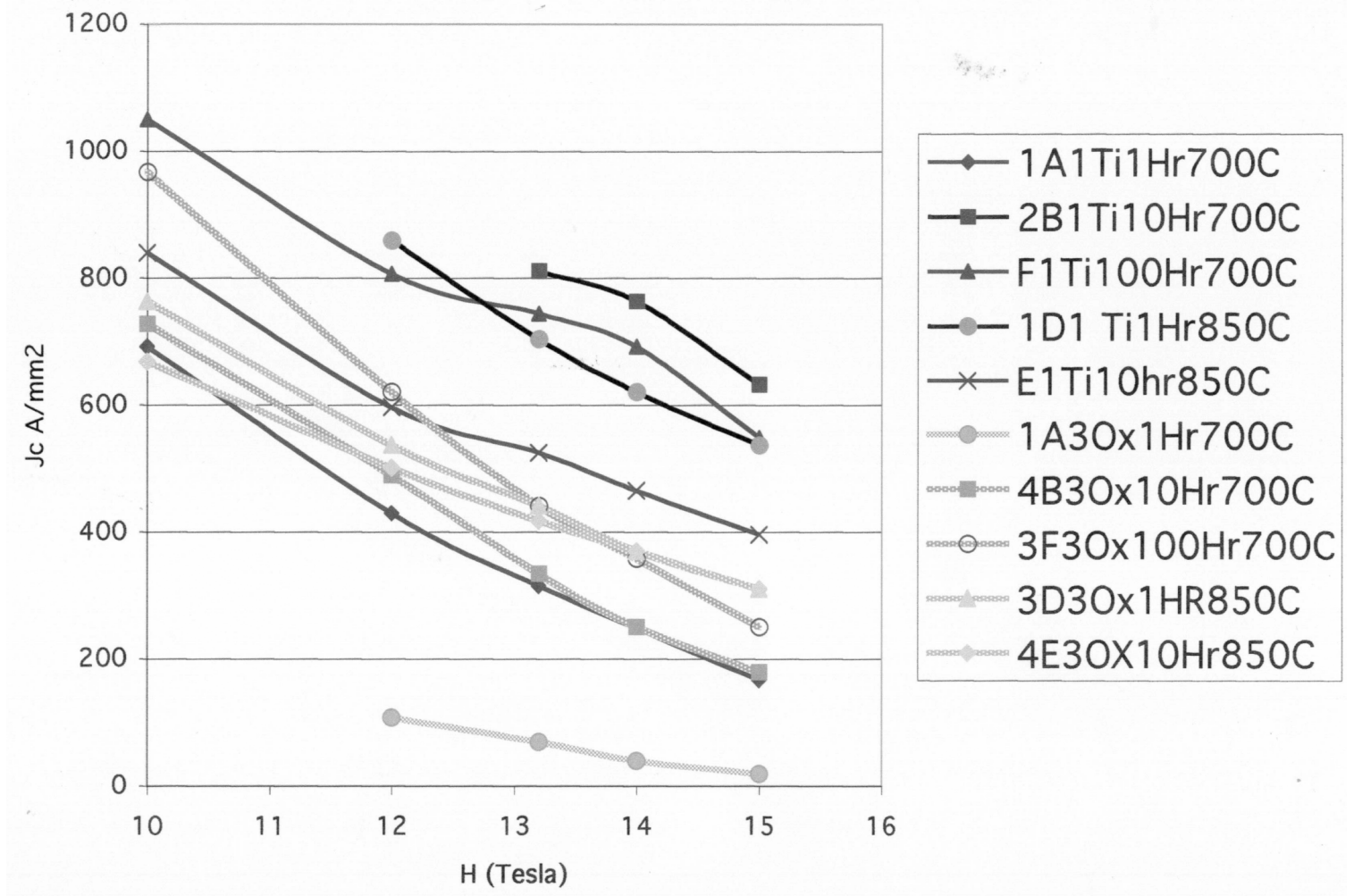

Figure 18. $\mathrm{J}_{\mathrm{c}}$ vs. $\mathrm{H}$ for $\mathrm{Sn}+\mathrm{Ti}$ and $\mathrm{Sn}+\mathrm{SnO}$ at various heat treatments.

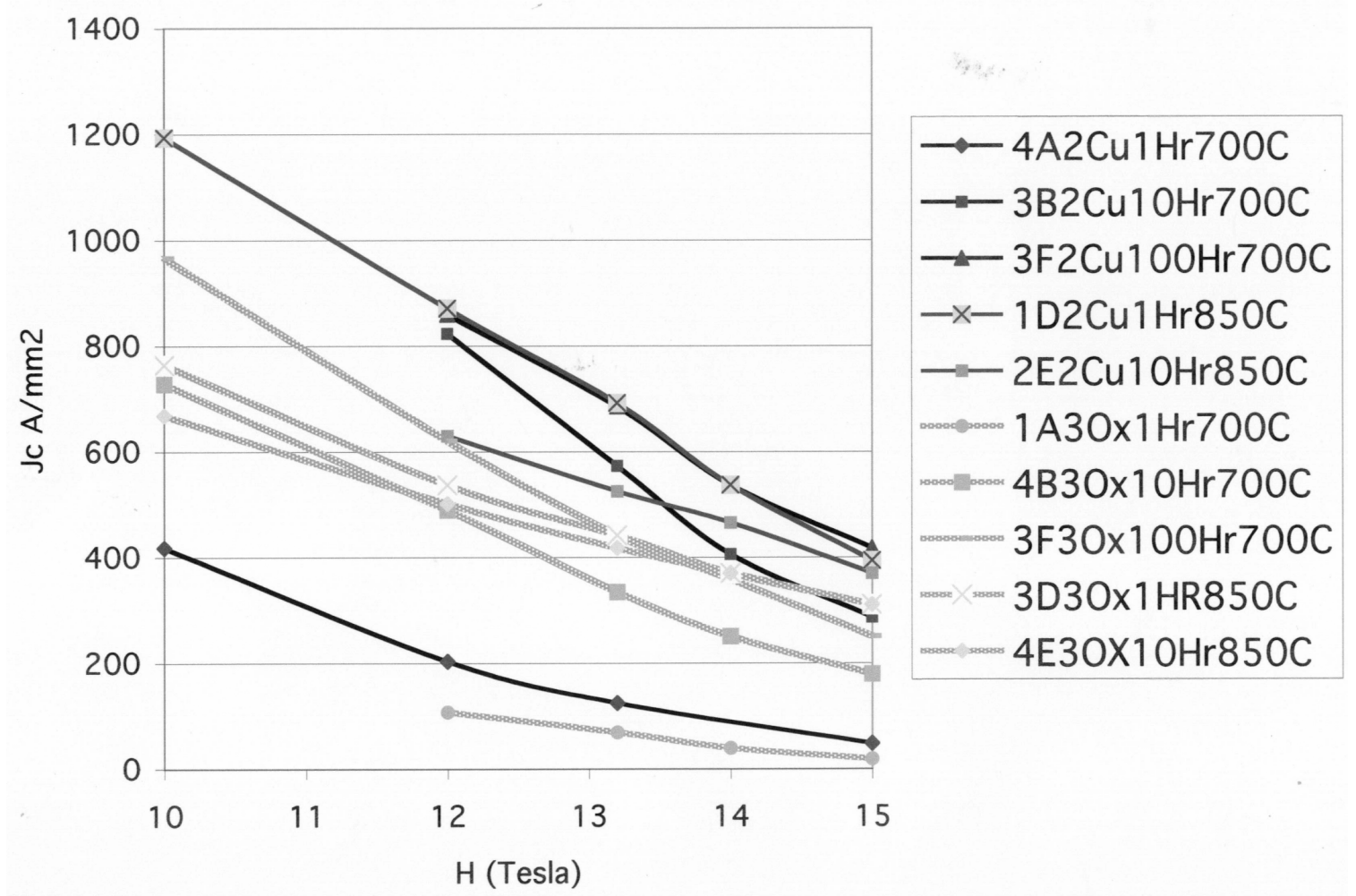

Figure 19. $\mathrm{J}_{\mathrm{c}}$ vs $\mathrm{H}$ for $\mathrm{Sn}+\mathrm{Cu}$ and $\mathrm{Sn}+\mathrm{SnO}$ for various heat treatments. 
TABLE VI

ZAB4 \% Reaction, Grain Size and Heat Treatment Condition

\begin{tabular}{|c|c|c|c|}
\hline Sample & $\begin{array}{l}\text { Reaction } \\
\%+/-8 \% \\
\end{array}$ & $\begin{array}{l}\text { Grain Size } \\
\mathrm{nm}\end{array}$ & $\begin{array}{l}\text { Grain Size } \\
\text { s.d }\end{array}$ \\
\hline $\mathrm{A} 1 \mathrm{Sn}+\mathrm{Ti} 700^{\circ} \mathrm{C} 1 \mathrm{hr}$ & 45 & 74 & 29 \\
\hline $\mathrm{A} 2 \mathrm{Sn}+\mathrm{Cu} 700^{\circ} \mathrm{C} 1 \mathrm{hr}$ & 37 & 69 & 31 \\
\hline $\mathrm{A} 3 \mathrm{Sn}+\mathrm{O} 700^{\circ} \mathrm{C} 1 \mathrm{hr}$ & 23 & 71 & 23 \\
\hline $\mathrm{B} 1 \mathrm{Sn}+\mathrm{Ti} 700^{\circ} \mathrm{C} 10 \mathrm{hr}$ & 87 & 85 & 29 \\
\hline $\mathrm{B} 2 \mathrm{Sn}+\mathrm{Cu} 700^{\circ} \mathrm{C} 10 \mathrm{hr}$ & 91 & 102 & 28 \\
\hline $\mathrm{B} 3 \mathrm{Sn}+\mathrm{O} 700^{\circ} \mathrm{C} 10 \mathrm{hr}$ & 57 & 89 & 23 \\
\hline $\mathrm{F} 1 \mathrm{Sn}+\mathrm{Ti} 700^{\circ} \mathrm{C} 100$ & 100 & 184 & 68 \\
\hline $\mathrm{F} 2 \mathrm{Sn}+\mathrm{Cu} 700^{\circ} \mathrm{C} 100$ & 100 & 155 & 57 \\
\hline $\mathrm{F} 3 \mathrm{Sn}+\mathrm{O} 700^{\circ} \mathrm{C} 100$ & 84 & 188 & 71 \\
\hline D1 Sn+Ti $850^{\circ} \mathrm{C} 1 \mathrm{hr}$ & 100 & 298 & 134 \\
\hline $\mathrm{D} 2 \mathrm{Sn}+\mathrm{Cu} 850^{\circ} \mathrm{C} 1 \mathrm{hr}$ & 100 & 210 & 110 \\
\hline $\mathrm{D} 3 \mathrm{Sn}+\mathrm{O} 850^{\circ} \mathrm{C} 1 \mathrm{hr}$ & 93 & 412 & 163 \\
\hline $\mathrm{E} 1 \mathrm{Sn}+\mathrm{Ti} 850^{\circ} \mathrm{C} 10 \mathrm{hr}$ & 100 & 463 & 218 \\
\hline $\mathrm{E} 2 \mathrm{Sn}+\mathrm{Cu} 850^{\circ} \mathrm{C} 10$ & 100 & 392 & 175 \\
\hline $\mathrm{E} 3 \mathrm{Sn}+\mathrm{O} 850^{\circ} \mathrm{C} 10 \mathrm{hr}$ & 93 & 406 & 177 \\
\hline G1 Sn+Ti $1000^{\circ} \mathrm{C} 1 \mathrm{hr}$ & 100 & 1651 & 715 \\
\hline $\mathrm{G} 2 \mathrm{Sn}+\mathrm{Cu} 1000^{\circ} \mathrm{C} 1$ & 100 & 943 & 427 \\
\hline $\mathrm{G} 3 \mathrm{Sn}+\mathrm{O} 1000^{\circ} \mathrm{C} 1 \mathrm{hr}$ & 100 & 719 & 259 \\
\hline
\end{tabular}

Figure 20 presents the layer current density as a function of time and reaction temperature. It is the clearest illustration of the effects of the additions. The layer current density of the $\mathrm{Cu}+\mathrm{Sn}$ and the $\mathrm{Cu}+\mathrm{Sn}+\mathrm{SnO}_{2}$ are similar at $700^{\circ} \mathrm{C}$ with the slightly higher value of the $\mathrm{Cu}+\mathrm{Sn}$ possibly due to the higher $\mathrm{Sn}$ content. The Ti sample is clearly superior though at $850^{\circ} \mathrm{C}$ the values converge with the increase in time. The $\mathrm{O}+\mathrm{Sn}$ sample appears it will be superior for times greater than 10 hours at $850^{\circ} \mathrm{C}$. 


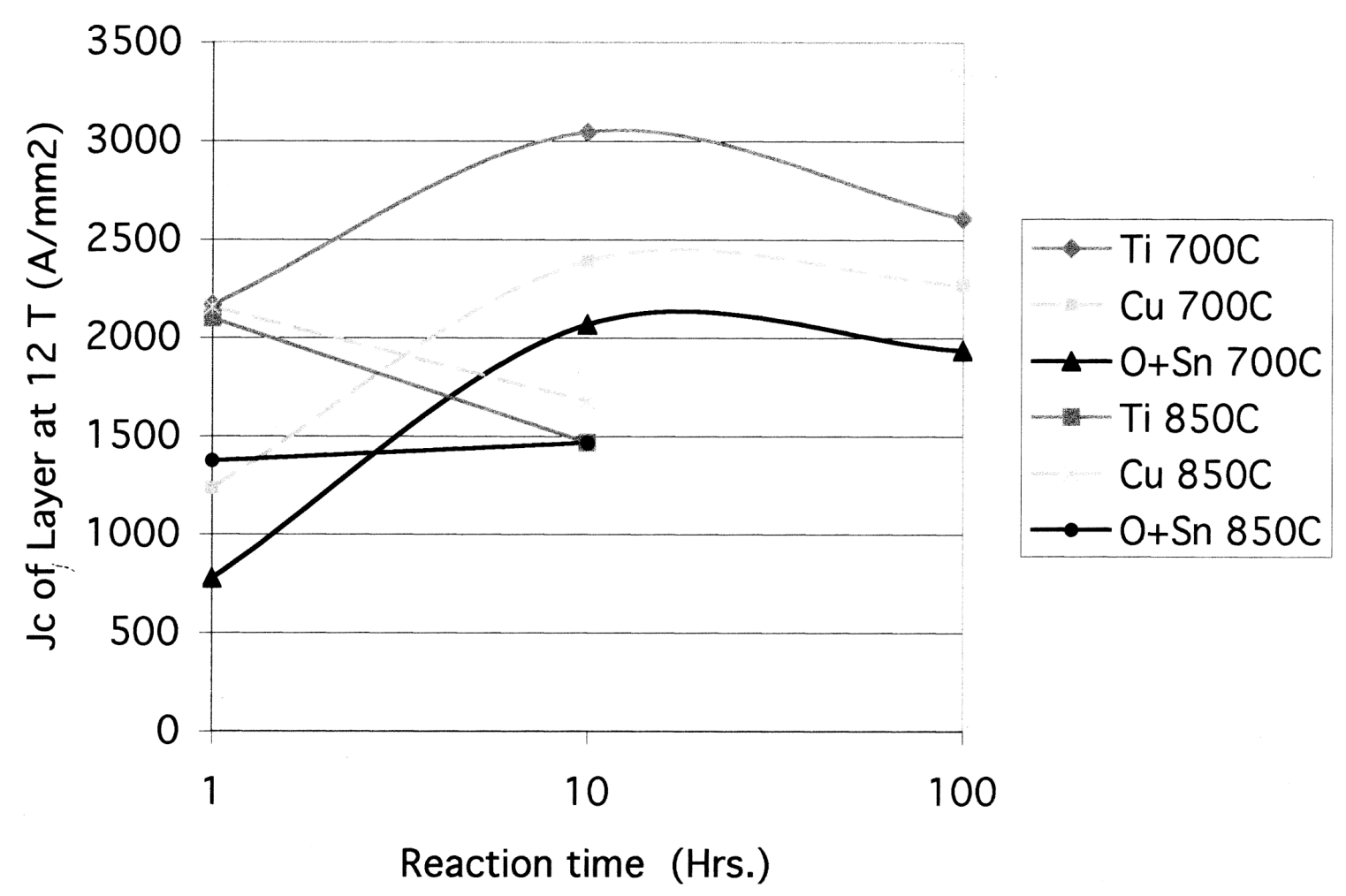

Figure 20. Layer Jc at $12 \mathrm{~T}$ vs. reaction time for $\mathrm{ZAB} 4$ with $\mathrm{Ti}, \mathrm{Cu}, \mathrm{SnO}_{2}$ additions.

Measurements of the $1000^{\circ} \mathrm{C}$ samples showed a marked drop in apparent $\mathrm{H}^{*}$ with the $\mathrm{SnO}_{2}$ sample having an $\mathrm{H}^{*}$ of $10 \mathrm{~T}$. The other samples appeared to be resistive above 6 $\mathrm{T}$. Kuranhashi, et al reported a marked drop in $\mathrm{T}_{\mathrm{c}}$ and $\mathrm{B}_{\mathrm{c} 2}$ in bronze matrix conductors between a peak of $850^{\circ} \mathrm{C}$ and $940^{\circ} \mathrm{C}$ with $\mathrm{B}_{\mathrm{c} 2}$ at $940^{\circ} \mathrm{C}$ of 20T[48]. Also the ternary appears to show 2 at $\%$ of $\mathrm{Cu}$ in solution though there is some disagreement in phase diagrams.

Recently work by Dr. L. Cooley (unpublished has raised concerns about the formation of $\mathrm{ZrO}_{2}$ because the great solubility of Oxygen in Nb. Work done by L.E. Rumaner indicates that the $\mathrm{ZrO}_{2}$ only forms in the $\mathrm{Nb}_{3} \mathrm{Sn}$ and in fact requires the solubility of $\mathrm{O}$ in $\mathrm{Nb}$ for the mechanism to work [49].

Heat treatments in the above work covered the range from $700^{\circ} \mathrm{C}$ to $1000^{\circ} \mathrm{C}$. The oxygen sample at $1000^{\circ} \mathrm{C}$ for one hour showed smaller grain size but depressed $\mathrm{H}^{*}$. Investigating more closely the $850^{\circ} \mathrm{C}$ to $900^{\circ} \mathrm{C}$ temperature range appeared called for. Samples were heat treated straight in flowing high purity $\mathrm{Ar}$ atmosphere within alumina tubes wrapped with Ta foil. The samples were ramped at $6^{\circ} \mathrm{C} / \mathrm{hr}$ to $210^{\circ} \mathrm{C}$ and held for $32 \mathrm{hrs}$., ramped at $10^{\circ} \mathrm{C} / \mathrm{hr}$. to $400^{\circ} \mathrm{C}$, held for $24 \mathrm{hrs}$., ramped to $575^{\circ} \mathrm{C}$ at $50^{\circ} \mathrm{C} / \mathrm{hr}$., held for $1 \mathrm{hr}$., and then ramped at $300^{\circ} \mathrm{C} / \mathrm{hr}$. to the final temperature. Table VII gives the final heat treatment times and temperatures in addition to the grain size, and area reaction. 
Table VII

Heat Treatment Results with Respect to Grain Size and Area Reaction for ZAB4

\begin{tabular}{|c|c|c|c|c|}
\hline $\begin{array}{l}\text { Sample and HT } \\
\text { Temperature }^{\cdot} \mathrm{C}\end{array}$ & $\begin{array}{l}\text { Time } \\
(\min )\end{array}$ & $\begin{array}{l}\text { Reaction Area } \\
\text { Microns }^{2}\end{array}$ & $\begin{array}{c}\% \\
\text { Reacted }\end{array}$ & $\begin{array}{c}\text { Mean Grain } \\
\text { Size (nm) and } \\
\text { S.D. }\end{array}$ \\
\hline \#15 Sn+Ti -850 & 6 & 61.2 & 97.7 & $429+/-19$ \\
\hline$\# 17 \mathrm{Sn}+\mathrm{Ti}-850$ & 30 & 62.6 & 100 & $550+/-18$ \\
\hline$\# 5 \mathrm{Sn}+\mathrm{Ti}-850$ & 60 & 62.6 & 100 & $454+/-19$ \\
\hline$\# 16 \mathrm{Sn}+\mathrm{SnO}_{2}-850$ & 6 & 40 & 65 & $273+/-43$ \\
\hline$\# 18 \mathrm{Sn}+\mathrm{SnO}_{2-} 850$ & 30 & 49 & 79 & $404+/-40$ \\
\hline$\# 6 \mathrm{Sn}+\mathrm{SnO}_{2}-850$ & 60 & 50 & 81 & $368+/-68$ \\
\hline \#4 Sn+Ti-900 & 6 & 62.6 & 100 & $415+/-19$ \\
\hline \#9 Sn+Ti-900 & 30 & 62.6 & 100 & $477+/-19$ \\
\hline \#13 Sn+Ti-900 & 60 & 62.6 & 100 & $439+/-19$ \\
\hline \#3 $\mathrm{Sn}+\mathrm{SnO}_{2}-900$ & 6 & 45 & 73 & $368+/-68$ \\
\hline$\# 10 \mathrm{Sn}+\mathrm{SnO}_{2}-900$ & 30 & 50 & 81 & $434+/-53$ \\
\hline$\# 14 \mathrm{Sn}+\mathrm{SnO}_{2}-900$ & 60 & 55 & 89 & $327+/-26$ \\
\hline
\end{tabular}

The heat treated samples of $\mathrm{ZAB} 4$ with $\mathrm{SnO}_{2}$ additions and $\mathrm{Sn}+\mathrm{Ti}$ were analyzed with respect to reaction area, percent reaction and grain size. Table VII presents the results of the measurements. Figure 21a. and b. compares the as reacted cross sections at 6 minutes for $850^{\circ} \mathrm{C}$ between the $\mathrm{Ti}$ and $\mathrm{SnO}_{2}$ samples. Figure 22a. and b. compares the effect at $900^{\circ} \mathrm{C}$ for 60 minutes.

Current vs. magnetic field measurements were made at Lawrence Berkeley National Laboratory $15 \mathrm{~T}$ superconducting magnet. The samples were straight and mounted perpendicular to the field on a four sample holder. The samples were about $31 \mathrm{~mm}$ long with $9.5 \mathrm{~mm}$ current contact pads and potential leads about $5 \mathrm{~mm}$ apart. One microvolt defined the current. The best of two values was used as the $0.25 \mathrm{~mm}$ wire was easy to damage. Figure $24 \mathrm{a}$, and b. give the layer current density of the $850^{\circ} \mathrm{C}$ and $900^{\circ} \mathrm{C}$ measurements of ZAB4. 


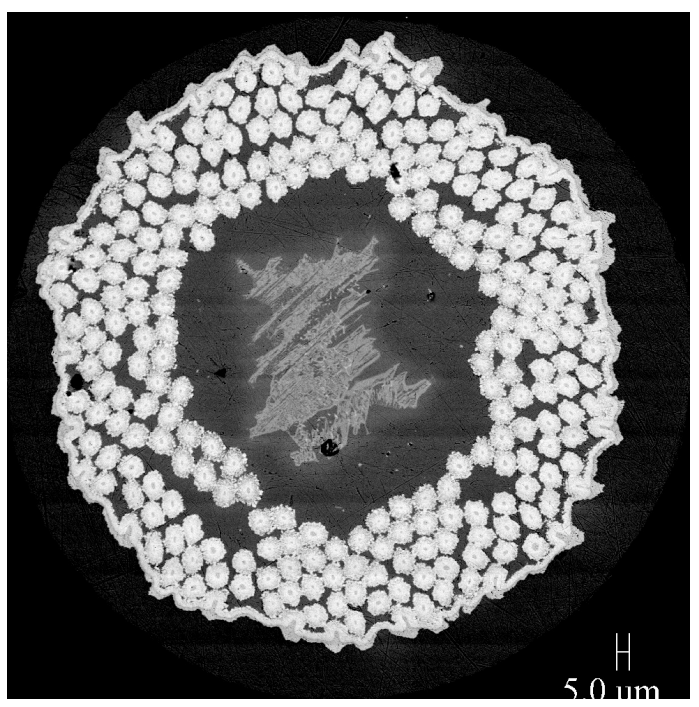

a.

Figure 21a. ZAB4 \#15 Sn+Ti 6 min at $850^{\circ} \mathrm{C}$

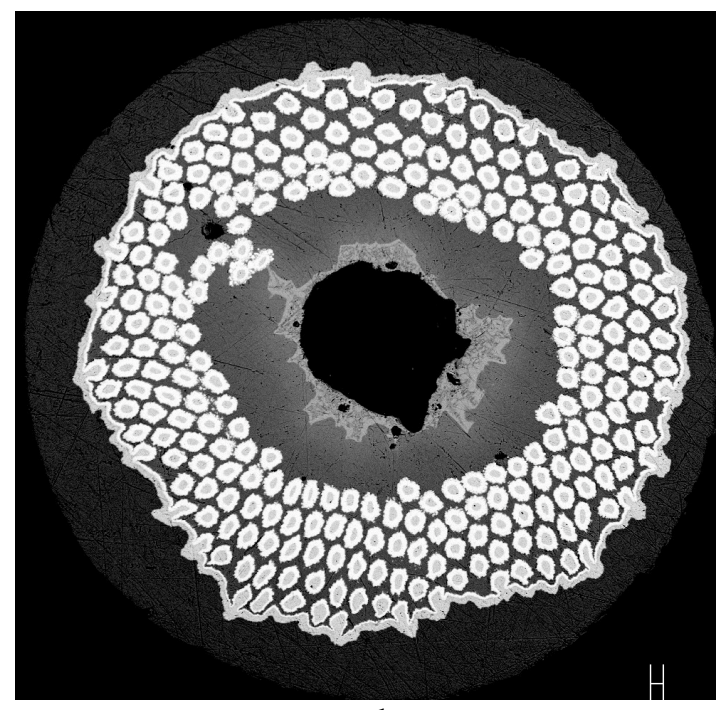

b.

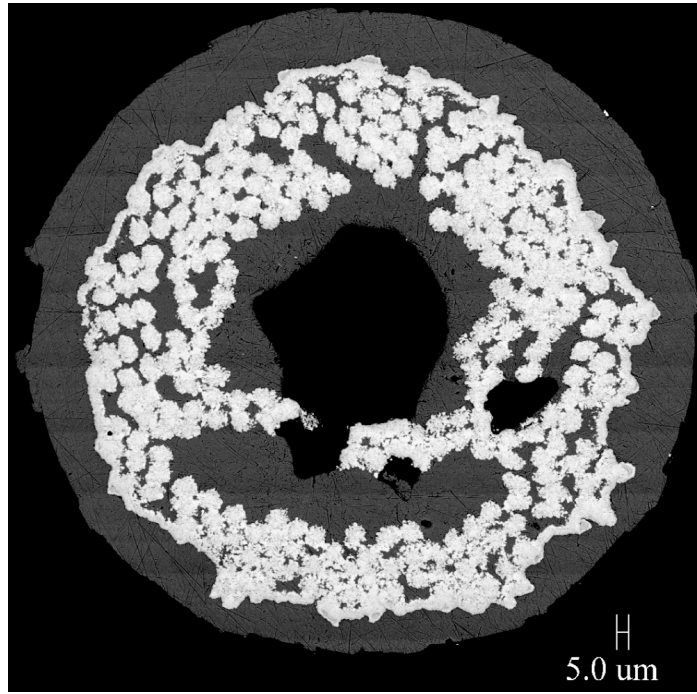

a.

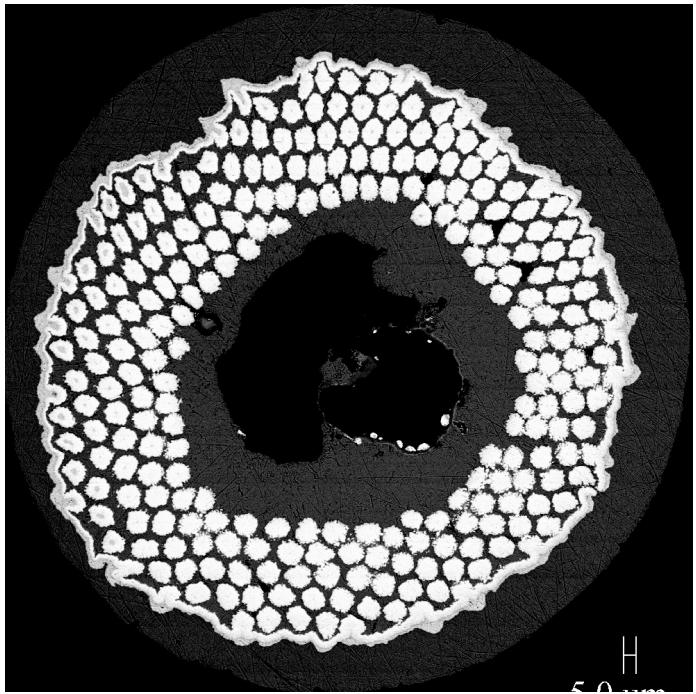

b.

Figure 22a. ZAB4\#13 Sn+Ti $60 \mathrm{~min}$ at $900^{\circ} \mathrm{C}$ b. ZAB4\#14 $\mathrm{Sn}+\mathrm{SnO}_{2} 60 \mathrm{~min}$ at $900^{\circ} \mathrm{C}$ 


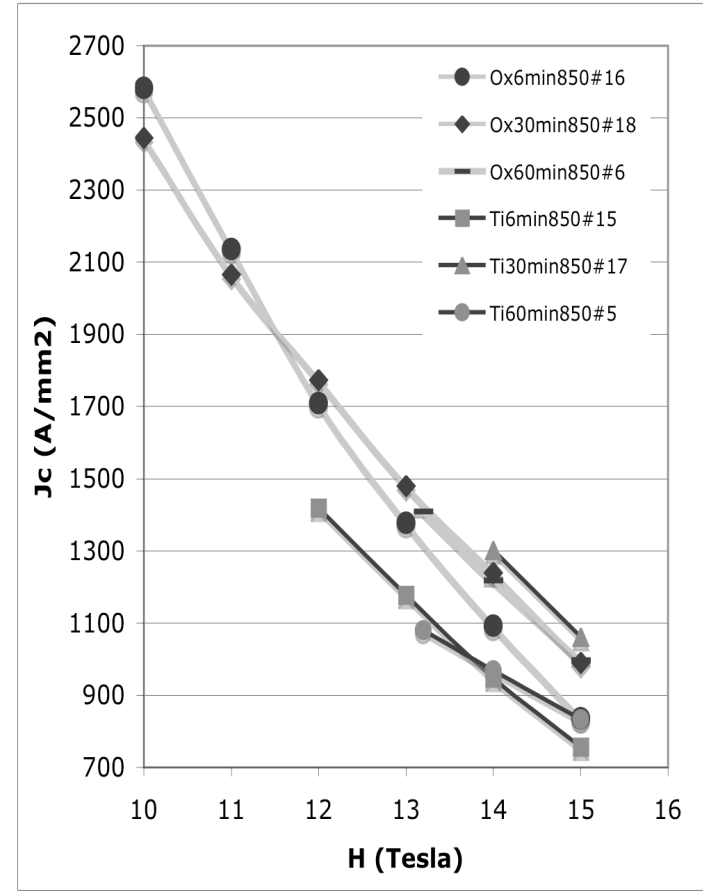

a.

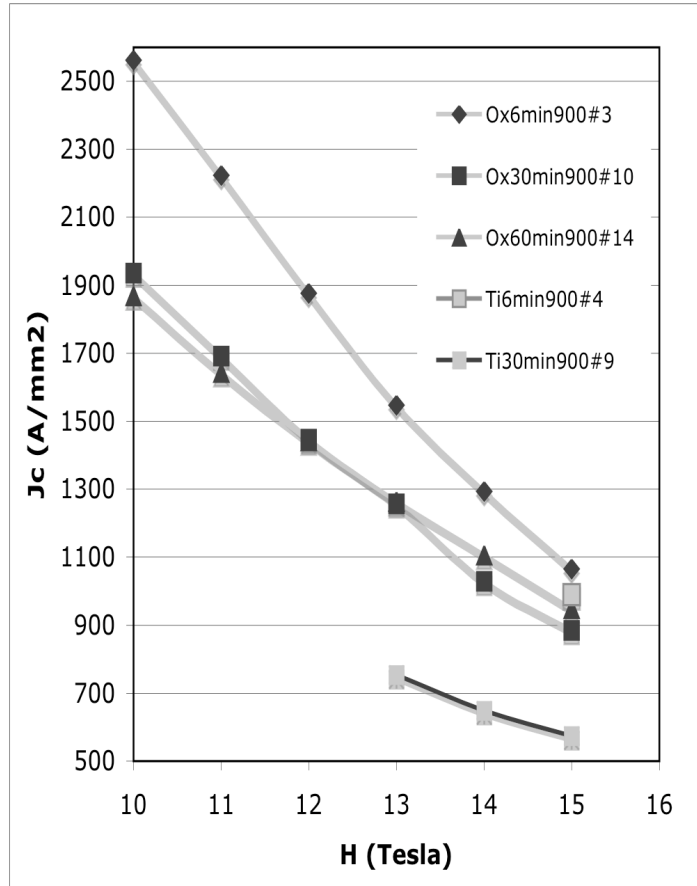

b.

Fig. 24a. Layer current density vs. $\mathrm{H}$ for $850^{\circ} \mathrm{C}$ b. Layer current density vs. $\mathrm{H}$ for $900^{\circ} \mathrm{C}$.

The cross sections in figure 21a with the Ti addition shows $97 \%$ reacted filaments that have partially dissolved and moved significantly. In contrast figure $21 \mathrm{~b}$ with oxygen addition shows a much more uniform $65 \%$ reacted filament and array. Previous work indicated that the addition of oxygen slowed the reaction by about a factor of 10 . Figure 22a shows a broken barrier with extreme movement of filaments suggesting local liquid phases while in figure 22b, the sample with the oxygen filaments are $89 \%$ reacted with an intact barrier.

The average grain size measurements seem to indicate that the 60 minutes gives smaller grains than the 30 minutes. The variation in the local tin concentration and environment as well as the accuracy of the measurement probably explains this. The average grain size of the two Ti samples $(\# 9, \# 13)$ at $900^{\circ} \mathrm{C}$ is $458+/-19$ while the two oxygen samples $(\# 10, \# 14)$ is $380+/-39.5$. There is not a dramatic effect on the grain size of the $\mathrm{Nb}_{3} \mathrm{Sn}$ due to the presence of the $\mathrm{SnO}_{2}$.

Figure 24a. illustrates the layer current for the reaction at $850^{\circ} \mathrm{C}$. At $12 \mathrm{~T}$ the $\mathrm{Ti}$ extrapolated value would be the best. Previous work at $700^{\circ} \mathrm{C}$ yielded a nominal 3045 $\mathrm{A} / \mathrm{mm}^{2}$ in the Ti samples vs. a nominal $2068 \mathrm{~A} / \mathrm{mm}^{2}$ for the oxygen samples. In figure $24 \mathrm{~b}$ the oxygen bearing samples $\mathrm{J}_{\mathrm{c}}$ has increased over the Ti samples for all fields. The $15 \mathrm{~T} 900^{\circ} \mathrm{C}$ value of the oxygen sample $\left(1065 \mathrm{~A} / \mathrm{mm}^{2}\right)$ is superior to its $850^{\circ} \mathrm{C}$ value $(998$ $\mathrm{A} / \mathrm{mm}^{2}$ ) though further optimization could change the result. Note, the layer $J_{c}$ for $700^{\circ} \mathrm{C}$ heat treatments of these conductors is comparable to ITER type conductors which are similar in $\mathrm{Nb}$ and $\mathrm{Sn}$ composition. 
The GE tape process conductors fully optimized to reaction time, temperature and full oxidation of the $\mathrm{Zr}$ to $\mathrm{ZrO}_{2}$ had an average grain size of 250-300 $\mathrm{nm}$. The current density of the GE tape extrapolated from $5 \mathrm{~T}$ data scaled from their $\mathrm{J}_{\mathrm{c}} \mathrm{vs}$. $\mathrm{H}$ curve measured to $20 \mathrm{~T}$ yielded at $12 \mathrm{~T}, 2700 \mathrm{~A} / \mathrm{mm}^{2}$ and $1300 \mathrm{~A} / \mathrm{mm}^{2}$ at $15 \mathrm{~T}$. By the GE model a grain size of $380 \mathrm{~nm}$ would yield current density of $1450 \mathrm{~A} / \mathrm{mm}^{2}$ at $12 \mathrm{~T}$ vs. our measured 1900 $\mathrm{A} / \mathrm{mm}^{2}$. This implies that with further work on optimization that $\mathrm{J}_{\mathrm{c}}$ values might be improved. Still, the extrapolated values to $12 \mathrm{~T}$ of GE's tape layer current density, 2700 $\mathrm{A} / \mathrm{mm}^{2}$ are significantly below 4300 to $4500 \mathrm{~A} / \mathrm{mm}^{2}$, currently achieved in the best internal tin conductors. The GE tape though does not use third element additions such as $\mathrm{Ti}$ and or $\mathrm{Ta}$ to improve the properties. The addition of $\mathrm{Ti}$ to the $\mathrm{Nb} 1 \mathrm{Zr}$ in addition to oxygen remains to be explored in the MEIT conductor.

The apparent effect of oxygen using the $\mathrm{SnO}_{2}$ method is to slow the reaction, and stabilize the filaments and matrix at high reaction temperatures. If, continuous high speed reaction is required in a multifilament process then the addition of oxygen by this method would make this feasible.

Reconsideration of the original GE process suggested that since the tape process reaction was in liquid phase that we should look to lower the temperature of reaction to just stay within the liquid phase region. This would reduce the grain size as well as better duplicating the reaction situation in which the $\mathrm{ZrO}_{2}$ restricted grain growth. The boundary in the tin content of our materials is at $798^{\circ} \mathrm{C}$ in the phase diagram.

A series of heat treatments were carried out on ZAB4 at 785 and $815^{\circ} \mathrm{C}$, straddling the phase boundary at Supramagnetics in their new box furnace. All samples had a pretreatment of $24 \mathrm{hr}$. at $210^{\circ} \mathrm{C}$, ramped to $400^{\circ} \mathrm{C}$ at $10^{\circ} \mathrm{C} / \mathrm{hr}$. held for $24 \mathrm{hrs}$. ramped to $575^{\circ} \mathrm{C}$ at $50^{\circ} \mathrm{C} / \mathrm{hr}$. held for $1 \mathrm{hr}$. and then heat treated at $785^{\circ} \mathrm{C}$ and $815^{\circ} \mathrm{C}$ for 1,3 and 10 hrs. Grain size was measured on each sample though only one filament of each was used. Figure 25 shows an un-reacted sample of ZAB4 at $0.254 \mathrm{~mm}$ dia. prior to reaction. The tin core is off center due to drill wander. This could lead to local melting in the reaction process.

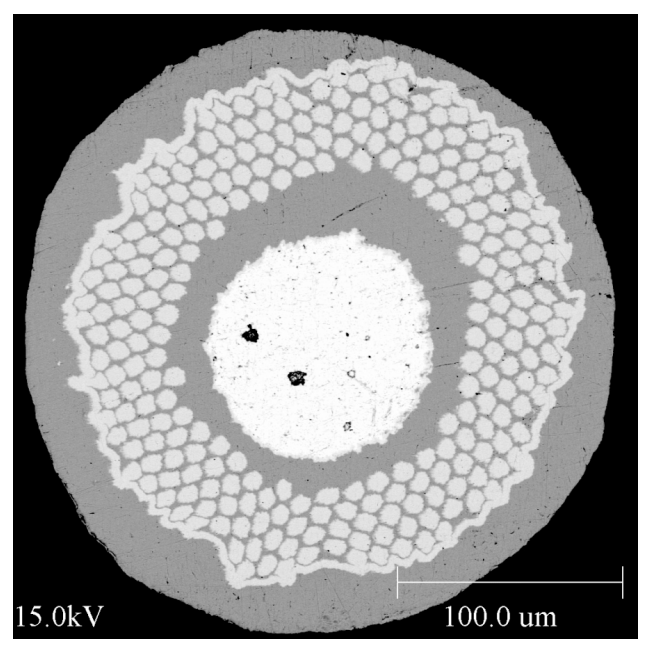

Fig. 25. ZAB4-1 Oxygen $0.254 \mathrm{~mm}$ 
Figure 26 a. and b. show the reacted cross sections of ZAB4 with for 3 hrs at 785 and $815^{\circ} \mathrm{C}$. These show the extremes of the images. The 10 hrs samples show $100 \%$ reaction for both temperatures. The $815^{\circ} \mathrm{C} 1 \mathrm{hr}$. sample shows about $90 \%$ reaction.

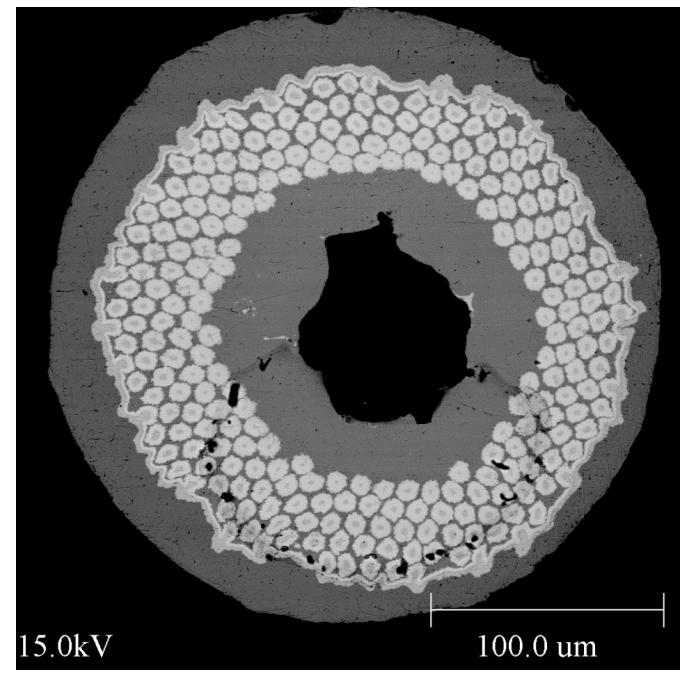

Fig.26a. ZAB4 Oxygen 3 hrs. $785^{\circ} \mathrm{C}$

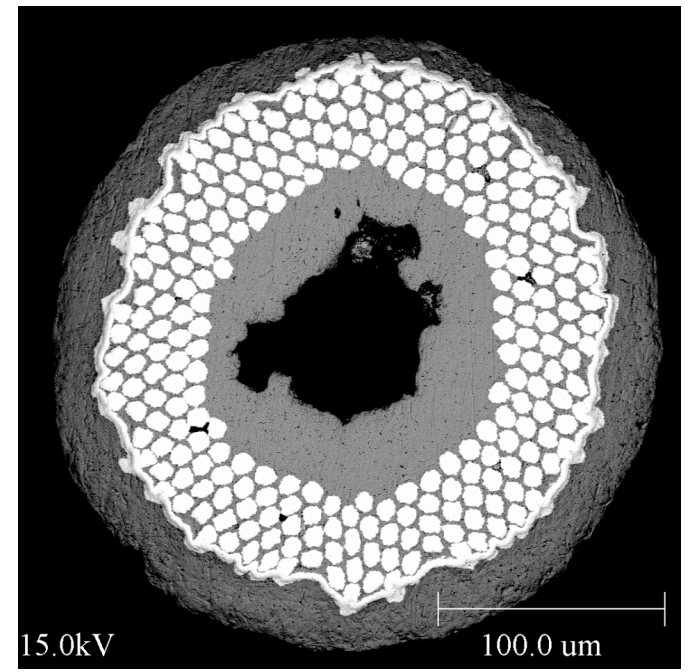

b. ZAB4 Ox $3 \mathrm{hrs} .815^{\circ} \mathrm{C}$

Fig. 27a shows the reacted cross section of the Ti addition to ZAB4. Both are essentially $100 \%$ reacted. This again illustrates the enhanced reaction kinetics from Ti addition. At 1 hour for both temperatures reaction is almost complete. Fig. 28a. and b. show ZAB4 without any additions. The $785^{\circ} \mathrm{C}$ shows signs of melting in the reaction sufficient to move the filaments though the $815^{\circ} \mathrm{C}$ does not. Reaction in both are $100 \%$. All the $785^{\circ} \mathrm{C}$ samples show distorted arrays due to local melting. The $815^{\circ} \mathrm{C}$ do not. The $1 \mathrm{hr}$ sample at $785^{\circ} \mathrm{C}$ showed quite a number of partly un-reacted filaments while the sample at $815^{\circ} \mathrm{C}$ showed fully reacted filaments. Thus the possibility of sample mix up seems not to be the explanation.

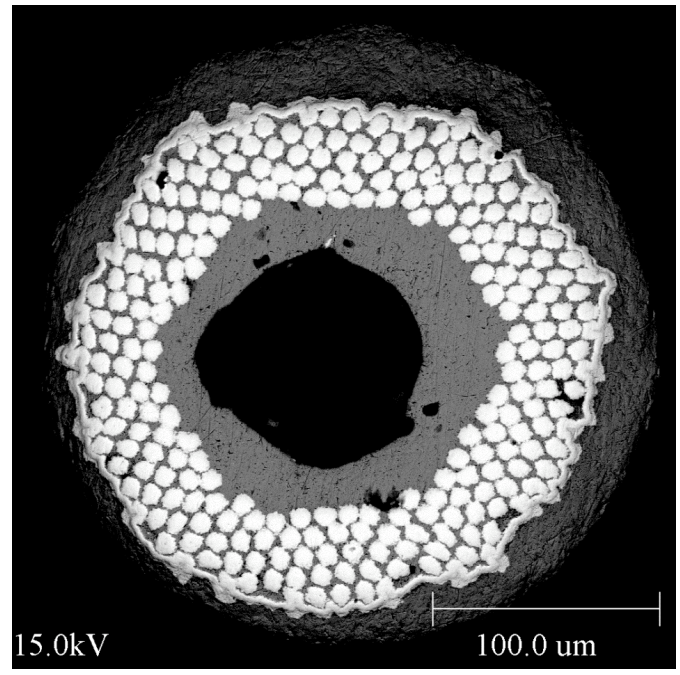

Fig. 27a. ZAB4+Ti 3 hrs. $785^{\circ} \mathrm{C}$

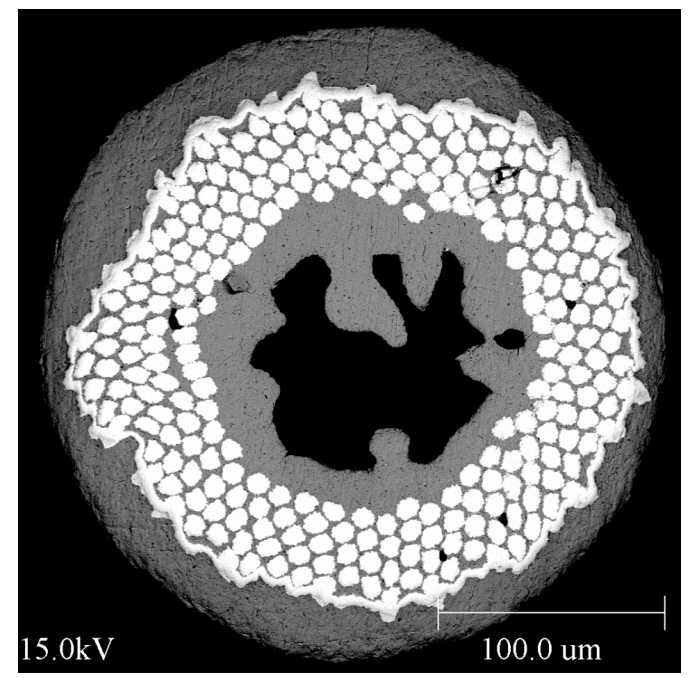

b. ZAB4+Ti 3 hrs. $815^{\circ} \mathrm{C}$ 


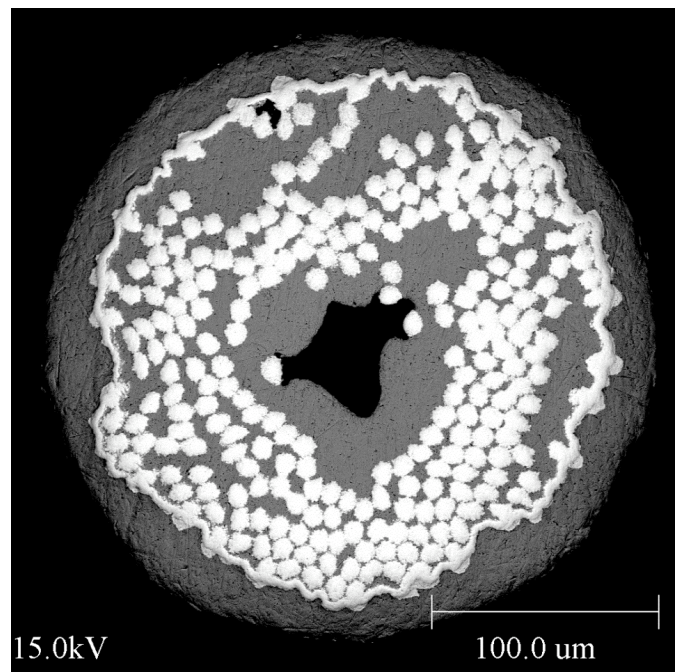

Fig. 28a. ZAB4 3 hrs. $785^{\circ} \mathrm{C}$

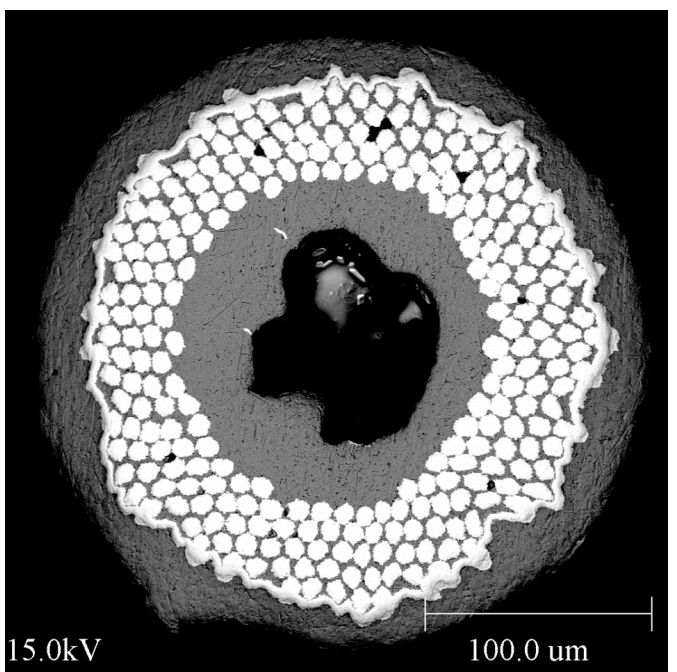

b. ZAB4 3 hrs. $815^{\circ} \mathrm{C}$

Additional cross sections of the samples at $785^{\circ} \mathrm{C}$ showed that 10 out of 12 non doped (Cu) samples had distorted arrays similar to Fig. 28a. while 2 out of 12 of the Ti samples also showed distorted arrays. No distorted arrays were found in any of the $815^{\circ} \mathrm{C}$ heat treatments nor were any found in the Oxygen samples.

Grain size measurements were made at GECR\&D using the linear intercept method. Figure 29 plots the results for the 3 and $10 \mathrm{hr}$. heat treatments for the samples. A typical filament was measured in each. Grain size appeared similar within a sample. The $10 \mathrm{hr}$. trend confirms that Oxygen is effective in controlling the grain size as is Ti. Grain sizes fit within the boundaries previously measured such as in Table VI.

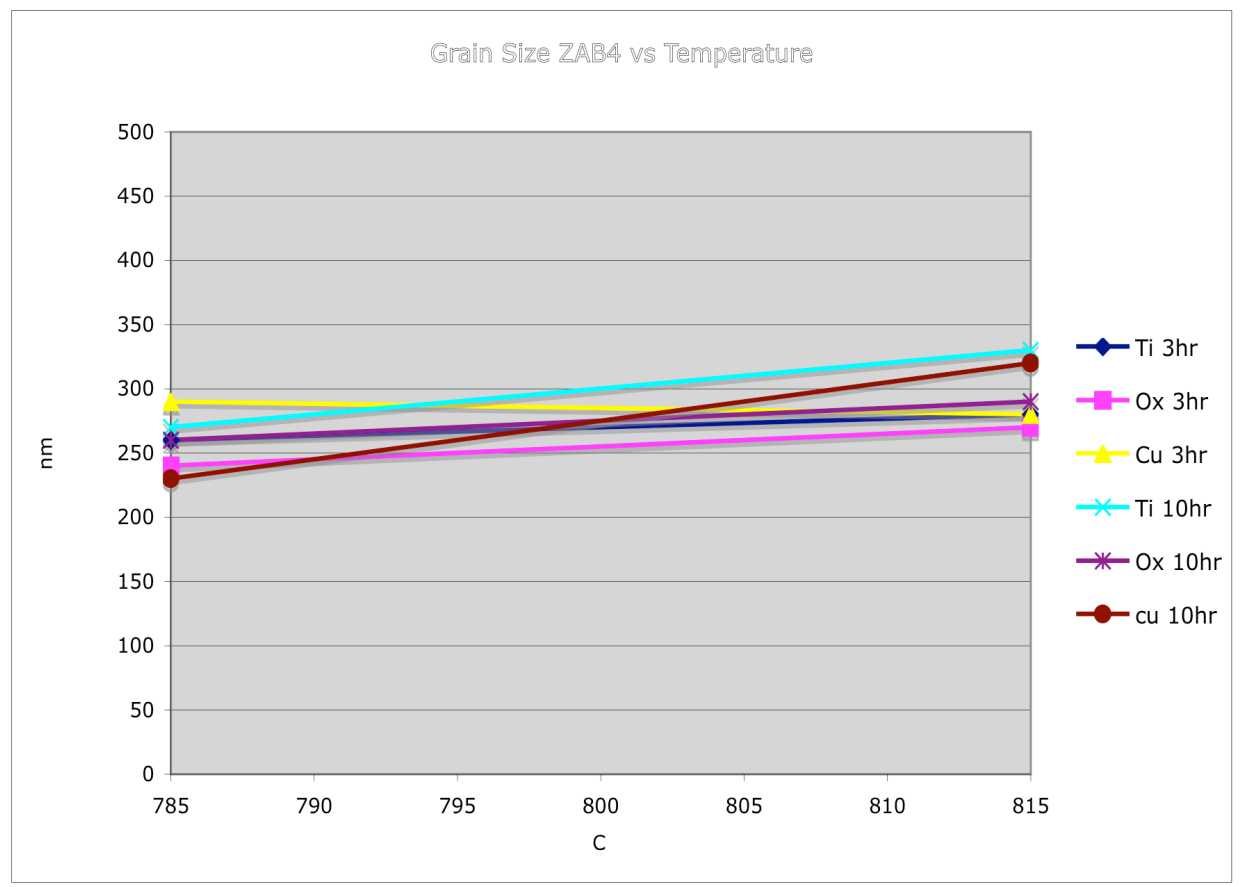

Fig. 29. Grain size vs. reaction temperature of various $\mathrm{ZAB} 4,+\mathrm{Cu},+\mathrm{Ox},+\mathrm{Ti}$ 
Table VIII

\begin{tabular}{|c|c|c|c|c|c|c|}
\hline Type & Temp ${ }^{\circ} \mathrm{C}$ & $\underline{\text { Time Hrs }}$ & eacted & reaction & Size & observation \\
\hline SnOx1 hr785 & 785 & 1 & 42.3 & $75.0 \%$ & 200 & \\
\hline SnOx1 hr785 & 785 & 1 & 56.3 & $90 \%$ & 200 & \\
\hline SnOx3hr785 & 785 & 3 & 62.6 & $100 \%$ & 240 & \\
\hline SnOx10hr785 & 785 & 10 & 62.6 & $100 \%$ & 260 & \\
\hline SnOx1hr815 & 815 & 1 & 61.4 & $98 \%$ & 270 & \\
\hline SnOx3hr815 & 815 & 3 & 62.6 & $100 \%$ & 270 & \\
\hline SnOx10hr815 & 815 & 10 & 62.6 & $100 \%$ & 290 & \\
\hline CuSn1hr785 & 785 & 1 & 56.3 & $90 \%$ & 260 & distorted array \\
\hline CuSn3hr785 & 785 & 3 & 62.6 & $100 \%$ & 290 & distorted array \\
\hline CuSn10hr785 & 785 & 10 & 62.6 & $100 \%$ & 230 & distorted array \\
\hline CuSn1hr815 & 815 & 1 & 62.6 & $100 \%$ & 250 & distorted array \\
\hline CuSn3hr815 & 815 & 3 & 62.6 & $100 \%$ & 290 & distorted array \\
\hline CuSn10hr815 & 815 & 10 & 62.6 & $100 \%$ & 320 & distorted array \\
\hline SnOxR10hr815 & 815 & 10 & 62.6 & $100 \%$ & 290 & \\
\hline CuSnR1hr815 & 815 & 1 & 62.6 & $100 \%$ & 250 & distorted array \\
\hline CuSnR3hr815 & 815 & 3 & 62.6 & $100 \%$ & 290 & distorted array \\
\hline
\end{tabular}

Table IX

\begin{tabular}{|llllr|}
\hline H (Tesla) & $\underline{12}$ & $\underline{13}$ & $\underline{14}$ & $\underline{15}$ \\
n values & & & & \\
SnOx1hr785 & 29 & 29 & 28 & \\
SnOx1hr785 & 33 & 32 & 25 & \\
SnOx3hr785 & 15 & 14 & 14 & \\
SnOx1 Ohr785 & 72 & 44 & 50 & \\
SnOx1hr815 & 20 & 29 & 33 & 44 \\
SnOx3hr815 & 52 & 25 & 97 & 17 \\
SnOx1 Ohr815 & & & 17 & 9 \\
CuSn1hr785 & 17 & 16 & 11 & 8 \\
CuSn3hr785 & 27 & 24 & 22 & 15 \\
CuSn1Ohr785 & 17 & 10 & 24 & 11 \\
CuSn1hr815 & 29 & 23 & 16 & 32 \\
CuSn3hr815 & & & 30 & 27 \\
CuSn1Ohr815 & & & & \\
SnOxR1Ohr815 & 62 & 35 & 21 & 11 \\
CuSnR1hr815 & & 37 & 10 & 28 \\
CuSnR3hr815 & 43 & 39 & 22 & \\
\hline
\end{tabular}

Table VIII lists the area of reaction, \% reaction, grain size and comments of the array of the samples tested. Table IX lists the " $n$ " values for the samples tested by Dr. Arno Goedeke and Dr Dan Dietderich of LBNL using the same probe and magnet as in previous tests. 


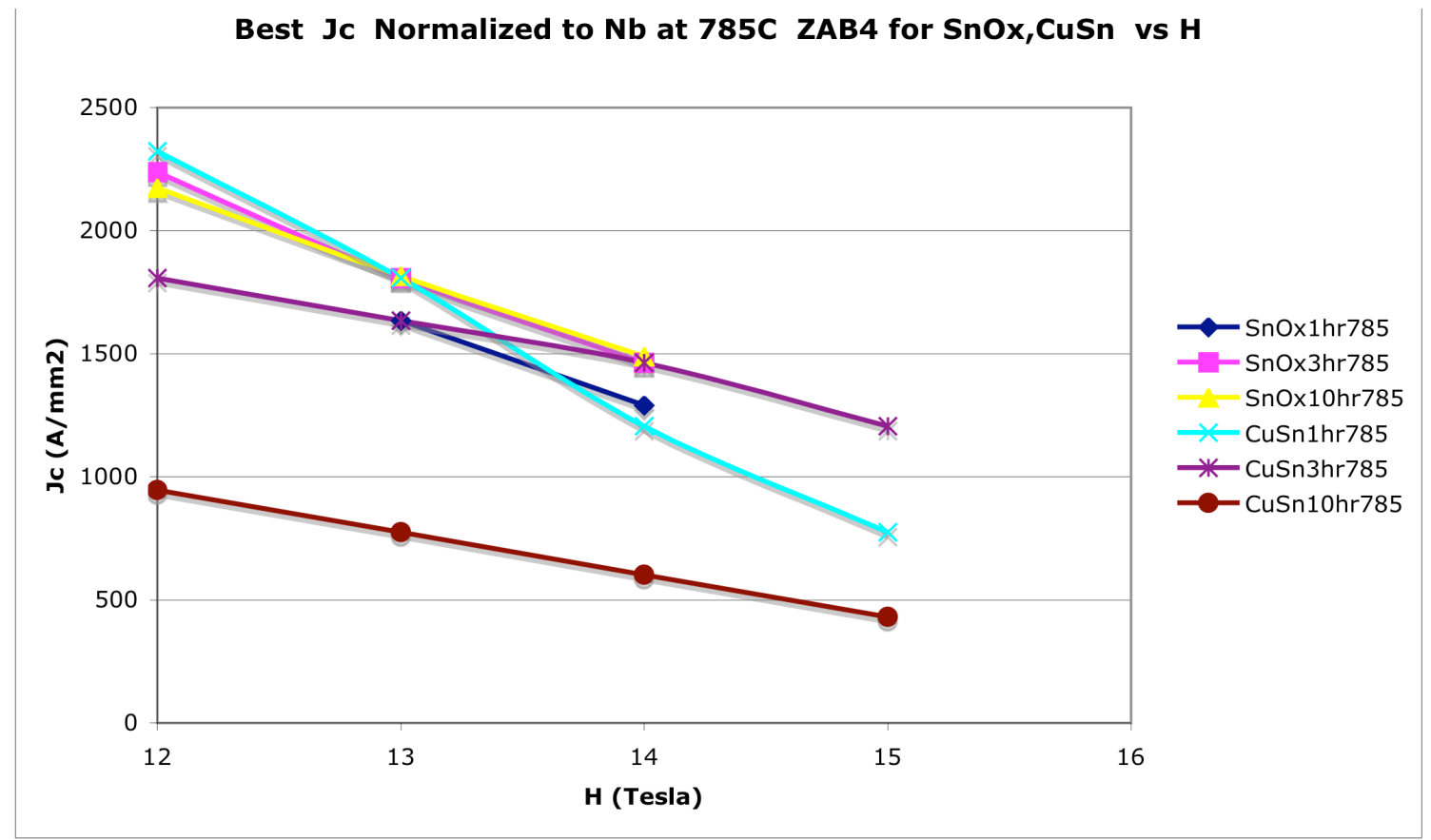

Figure 30

Some samples exhibited flux jumping, and or motion effects that resulted in quenching at lower fields. The best results for current density normalized to the $\mathrm{Nb}$ at $775^{\circ} \mathrm{C}$, and $815^{\circ} \mathrm{C}$ are graphed in figure 30 and 31 . The best layer current density as a function of temperature for all samples is summarized in figure 32 .

Figure 31

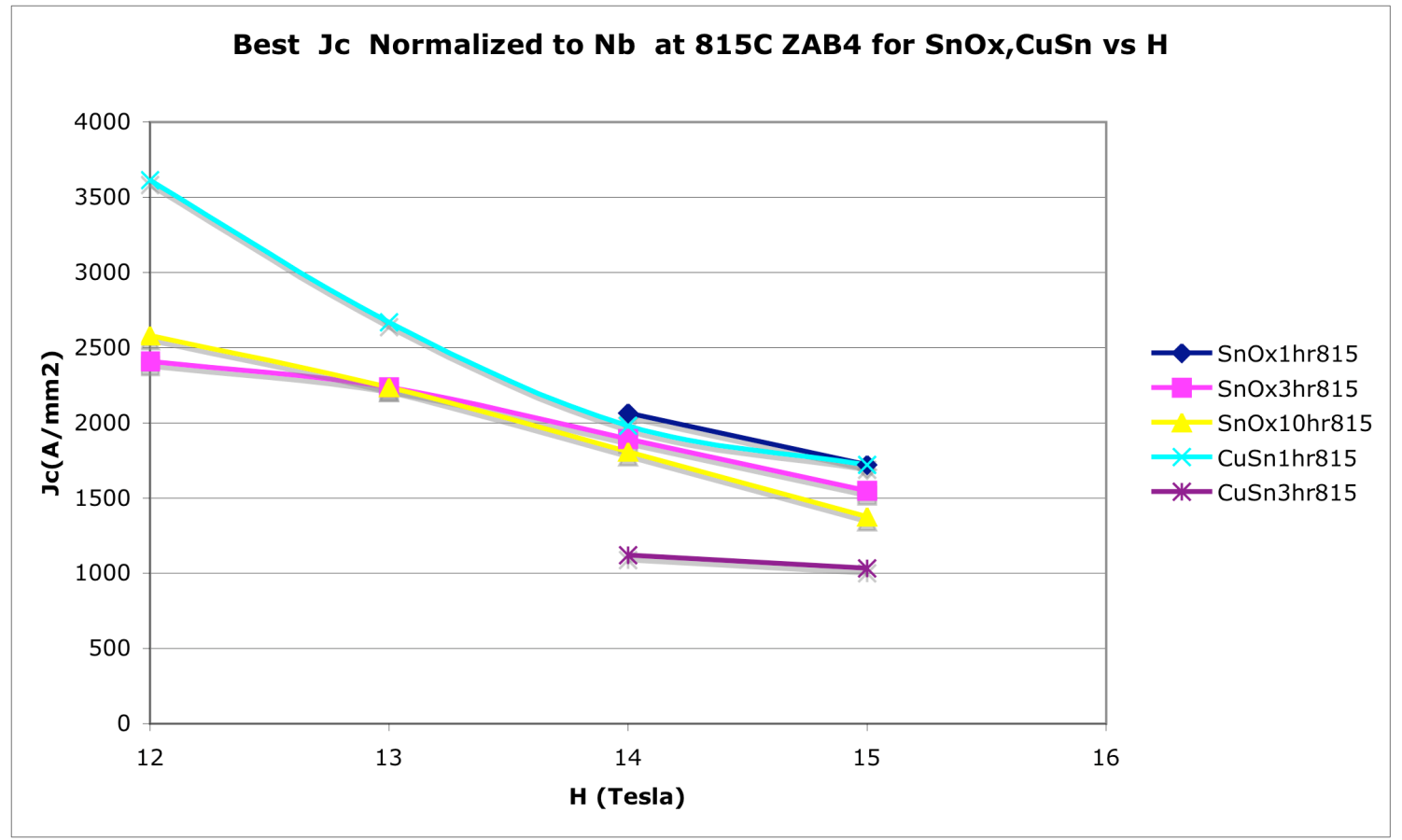




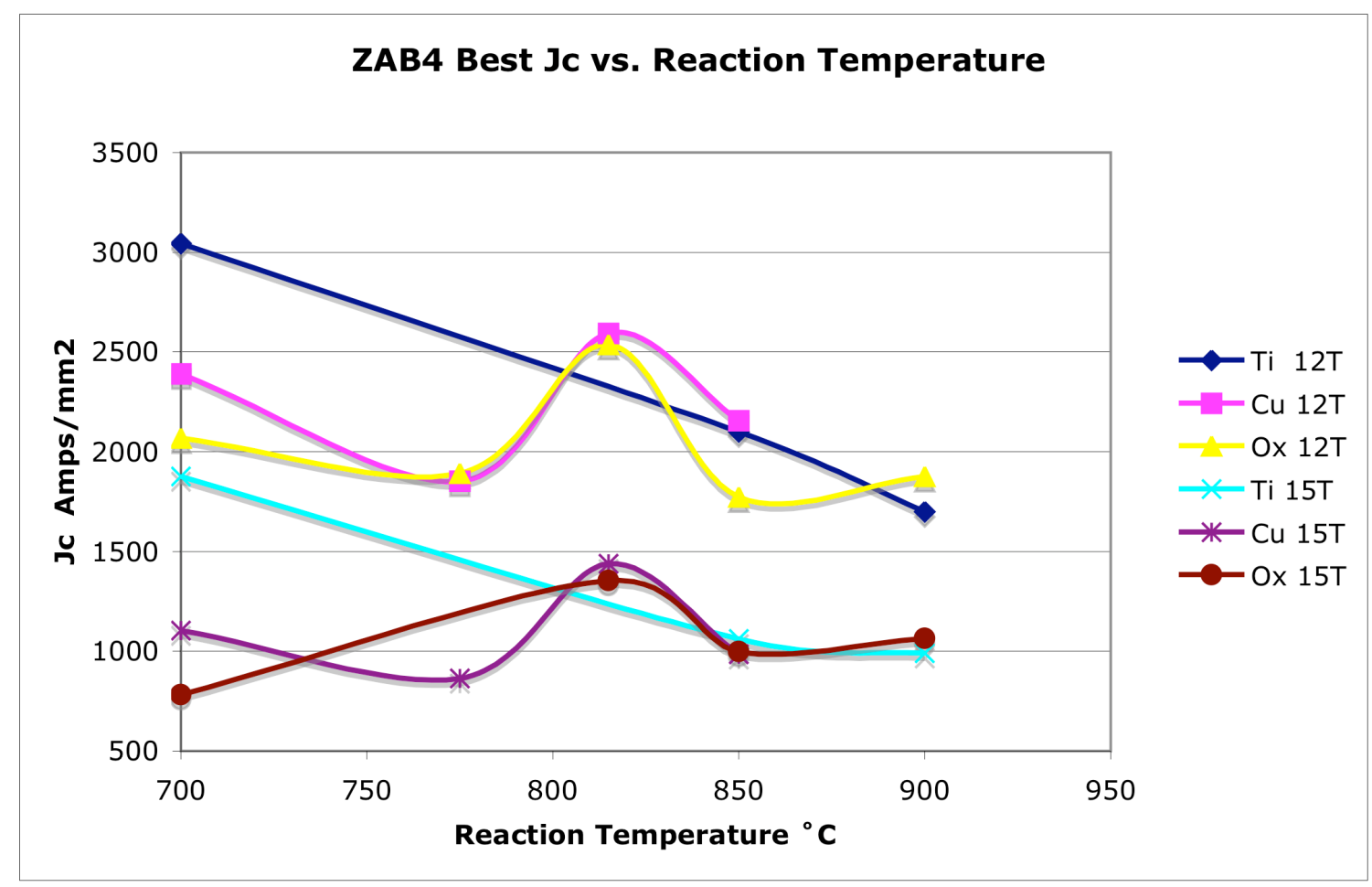

Figure 32

Both the $\mathrm{SnOx}$ sample and $\mathrm{CuSn}$ samples have a peak at the $825^{\circ} \mathrm{C}$ reaction temperature for both 12 and 15T. 15T results are felt to best represent the maximum values as at those currents and fields the samples were stable. Ti samples were not measured due to insufficient funds. The grain size of the samples are similar at $1 \mathrm{hr} 815^{\circ} \mathrm{C}$ as seen in table VIII $(270,250 \mathrm{~nm})$. These grain sizes are substantially below the 1 hour at $850^{\circ} \mathrm{C}, 368+/-$ $68 \mathrm{~nm}$. Even though the $\mathrm{Cu}$ samples have no intentional Oxygen added there is probably detectable amounts sufficient to form some $\mathrm{ZrO}_{2}$. Since we don't know how much is actually needed to have an effect we can only conjecture that it might have been enough. Further work is needed with $(\mathrm{Nb} 1 \mathrm{Zr})_{3} \mathrm{Sn}$ with higher tin and more filaments to see if this enhancement in layer $J_{c}$ will be additive to the effect associated with higher tin contents.

Attempts to incorporate $\mathrm{TiO}_{2}$ with the $\mathrm{Sn}$ core yielded a low density core which we were unable to process. Other methods could not be explored due to insufficient funds.

\subsection{The effect of $\mathrm{Zr} \& \mathrm{O}_{2}$ on properties in rod-in-tube billet materials}

Work on this was based on being able to add oxygen to the copper matrix. That has proven unfeasible as well as unnecessary now that we have other techniques. Efforts intended in this area were shifted to 8.1 which had proven more difficult than planned.

\subsection{Use of clad rods in two conditions to improve non-Cu Jc}

Two five inch $(127 \mathrm{~mm})$ diameter billets were designed $(.71 / 1 \& .57 / 1)$. These designs use copper clad $\mathrm{Nb} 1 \mathrm{Zr}$ rods to increase the local $\mathrm{Nb} 1 \mathrm{Zr}$ ratio. The resulting conductor 
are more representative of present HEP conductors which have high $\mathrm{Nb}$ percentages as well as high Sn percentages while minimizing copper. Hopefully the high LAR will process with less sausaging than in low LAR conductor ZAB4. Materials were ordered and delivered

The $\mathrm{Nb} 1 \mathrm{Zr}$ rods were clad with copper at Outokumpu A.S. for the two ratios and drawn to 0.129 " across the flats hexes. Work was stopped after the testing results at LBL were analyzed. There were insufficient funds to complete this task.

\subsection{Repeat of work with Nb1Zr cast with 2 at\% Oxygen}

Several hundred rods of $2.348 \mathrm{~mm}$ diameter $\mathrm{Nb} 1 \mathrm{Zr}$ rods were heat treated with $\mathrm{Nb}_{2} \mathrm{O}_{5}$ powder in vacuum at $1100 \mathrm{C}$ for 100 hours to add oxygen. Analysis indicated $0.415 \mathrm{wt} \%$ was absorbed by the rods. Section 8.1 in this covers this in more detail. Two $51 \mathrm{~mm}$ billets, ZAB5 \& 6, were assembled with these rods and a $\mathrm{Nb}$ diffusion barrier. Three pure $\mathrm{Nb}$ marker filaments were included to compare filament reaction within the matrix. ZAB5 had 89 filaments while ZAB6 had 90. The billets were hipped and extruded to $12.192 \mathrm{~mm}$ with ZAB5 extruded at $450^{\circ} \mathrm{C}$ and ZAB6 at $500^{\circ} \mathrm{C}$. As can be seen in figure 25 there is some non-uniformity of the filaments though not as severe as some of the original extrusions in Phase I.

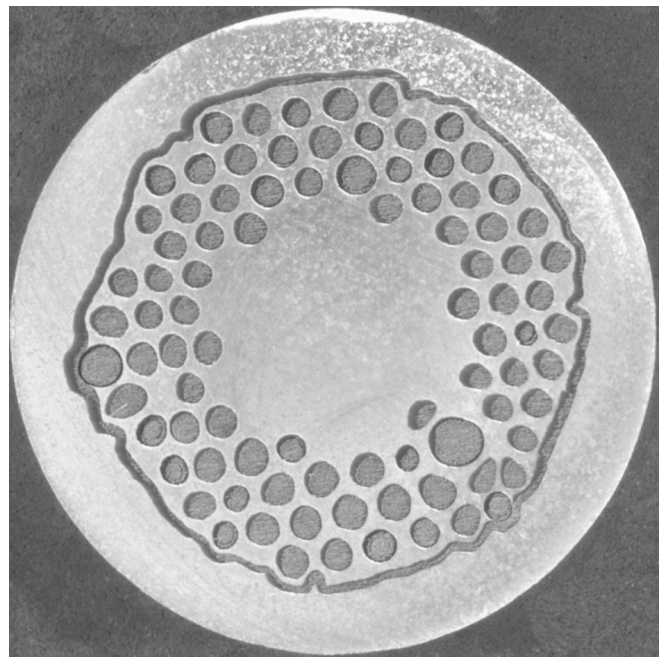

a.

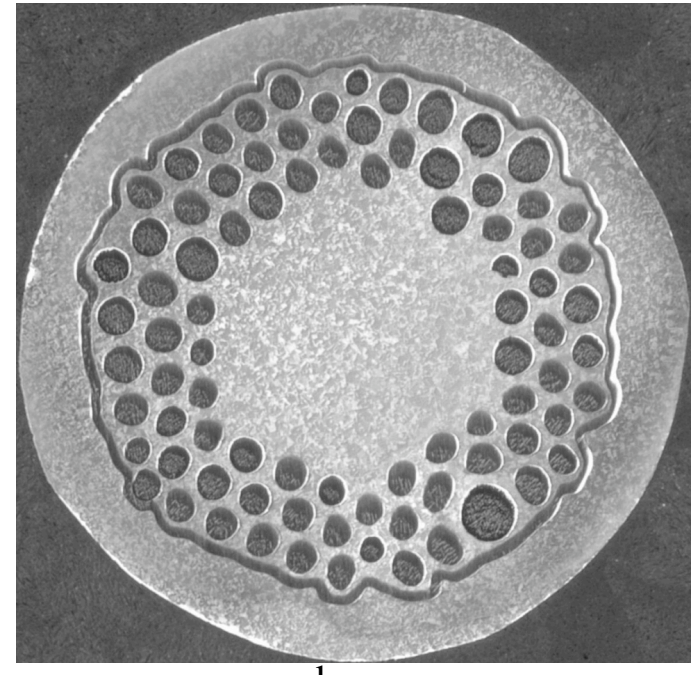

b.

Figure 25a. ZAB5 $12.19 \mathrm{~mm}$ dia. extruded at $450{ }^{\circ} \mathrm{C}$ and (b) ZAB6 extruded at $500^{\circ} \mathrm{C}$

Micro-hardness measurements were made on the as extruded rod. The large filaments had a VHN of 420 while the regular filaments had a VHN of 130. This large variation in hardness may indicate that the oxygen absorption was far from uniform. It is possible that some rods were touched by the powder. As discussed in the first section hardness of the starting material was not uniform across the radius. Figure 26 shows the sausaged filaments after extrusion once the copper has been removed. 
The rod was gun drilled by Grover with a 0.147 " I.D. Then drawn with a high reduction schedule of $0.410 ", 0.348 ", 0.295 "$ and finally with a standard $20 \%$ die schedule. Breakage began at $0.224 " \mathrm{~mm}$ with the second break at $0.157 " \mathrm{~mm}$ and a final break at 0.122 " $\mathrm{mm}$ where drawing was stopped. Figure 27 shows the wire at 0.122 " with highly variable filament sizes.

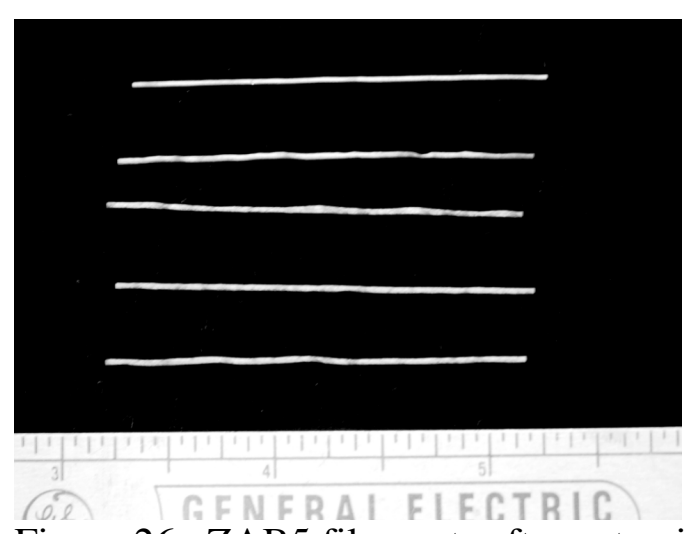

Figure 26. ZAB5 filaments after extrusion

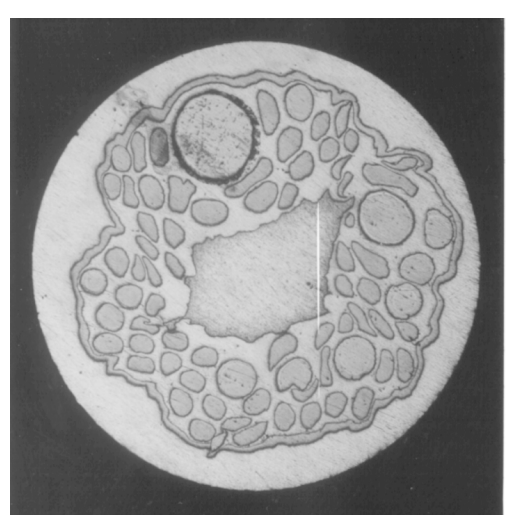

Figure 27. ZAB5 at 0.122" dia.

The $\mathrm{Nb} 1 \mathrm{Zr}$ rods used as used in the prior billets were further heat treated at $1600^{\circ} \mathrm{C}$ for one hour to diffuse the oxygen in further. Figure 28 shows that the oxygen has diffused in to give a more uniform and lower hardness. Figure 29 shows the rod's hardness profile as in ZAB5,6. A $50 \mathrm{~mm}$ billet was assembled with 0.097" rods and extruded using the same parameters as in ZAB5 and ZAB6. The extruded section is shown in figures $30 \mathrm{a}$. and $\mathrm{b}$. Several filaments are irregular but do not appear to be harder than the other filaments.

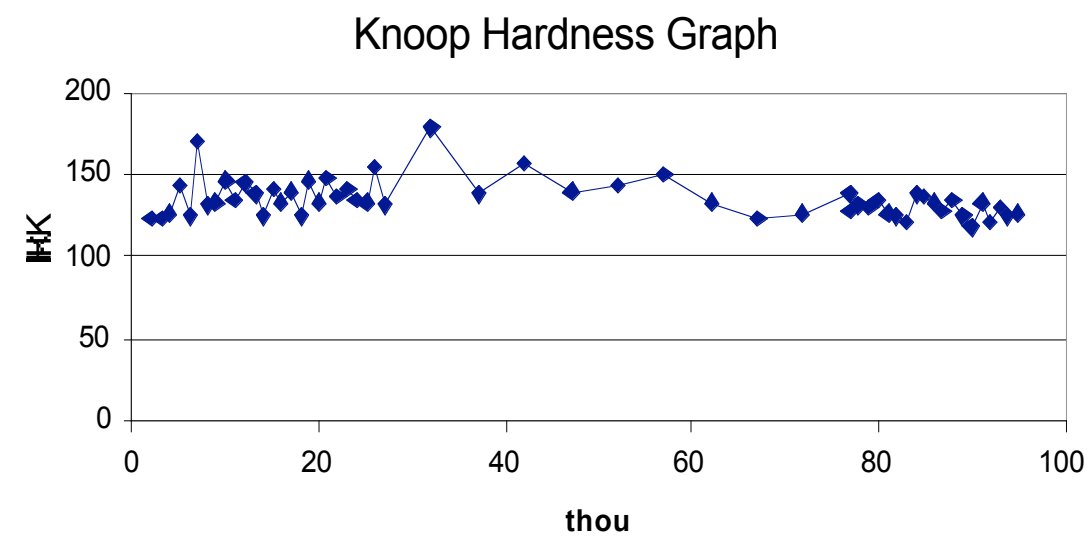

Figure 28. Knoop Hardness vs. distance in thousandths of an inch from edge of rod annealed at $1600^{\circ} \mathrm{C}$ for $1 \mathrm{hr}$. 


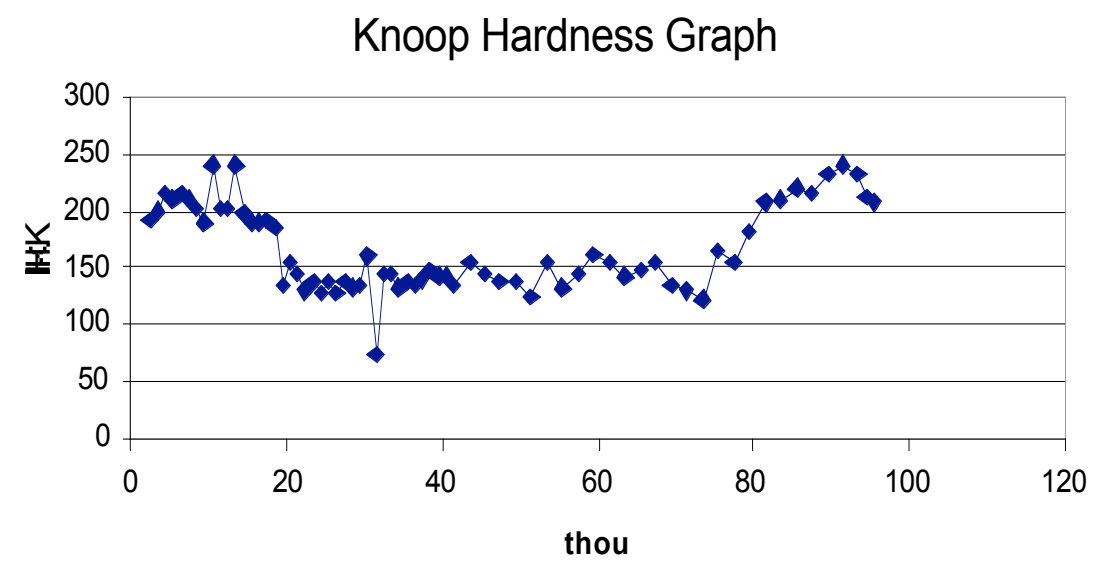

Figure 29. Knoop Hardness of same rod after $1100^{\circ} \mathrm{C}$ for $1 \mathrm{hr}$.

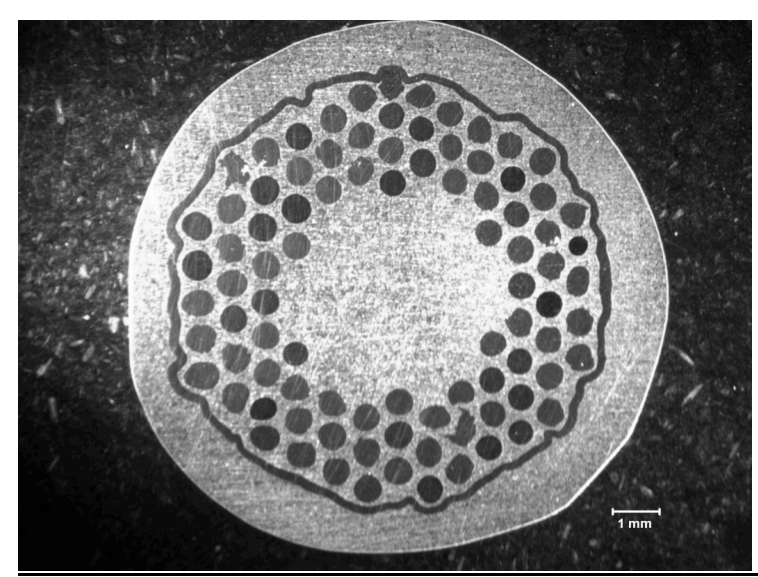

a.

Figure 30a. ZAB8 at $12.7 \mathrm{~mm}$ diameter

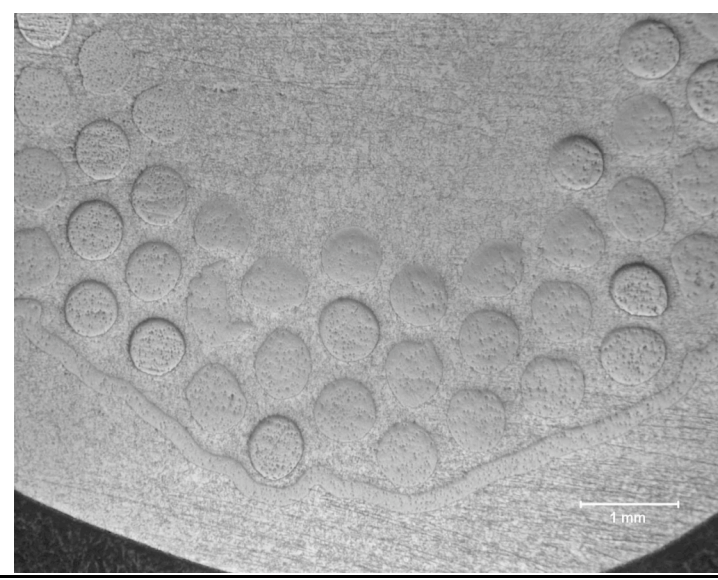

b.

b. ZAB8 filament barrier area 


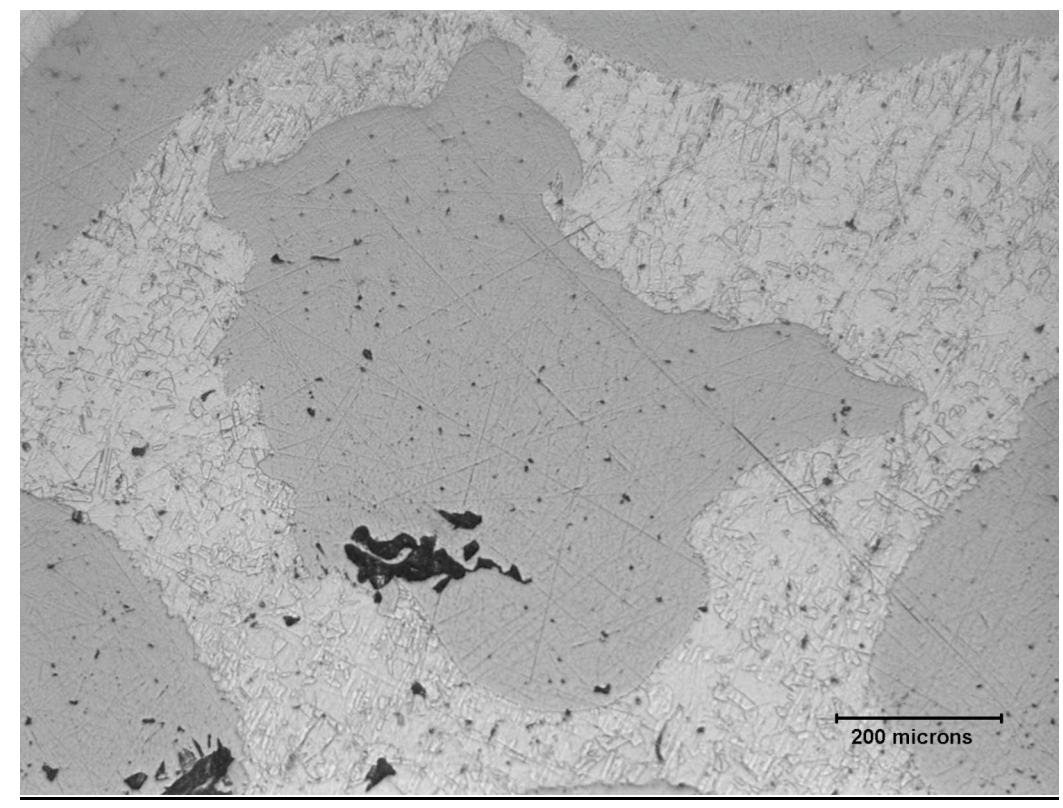

Figure 31. ZAB8 irregular filament

Oxygen analysis on the rods used in ZAB8 indicated that $0.41 \mathrm{wt} \%$ was absorbed more than sufficient to react with the Zr. The resulting rod was gun drilled with a $3.73 \mathrm{~mm}$ hole, tin inserted and drawn to $10.41 \mathrm{~mm}, 8.83 \mathrm{~mm}, 7.49 \mathrm{~mm}$, and then using a standard $20 \%$ area reduction die schedule. Breaks began at $2.59 \mathrm{~mm}$ and continued to $1.62 \mathrm{~mm}$ where drawing was stopped. Further cross sections were taken at the as extruded size which indicated some large filaments. Figure 32 shows the as extruded rod and the wire at $1.62 \mathrm{~mm}$.

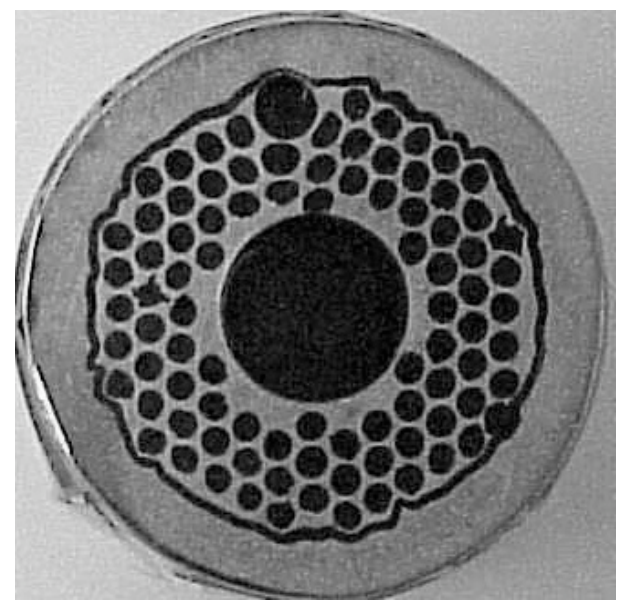

a.

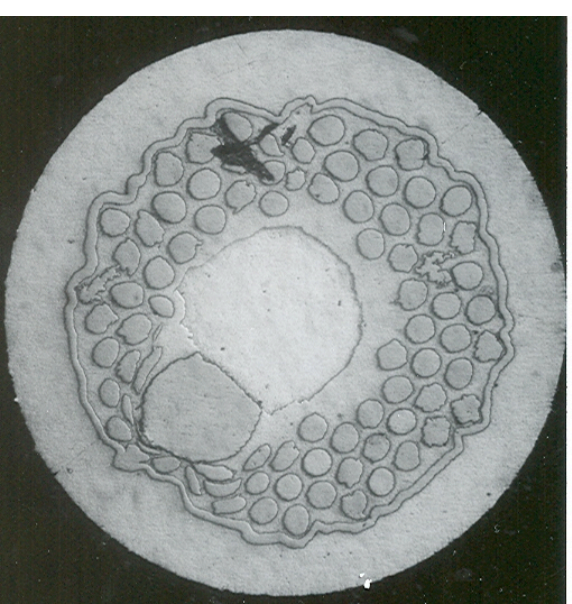

b.

Figure 32a. As extruded ZAB8

b. As drawn to $1.62 \mathrm{~mm}$ 
Hardness measurements were made on ZAB8 extruded filaments. The large filaments were $366 \mathrm{VH}$ ( 20 gram load). The regular filaments were $177 \mathrm{VH}$ while the deformed filaments were $150 \mathrm{VH}$. The $\mathrm{Nb}$ barrier was $167 \mathrm{VH}$.

Samples of the wire at $1.62 \mathrm{~mm}$ were sent to SupraMagnetics Inc. for grooved rolling. They were able to reduce the material to $0.91 \mathrm{~mm}$ and to a $0.22 \mathrm{~mm}$ tape. This was encouraging as it demonstrated that the material on average was sufficiently ductile. These samples after heat treatment showed extreme tin leaks as the rolling process broke the barriers. They were unsuitable for further analysis.

\section{Conclusion}

The addition of Oxygen to $\mathrm{Nb} 1 \mathrm{Zr}$ multifilament conductors has been shown to allow higher reaction temperatures from $815^{\circ} \mathrm{C}$ to $1000^{\circ} \mathrm{C}$. The oxygen addition appears to stabilize the filament matrix in comparison to the nondoped samples. A continuous reaction of the conductor would be feasible if so required. The $\mathrm{J}_{\mathrm{c}}$ enhancement effects were only seen at $815^{\circ} \mathrm{C}$, though the effect was substantial (approximately $50 \%$ at $15 \mathrm{~T}$ ). This appeared in both the $\mathrm{Sn}+\mathrm{Ox}$, and $\mathrm{Cu}+\mathrm{Sn}$ samples. The Ti sample was not tested. Further work on higher Sn composites would be warranted to see if the effects on layer Jc would be additive.

Techniques were developed to incorporate and process $\mathrm{Nb} 1 \mathrm{Zr}$ with controlled amounts of Oxygen. Unfortunately local variations on some rods led to difficulties in processing.

Finally, work to combine the known benefits of $\mathrm{Ti}$ additions with Oxygen in $\mathrm{Nb} 1 \mathrm{Zr}$ might yield substantial improvements.

\section{Papers Published Under Grant}

1. B.A. Zeitlin, J. Marte, D. Ellis, M. Benz, and E. Gregory,"Some Effects of the Addition of $1 \mathrm{At} \% \mathrm{Zr}$ to $\mathrm{Nb}$ on the Properties and Ease of Manufacture of Internal-Tin $\mathrm{Nb}_{3} \mathrm{Sn}$ ", Advances in Cryogenic Engineering, Vol.50B, pp 895-902, (2003).

2. B.A. Zeitlin, E. Gregory, J. Marte, M. Benz, Tae Pyon, R. Scanlan, D. Dietderich,"Results on Mono Element Internal Tin Nb3Sn Conductors (MEIT) with $\mathrm{Nb7.5Ta}$ and $\mathrm{Nb}\left(1 \mathrm{Zr}+\mathrm{O}_{\mathrm{x}}\right)$ Filaments", ASC 2004, IEEE Trans. Appl. Supercond. pp 3393-3398,(2005).

3. B. A. Zeitlin, E. Gregory, J. Marte, M, Benz, R. Scanlan, D. Dietderich, "The Effects on the Superconducting Properties on the Addition of Oxygen and Titanium to $(\mathrm{Nb}-1 \mathrm{Zr})_{3} \mathrm{Sn}$ Mono Element Internal Tin(MEIT) Conductors", Advances in Cryogenic Engineering, Vol. 52B pp. 513-519, (2006).

\section{$\underline{\text { References }}$}

1. R.M. Scanlan and D.R. Dietderich, "Development of cost-effective $\mathrm{Nb}_{3} \mathrm{Sn}$ conductors for the next generation hadron colliders", Paper I-15A-01, Proc. CEC/ICMC, Madison, WI July 16-20, 2001. 
2. R. Benjegerdes et al., "Fabrication and test results of a high field, $\mathrm{Nb}_{3} \mathrm{Sn}$ superconducting racetrack dipole magnet”, Particle Accelerator Conf. in Chicago, June 2001.

3. G. Ambrosio et al., "Fabrication of the shell-type $\mathrm{Nb}_{3} \mathrm{Sn}$ dipole magnet at Fermilab", IEEE Trans. Appl. Supercond. 11 pp. 2160-2163, 2001.

4. M. Anarella et al., "Common coil magnet program at BNL", IEEE Trans. Appl. Supercond. 11 pp. 2168-2171, 2001.

5. P. McIntyre et al., "12 Tesla hybrid block-coil dipole for future hadron colliders" IEEE Trans. Appl. Superconductivity, 11 pp. 2264-2267, 2001.

6. R. Kaufman, J .J. Pickett, “ Multifilament $\mathrm{Nb}_{3} \mathrm{Sn}$ superconductor wire,” Bull. Am Phys. Dec. 15, 1970.

7. K. Tachikawa, Proc. $3^{\text {rd }}$ ICEC, Berlin, p. 339, Ilffe Science and Technology Pub. Ltd., Surrey, England, (1970).

8. Y. Hashimoto, K. Yoshizaki, M. Tnetiu, Proceedings of the 5th ICMC, IPC Science and Technology Press London 1974 pg. 332.

9. B. A. Zeitlin, G. M. Ozeryansky, K. Hemachalam, "An overview of the IGC Internal Tin $\mathrm{Nb}_{3} \mathrm{Sn}$ conductor", IEEE Trans. Magn. Vol. MAG-21 No. 2 March 1985

10. R. M. Scanlan, R. J Benjegerdes, P. A. Bish, S. Caspi, K. Chow, D. Dell'Orco, D. R. Dietderich, M. A. Green, R. Hannaford, W. Harnden, H. C. Higley, A. F. Lietzke, A. D. McIntruff, L. Morrison, M. E. Morrison, C. E Taylor, and J.M Van Oort, "1997 Preliminary Test Results of a 13T Niobium Tin Dipole", Applied Superconductivity Vol. 2 IOP Conference Series No. 158 pp.1503-1506, (1997).

11. E. Gregory, E.A. Gulko, and T. Pyon, "Development of $\mathrm{Nb}_{3} \mathrm{Sn}$ wires made by the internal-tin process". Adv. in Cryo. Eng. Vol. 44B, pp. 903-909, Plenum Press, N.Y. 1998.

12. C. Taylor, R. Wollgast, R. Scanlan, C. Peters, W. Gilbert, W. Hassenzahl, J. Recem and R. Measer, "Nb 3 Sn dipole magnet reacted after winding," Applied Superconductivity Conference, 1984 Proceedings, IEEE Trans. Magn. Vol. MAG-21 No. 2, pp. 967-970.

13. T. Pyon and E. Gregory, " $\mathrm{Nb}_{3} \mathrm{Sn}$ Conductors for High Energy Physics and Fusion Applications", IEEE Trans. Appl. Superconductivity 11, 1, pp. 3688-3691 (2001). (ASC Sept 2000 Virginia Beach VA.).

14. T. Pyon and E. Gregory, "Internal-tin $\mathrm{Nb}_{3} \mathrm{Sn}$ Conductor Development for High Energy Physics Applications", Paper I 15A-02, CEC/ICMC Madison, WI, July 16-20, 2001.

15. T. Pyon and E. Gregory, "Internal-Tin $\mathrm{Nb}_{3} \mathrm{Sn}$ Program for DOE", and T. Pyon and E. Gregory "Fabrication of Production Lengths of Internal-Tin Conductors", Low Temperature Superconducting Workshop, Napa, CA, Nov. 2001.

16. . B. A. Zeitlin, E. Gregory, and T. Pyon, " A high current density low cost niobium $_{3}$ tin conductor scalable to modern niobium titanium production economics” IEEE Trans. Appl. Superconductivity 11, 1, pp. 3683-3687 (2001). (ASC Sept 2000 Virginia Beach VA.). Applied Superconductivity Conference, Virginia Beach Va. Sept. 2000.

17. M. Suenaga, D.O. Welch, R.L Sabatini, O.F. Kammerer, and S. Okuda, "Superconducting critical temperatures, critical magnetic fields, lattice 
parameters, and chemical compositions of bulk pure and alloyed $\mathrm{Nb}_{3} \mathrm{Sn}$ produced by the bronze process" J. Appl. Physics, 59(3), 1 Feb. 1986 pg. 840.

18. M. Suenaga, C. J. Klamut, N. Higuchi, and T. Kuroda, "Properties of Ti alloyed mutifilamentary $\mathrm{Nb}_{3} \mathrm{Sn}$ wires by Internal Tin process", IEEE Trans. on Magn. MAG-21: 3051985.

19. R. H. Hammond, B. E. Jacobson, T. H. Geballe, J. Talvacchio, J. R. Salem, “ Studies of electron beam evaporated $\mathrm{Nb}_{3} \mathrm{Sn}$ composites; critical current and microstructure," IEEE Transaction on Magnetics, Vol., MAG-15, No. 1, January 1979.

20. J. C. McKinnell, M. B. Siddall, P. M. O’Leary, and D. B. Smathers, "Increased superconducting critical current density in Internal Tin Niobium-tin $\left(\mathrm{Nb}_{3} \mathrm{Sn}\right)$ composite wires by Magnesium doping", Adv. in Cryo. Eng. Vol. 40, pp. 945952, 1994.

21. M. G. Benz, "The superconducting performance of diffusion processed $\mathrm{Nb}_{3} \mathrm{Sn}$ $\left(\mathrm{Cb}_{3} \mathrm{Sn}\right)$ doped with $\mathrm{ZrO}_{2}$ particles", Trans. of Met. Soc. of AIME, Vol.242, June 1968, pp.1067-1070.

22. L.E. Rumaner and M. G. Benz, "Effect of oxygen and zirconium on the growth and superconducting properties of Nb3Sn", Metallurgical and Materials Trans. A Vol. 25A, Jan 1994 pp. 203-212.

23. R.M. Scanlan, W.A. Fietz and E.F. Koch, "Flux pinning centers in superconducting $\mathrm{Nb}_{3} \mathrm{Sn}$, J. Appl. Phys. 1975, vol. 46 (5), pp.2244-49.

24. D. R. Dietderich, M. Kelman, J. R. Litty, and R. M. Scanlan, "High critical current densities in $\mathrm{Nb}_{3} \mathrm{Sn}$ films with engineered microstructures - Artificial Pinning microstructures" Adv. In Cryo. Eng. V. 44B, pp. 951-958, Plenum Press. N.Y. 1998.

25. Private communication with D. R. Dietderich Jan. 31, 2001.

26. P. J. Lee, A. Squitieri and D. C. Larbalestier, " $\mathrm{Nb}_{3} \mathrm{Sn}$ : macrostructure, microstructure, and property comparisons for bronze and Internal Sn process strands", IEEE Trans on Appl. Superconductivity, vol.10 no.1, March 2000, pp 979-982, (MT-16, Ponte Vedra Beach, Fl., 1999).

27. Private communication with J Marte, GECR\&D, Jan 24, 2001.

28. C. English, "The Physical, Mechanical and Irradiation Behavior of Niobium", pp.239-324, Proc. of Int. Symp. on Niobium, ed. H. Stuart, TMS AIME 1981 (Meeting San Fran. Nov. 8-11, 1981).

29. . D.J. Rowcliffe, R.M. Bonesteel and T.E. Tietz, "Strengthening of Niobium Zirconium alloys by internal oxidation". Metallurgical Society Conferences, Vol. 47 pp. 741-750, 1966, eds. G.S. Ansell, T.D. Cooper and F.V. Lenel, Gordon and Breach Science Publishers.

30. F.N. Rhines, Trans. AIME, 137, p. 246, 1940.

31. J.L. Meijering and M. J. Druyvesteyn, Philips Research Reports, 2 (1947) pp. 81102 and pp.260-280.

32. G.C. Smith and D.W Dewhirst, Australasian Engineer Nov. 1950 p.60 and Research 2, (1949) p. 492.

33. E. Gregory, PhD. Thesis Univ. of Cambridge, 1954.

34. N.J. Grant and O. Preston, "Dispersed Hard Particle Strengthening of Metals", Trans. AIME, Journal of Metals, pp. 349-357, March 1957. 
35. E. Gregory and G.C. Smith, "The Effects of Internal Oxidation on the Tensile Properties of Some Silver Alloys at Room and Elevated Temperatures", Journal of the Institute of Metals, Vol. 85, pp. 81-88, 1956.

36. W.R. Webster, J.L. Christie and R.S. Pratt, "Comparative Properties of OxygenFree, High Conductivity, Phosporized and Tough Pitch Coppers," Trans. AIME Vol. 104, 1933, p. 166.

37. U. J. Hochschild "Scaling Test for OFHC Copper for the Housekeeper Seal," Electronics, Dec 1944, p. 252.

38. F.N. Rhines, "Gas-Metal Diffusion and Internal Oxidation" pp.174-191 in Atom Movements, ASM 1951, seminar in the $32^{\text {nd }}$ Nat Metal Congress, Chicago 1950.

39. R. Kirchheim, "Metals As Sinks And Barriers For Interstitial Diffusion In Copper, Niobium and Tantalum, Acta Metallurgica, Vol.27 pp 869-878, Pergamon Press Ltd 1979.

40. L.S. Darken, "Formal Basis of Diffusion Theory", pp.1-24 Atom Movements, ASM 1951, seminar in the $32^{\text {nd }}$ Nat Metal Congress, Chicago 1950.

41. L. T. Summers, M. W, Guinan, J. R. Miller, and P. A. Hahn, " A model for the prediction of $\mathrm{Nb}_{3} \mathrm{Sn}$ critical current as a function of field, temperature, strain, and radiation damage", IEEE Trans. on Magn. Vol.27, No.2, 1763-1766, March 1998.

42. B.A. Zeitlin, "The future of low temperature $\mathrm{Nb}$ based Superconductors", to be published by TMS, Proc. of Niobium 2001, Orlando FL 2001.

43. B. Avitzur, "Handbook of Metal-Forming Processes XXX1", New York, Wiley, 1983. A Wiley-Interscience Publication.

44 J.R. Stewart, W. Lieberman and G.H. Rowe, "Recovery and Recrystallization of Columbium-1.0\% Zirconium Alloy, in "Columbium Metallurgy" Vol. 10 Metallurgical Conferences AIME, eds. D.L. Douglass and R.W. Kunz, Interscience Publishers New York / London 1961.

45 E. Gregory, T. S. Kreilick, A. K. Ghosh and W. B. Sampson, "Importance of spacing in the development of high current densities in multifilamentary superconductors", Cryogenics, 27, 4, pp.178-182, 1987.

46 T. S. Kreilick and E. Gregory, "Further improvements in current density by reduction of filament spacing in multifilamentary NbTi superconductors", Cryogenics, 27, 7, 401-404, 1987.

47 M.F. Ashby and G.C. Smith "Structures of Internally Oxidized Copper Alloys" J. of the Institute Metals, 1962-63, Vol. 91 (5) pp 182-187.

48. H. Kurahashi, K. Itoh, S. Matsumoto, T. Kiyoshi, H. Wasa, Y. Murakami, H. Yasunaka, S. Hayshi, and Y. Otani, " Effect of third element additions on the upper critical field of bronze-processed Nb3Sn", paper 1MF01, ASC. Jacksonville Fl. Oct. 2004.

49. L. E. Rumaner, "The Effect of Oxygen and Zirconium On the Growth and Superconducting Properties of Nb3Sn", GE Research and Development Center, Technical Information Series, June 1991 